\title{
50 years of Computational Wind Engineering: Past, present and future ${ }^{1}$
}

\author{
Bert Blocken \\ Building Physics and Services, Department of the Built Environment, Eindhoven University of Technology, \\ P.O. box 513, 5600 MB Eindhoven, the Netherlands, b.j.e.blocken@tue.nl
}

Building Physics Section, Department of Civil Engineering, Leuven University, Kasteelpark Arenberg 40 - bus 2447, 3001 Heverlee, Belgium

\begin{abstract}
In the past 50 years, Computational Wind Engineering (CWE) has undergone a successful transition from an emerging field into an increasingly established field in wind engineering research, practice and education. This paper provides a perspective on the past, present and future of CWE. It addresses three key illustrations of the success of CWE: (1) the establishment of CWE as an individual research and application area in wind engineering with its own successful conference series under the umbrella of the International Association of Wind Engineering (IAWE); (2) the increasing range of topics covered in CWE; and (3) the history of overview and review papers in CWE. The paper also outlines some of the earliest achievements in CWE and the resulting development of best practice guidelines. It provides some views on the complementary relationship between reduced-scale wind-tunnel testing and CFD. It re-iterates some important quotes made by CWE and/or CFD researchers in the past, many of which are still equally valid today and which are provided without additional comments, to let the quotes speak for themselves. Next, as application examples to the foregoing sections, the paper provides a more detailed view on CFD simulation of pedestrian-level wind conditions around buildings, CFD simulation of natural ventilation of buildings and CFD simulation of wind-driven rain on building facades. Finally, a non-exhaustive perspective on the future of CWE is provided.
\end{abstract}

Keywords: Review; Historical overview; Computational Fluid Dynamics; Urban physics; Building physics; Fluid mechanics

\section{Introduction}

Computational Wind Engineering (CWE) is primarily defined as the use of Computational Fluid Dynamics (CFD) for wind engineering applications, although it also includes other approaches of computer modelling and in the broadest sense also field and wind-tunnel measurements supporting CWE model development and evaluation (Murakami, 1990a, 1990b, 1993a, 1997, 1998, Meroney, 1997, Stathopoulos, 1997, 2002, Baker, 2000, Murakami et al., 2008, Huber and Blocken, 2011). In the present paper however, I will restrict the definition of CWE to the use of CFD and other computer approaches in wind engineering. Wind engineering itself is best defined as "the rational treatment of interactions between wind in the atmospheric boundary layer and man and his works on the surface of Earth." (Cermak 1975). CWE has come a long way. 50 years ago, the present extent of achievements and applications in CWE could hardly have been imagined.

At the occasion of the $6^{\text {th }}$ European and African Conference on Wind Engineering (6EACWE) in Cambridge in July 2013, the International Association of Wind Engineering (IAWE) celebrated the $50^{\text {th }}$ anniversary of the historical meeting in Teddington in 1963. Also the historical starting point of CWE could also be situated around 1963, when Smagorinsky (1963) developed one of the first successful approaches to Large Eddy Simulation (LES), the Smagorinsky-Lilly model, which is still intensively used in many areas of fluid mechanics today. Which is the actual historical starting point of CWE depends on the spatial scale considered (see section 2). The main research area of Smagorinsky was Numerical Weather Prediction (NWP), applied at the synoptic scale or meteorological macroscale. However, the practical deployment of NWP already started in the 1950s (e.g. Charney et al. 1950, Smagorinsky 1953, 1958, Charney 1955, Phillips 1956).

In meteorology, the 1960s and later years were characterised by the continued development and application of NWP (e.g. Phillips 1960, Smagorinsky 1963, 1969, Kasahara and Washington 1967, Shuman and Hovermale 1968, Kasahara 1974). In addition, there was the emergence of mesoscale analyses in 2D (i.e. in a vertical section) of phenomena such as sea breezes with and without prevailing (synoptic) winds (e.g.

\footnotetext{
${ }^{1}$ This paper is an extended version of a keynote paper presented at the $6^{\text {th }}$ European and African Conference on Wind Engineering, Cambridge, UK, July 7-11, 2013.
} 
Pearce 1955, Fisher 1961, Estoque 1961, 1962, Magata 1965), convective motions over mountain ridges (e.g. Fosberg 1967, 1969) and flow over (simplified urban) heat islands with and without prevailing winds (e.g. Estoque and Bhumralkar 1969, Delage and Taylor 1970, Meroney and Yamada 1971, Meroney and Yamada 1972). Other numerical studies addressed the microscale flow around explicitly modelled surface-mounted obstacles such as buildings (e.g. Yamada and Meroney 1972, Hirt and Cook 1972, Frost et al. 1974) and complex terrain (e.g. Hirt and Cook 1972, Deaves 1975, Derickson and Meroney 1977). Of particular importance for CWE were the pioneering studies by Meroney and his co-workers in which the so-called hybrid approach was pursued: systematic comparison of numerical simulations with dedicated wind-tunnel measurements in an atmospheric boundary layer wind tunnel (e.g. Meroney and Yamada 1971, 1972, Yamada and Meroney 1972, Derickson and Meroney 1977).

In Aerospace Engineering, the T3 group at the Los Alamos National Laboratories in 1963 first used computers to model the 2D swirling flow around an object, using the vorticity stream function method, followed by the first 3D application by Hess and Smith (1967) using the so-called panel method.

Driven by these early achievements, later efforts in CWE focused on the determination and analysis of the wind velocity and pressure fields around buildings (e.g. Vasilic-Melling 1977, Hanson et al. 1986, Paterson and Apelt 1986, 1989, 1990, Murakami 1990a, 1990b, 1990c, 1993a, 1993b, Murakami et al. 1987, 1990, 1992, Murakami and Mochida 1988, 1989, Baskaran and Stathopoulos 1989, 1992, Stathopoulos and Baskaran 1990, Baetke et al. 1990, Wu et al. 1992, Mochida et al. 1993, Nicholls et al. 1993). A strong impetus to CWE was provided by the organisation of a new symposium in 1992 by S. Murakami in Tokyo, Japan: the International Symposium on Computational Wind Engineering (CWE). The importance of this symposium cannot be overemphasised (Stathopoulos 2013): For the first time, it joined wind engineering delegates with classical aerodynamicists, who were using CFD rather routinely to address and solve aeronautical problems. As these problems are very different from wind engineering problems, the first CWE symposium led to a very fruitful interaction between the different groups of delegates. It also marked the beginning of a period of impressive growth in CWE developments and applications, and the beginning of a whole new series of symposia, demonstrating not only the growing importance of CWE, but also the pioneering and visionary character of their founder, S. Murakami.

The difference in time between the earliest CFD developments in the 1950s and the later application of CFD in CWE for wind velocity and pressure fields around buildings is attributed to the specific difficulties associated with the flow field around bluff bodies with sharp edges, many of which are not encountered in CFD computations for simple flows such as channel flow and simple shear flow (e.g. Ferziger, 1990, Leschziner, 1990, 1993, Stathopoulos, 1997, Murakami, 1998). Murakami (1998) meticulously outlined the main difficulties in CWE: (1) the high Reynolds numbers in wind engineering applications, necessitating high grid resolutions, especially in near-wall regions as well as accurate wall functions; (2) the complex nature of the 3D flow field with impingement, separation and vortex shedding; (3) the numerical difficulties associated with flow at sharp corners and consequences for discretisation schemes; and (4) the inflow (and outflow) boundary conditions, which are particularly challenging for LES. These difficulties were directly linked to limitations in physical modelling and in computational requirements at those times, but many of those limitations are still to some extent present today.

In spite of these difficulties, in the past decades and driven by the pioneering studies mentioned above, CWE has undergone a successful transition from an emerging field into an increasingly established field in wind engineering research, practice and education. This transition and the success of CWE are illustrated by (1) the establishment of CWE as an individual research and application area in wind engineering with its own successful conference series under the umbrella of the IAWE (Solari, 2007); (2) the increasingly wide range of topics covered in CWE, ranging from pedestrian-level wind conditions over natural ventilation of buildings and wind loads on buildings and bridges to sports aerodynamics; and (3) the history of review and overview papers in CWE. Each of these three illustrations will be addressed in this paper. In addition, the paper will focus more in detail on CFD applications for pedestrian-level wind conditions around buildings, natural ventilation of buildings and wind-driven rain on building facades.

CWE is complementary to other, more traditional areas of wind engineering, such as full-scale on-site experimentation and reduced-scale wind-tunnel testing. Each approach has its specific advantages and disadvantages. The main advantage of on-site measurements is that they are able to capture the real complexity of the problem under study. Important disadvantages however are that they are not fully controllable due to among others - the inherently variable meteorological conditions, that they are not possible in the design stage of a building or urban area and that usually only point measurements are performed. The latter disadvantage also holds for wind-tunnel measurements. Techniques such as Particle Image Velocimetry (PIV) and LaserInduced Fluorescence (LIF) in principle allow planar or even full 3D data to be obtained in wind-tunnel tests, but the cost is considerably higher and application for complicated geometries can be hampered by laser-light shielding by the obstructions constituting the model, e.g. in case of an urban model consisting of many buildings. Another disadvantage is the required adherence to similarity criteria in reduced-scale testing, which 
can limit the extent and the range of problems that can be studied in wind tunnels.

CWE/CFD has some particular advantages over experimental (full-scale or reduced-scale) testing. It can provide detailed information on the relevant flow variables in the whole calculation domain ("whole-flow field data"), under well-controlled conditions and without similarity constraints. However, the accuracy and reliability of CFD simulations are of concern and solution verification and validation studies are imperative. This requires high-quality full-scale or reduced-scale measurements, which in turn should satisfy important quality criteria. Therefore, experiments remain indispensable for CWE. In addition, it is widely recognised that the results of CFD simulations can be very sensitive to the wide range of computational parameters that have to be set by the user. For a typical simulation, the user has to select the target variables, the approximate form of the governing equations, the turbulence model, the computational domain, the computational grid, the boundary conditions, the discretisation schemes, the convergence criteria, etc. This expresses the need for best practice guidelines for CWE. Best practice guidelines will also be addressed in this paper. While the foundations for these best practice guidelines were already laid in the early years of CWE applied to buildings and structures, only in the past 14 years have these efforts been compiled into extensive best practice guideline documents (e.g. Casey and Wintergerste, 2000, Franke et al. 2004, 2007, 2011, Britter and Schatzmann 2007, Tominaga et al. 2008a, Tamura et al., 2008, Blocken et al., 2012, Blocken and Gualtieri, 2012).

This paper provides a perspective on the past, present and future of CWE. But it does not start without a major disclaimer. It will also not end without a major acknowledgement section. CWE has grown to a strongly established field in wind engineering research, practice and education. It is employed daily by probably thousands of researchers, practitioners and teachers all over the world. In addition, the realm of CWE has now spread to so many topics that it becomes increasingly difficult to oversee them all. The perspective presented in this paper is therefore inherently incomplete. And the author apologises to all researchers, practitioners and teachers whose valuable contributions are not included in this paper.

The paper starts with outlining some of the earliest CWE achievements, followed by an overview of the CWE best practice guidelines that originated from those achievements, and some main aspects of these guidelines. Next, the historical background of the CWE symposia is presented, and the increase in scope of these symposia throughout the years is demonstrated. In addition, an overview of CWE review and overview papers is provided and the complementary character of reduced-scale wind-tunnel testing and CWE is discussed. The paper also reiterates some important quotes made by CWE and/or CFD researchers in the past, many of which are still equally valid today. They are provided without additional comments, to let the quotes speak for themselves. Next, as application examples to the preceding sections, the paper provides a more detailed perspective on CFD simulation of pedestrian-level wind conditions (PLW) around buildings, on CFD simulation of natural ventilation (NV) of buildings and on CFD simulation of wind-driven rain (WDR) on building facades. A main reason for the choice of PLW, NV and WDR is that these are increasingly recognised as topics that can be studied successfully with CFD and, as a result, some extensive case studies have been performed. In addition, for PLW, many early applications in CWE focused on this topic, and the best practice guidelines by the COST732 (Franke et al., 2004) and AIJ groups (Tominaga et al., 2008a) were initially intended to support PLW studies. Finally, some perspectives on the future of CWE are provided.

The reader will notice that this paper has a larger focus on Environmental Wind Engineering than on Structural Wind Engineering. This is also reflected in the choice of the applications PLW, NV and WDR that are all part of Environmental Wind Engineering. The reason for this is threefold: (1) CWE has most extensively been applied in the field of Environmental Wind Engineering; (2) CWE is at present considered to be a potentially suitable approach for more topics in Environmental Wind Engineering than in Structural Wind Engineering (e.g. it is easier to obtain fairly accurate estimates of mean pressures for NV than similarly accurate peak pressures for wind loading); (3) this paper and especially the sections on PLW, NV and WDR unavoidably reflect the expertise of the author which is Environmental rather than Structural Wind Engineering.

\section{Some early CWE achievements at macroscale, mesoscale and microscale}

As mentioned in the previous section, the historical starting point of CWE depends on the spatial scale considered. Figure 1, adopted from (Schlünzen et al. 2011), provides an overview of the spatial and temporal scales of atmospheric phenomena. A distinction is made between the meteorological macroscale (or synoptic scale), the mesoscale and the microscale. The American Meteorological Society (AMS 2014) provides the following definitions:

- Macroscale or synoptic scale: the scale of atmospheric motions with a typical range of many hundreds of kilometres, including such phenomena as cyclones and tropical cyclones.

- Mesoscale: the scale of atmospheric phenomena having horizontal scales ranging from a few to several hundred kilometres, including thunderstorms, squall lines, fronts, precipitation bands in tropical and extratropical cyclones, and topographically generated weather systems such as mountain waves and sea and land breezes. 
- Microscale: the scale of atmospheric motions with Lagrangian Rossby numbers greater than 200 or spatial scales of $2 \mathrm{~km}$ or less.

In its broadest sense, CWE encompasses the entire range of spatial scales, from the synoptic scale down to the microscale. It even includes effects of microscale wind conditions on wind flow inside buildings (natural ventilation and infiltration) and in building components (e.g. ventilation of wall and roof cavities; see Nore et al. 2010). However, in the wind engineering community, as represented by the IAWE and its official journal (the Journal of Wind Engineering and Industrial Aerodynamics - JWEIA), the focus is mainly - but not exclusively - on the meteorological microscale. This focus is also clearly reflected in this review paper. From the perspective of the broadest interpretation of CWE, some - but definitely not all - early achievements in CWE at the different spatial scales are briefly mentioned below.

\subsection{Synoptic scale}

At the synoptic scale or macroscale ${ }^{2}$, the numerical integration of the governing equations for atmospheric dynamics subject to specified initial conditions is termed "Numerical Weather Prediction" (NWP). NWP was proposed by L.F. Richardson ${ }^{3}$ in 1922 in his book "Weather Prediction by Numerical Process" (Richardson 1922), in which he suggested the numerical solution based on finite differences of the governing differential equations to predict the change of atmospheric recirculation. However, at his time, the numerical computations required were unattainable and the manual computations took much longer than the weather advances to be predicted. Although his work received generally favourable review comments, its - at that time - excessively time-consuming and unrealisable character in combination with an unfortunate example calculation attracted adverse criticism. Richardson (1922) stated:

"Perhaps some day in the dim future it will be possible to advance the computations faster than the weather advances and at a cost less than the saving to mankind due to the information gained. But that is a dream.”

It was only in 1950 that NWP could be applied thanks to the first electronic computers combined with further developments in atmospheric dynamics, instrumentation and observing practice. As stated by Lynch (2006), history has shown that Richardson's approach was fundamentally sound and his suggested methodology is essentially that used in practical weather forecasting today. According to Chapman (1965), Charney, after his successful achievements in NWP with digital computing, addressed the Royal Meteorological Society stating that:

“... to the extent that my work in weather prediction has been of value, it has been a vindication of the vision of my distinguished predecessor, Lewis F. Richardson..."

Moreover, Charney sent copies of several reports to Richardson who responded them to be "an enormous scientific advance" (Lynch 2008). Indeed, some decades after his now very famous book, Richardson's dream had come true.

NWP was also the main field in which Smagorinsky - briefly mentioned in section 1 of this paper - was active. Smagorinsky (1963) extended early weather models to include variables such as wind, cloud cover, precipitation, atmospheric pressure and radiation emanating from the earth and sun. This required a method to account for atmospheric turbulence occurring on scales smaller than the model grid size and led to the development of one of the first successful approaches to Large-Eddy Simulation: the Smagorinsky-Lilly model.

Early macroscale studies were reported by e.g. Charney et al. (1950), Smagorinsky (1953, 1958), Charney (1955), Phillips (1956, 1960), Smagorinsky (1963, 1969), Kasahara and Washington (1967), Shuman and Hovermale (1968) and Kasahara (1974). For historical and contemporary review and overview papers on NWP, the reader is referred to (Platzman 1979, Haltiner and Williams 1980, Shuman 1989, Kimura 2002, Lynch 2006, 2008).

\footnotetext{
${ }^{2}$ And increasingly also the mesoscale, as the spatial resolution of numerical weather prediction increases.

${ }^{3}$ Lewis Fry Richardson (1881-1953), English mathematician, physicist, meteorologist, psychologist, pacifist. The Richardson number (dimensionless number of ratio of potential to kinetic energy) and Richardson extrapolation are named after him in appreciation of his scientific achievements.
} 


\subsection{Mesoscale}

Early mesoscale CWE studies include 2D numerical analyses (i.e. in a vertical section) of sea breezes with and without prevailing (synoptic) winds (e.g. Pearce 1955, Fisher 1961, Estoque 1961, 1962, Magata 1965), convective motions over mountain ridges (e.g. Fosberg 1967, 1969) and flow over (simplified urban) heat islands with and without prevailing winds (e.g. Estoque and Bhumralkar 1969, Delage and Taylor 1970). Pioneering studies that combined numerical simulations with dedicated wind-tunnel experiments were performed by R.N. Meroney and his co-workers. Meroney and Yamada (1971) provided the first validation study of CFD simulations of the urban heat island effect for 2D stratified airflow over the island. Later, this study was extended to two identical heated islands in series (Meroney and Yamada 1972).

\subsection{Microscale}

At the microscale, the flow around surface-mounted obstacles such as buildings is explicitly resolved, i.e. these obstacles are represented with their actual shape instead of parameterised as is typically the case in mesoscale and macroscale simulations. Yamada and Meroney (1972) studied 2D airflow over a square surfacemounted obstacle in a stratified atmosphere, both in the wind tunnel and with CFD. Hirt and Cook (1972) calculated 3D flow around structures and over rough terrain. Frost et al. (1974) numerically analysed the 2D neutrally stratified wind flow over a semi-elliptical surface obstruction, used to represent an idealised building. Deaves (1975) reported numerical simulations of 2D neutrally stratified wind flow over several particular hill shapes.

In addition, numerical studies of flow over hills were also reported by - among others - Wallington and Portnall (1958), Sawyer (1960), Taylor and Gent (1974) and Derickson and Meroney (1977). The latter authors also provided a comparison with wind-tunnel experiments for neutrally stratified flow and further numerical experiments with stable and unstable stratification.

CFD simulation of wind flow around 3D buildings started with fundamental studies for isolated buildings, often with a cubical shape, to analyse the velocity and pressure fields (e.g. Vasilic-Melling, 1977, Hanson et al., 1986, Paterson and Apelt, 1986, 1989, 1990, Murakami et al., 1987, 1990, 1992, Murakami and Mochida, 1988, 1989, Baskaran and Stathopoulos, 1989, 1992, Stathopoulos and Baskaran, 1990, Murakami, 1990b, 1990c, 1993b, Baetke et al., 1990, Mochida et al., 1993). Together with later studies, they laid the foundations for the current best practice guidelines, by focusing on the importance of grid resolution (e.g. Murakami and Mochida, 1989, Murakami 1990b, 1990c, Baskaran and Stathopoulos, 1992), the influence of the boundary conditions on the numerical results (e.g. Murakami and Mochida, 1989, Paterson and Apelt, 1990, Baetke et al., 1990, Stathopoulos and Baskaran, 1990, Baskaran and Stathopoulos, 1992) and by comparing the performance of various types of turbulence models in steady RANS simulations (e.g. Baskaran and Stathopoulos, 1989, Murakami et al., 1992, Murakami, 1993b, Mochida et al., 2002). Also comparisons of steady RANS versus LES were performed (e.g. Murakami et al., 1990, 1992, Murakami, 1990c, 1993b).

In the past, especially the deficiencies of the steady RANS approach with the standard k- $\varepsilon$ model (Jones and Launder 1972) for wind flow around buildings were addressed. These include the stagnation point anomaly with overestimation of turbulent kinetic energy near the frontal corner and the resulting underestimation of the size of separation and recirculation regions on the roof and the side faces, and the underestimation of turbulent kinetic energy in the wake resulting in an overestimation of the size of the cavity zone and wake. Various revised linear and non-linear k- $\varepsilon$ models and also second-moment closure models were developed and tested, and showed improved performance for several parts of the flow-field (e.g. Baskaran and Stathopoulos, 1989, Murakami et al., 1992, Murakami, 1993b, Wright et al., 2001, Mochida et al., 2002). However, the main limitation of steady RANS modelling remained: its incapability to model the inherently transient features of the flow field such as separation and recirculation downstream of windward edges and vortex shedding in the wake. These large-scale features can be explicitly resolved by LES. While unsteady RANS (URANS) has hardly been used to study wind flow around buildings, early applications of LES for this purpose were already made by Murakami et al. in 1987 (Murakami et al., 1987), and later by Murakami et al. (1990, 1992) and Murakami (1990c). These studies illustrated the intrinsically superior performance of LES compared to RANS. Nevertheless, as will be discussed further, LES entails specific disadvantages that are not easy to overcome, including the strongly increased computational requirements and the difficulty in specifying appropriate time-dependent inlet and wall boundary conditions.

The studies mentioned above are not all studies that were performed for isolated buildings. But starting from the 1990s, supported by the previous studies and the increased availability of computational power and CFD codes, fundamental studies gradually shifted their focus to multiple-building configurations, and also application studies were increasingly performed. In addition, the sensitivity of the CFD results to the large number of computational parameters to be set by the user and the possibility of applying CFD in practice led to the development of best practice guidelines, as discussed in the next section. 


\section{CWE best practice guidelines}

In CFD simulations, a large number of choices need to be made by the user. It is well known that these choices can have a very large impact on the results. Already since the start of the application of CFD for wind flow around bluff bodies in the late $70 \mathrm{~s}$ and $80 \mathrm{~s}$, researchers have been testing the influence of these parameters on the results, which has provided a lot of valuable information (e.g. Murakami and Mochida, 1989, Baetke et al., 1990, Stathopoulos and Baskaran, 1990, Cowan et al., 1997, Hall, 1997). In addition, Schatzmann et al. (1997) provided an important contribution on validation with field and laboratory data. However, initially this information was dispersed over a large number of individual publications in different journals, conference proceedings and reports.

In 2000, the ERCOFTAC ${ }^{4}$ Special Interest Group on Quality and Trust in Industrial CFD published an extensive set of best practice guidelines for industrial CFD users (Casey and Wintergerste, 2000). These guidelines were focused on RANS simulations. Although they were not specifically intended for wind engineering, many of these guidelines also apply for CWE. Within the EC project ECORA ${ }^{5}$, Menter et al. (2002) published best practice guidelines based on the ERCOFTAC guidelines but modified and extended specifically for CFD code validation. Within QNET-CFD 6 , the Thematic Area on Civil Construction and HVAC (Heating, Ventilating and Air-Conditioning) and the Thematic Area on the Environment presented some best practice advice for CFD simulations of wind flow and dispersion (Scaperdas and Gilham, 2004, Bartzis et al., 2004).

In 2004, Franke et al. (2004) compiled a set of specific recommendations for the use of CFD in wind engineering from a detailed review of the literature, as part of the European $\mathrm{COST}^{7}$ Action C14: Impact of Wind and Storm on City Life and Built Environment. Later, this contribution was extended into an extensive "Best Practice Guideline for the CFD simulation of flows in the urban environment" (Franke et al., 2007, 2011), in the framework of the COST Action 732: Quality Assurance and Improvement of Microscale Meteorological Models, managed by Schatzmann and Britter (http://www.mi.unihamburg.de/Home.484.0.html). Like the ERCOFTAC guidelines, also these guidelines primarily focused on steady RANS simulations, although also some limited information on URANS, LES and hybrid URANS/LES was provided. When using CFD tools, whether they are academic/open source or commercial codes, it is also important that the code is well documented, and that basic verification tests and validation studies have been successfully performed and reported. A good description of how a microscale airflow and dispersion model has to be documented can be found in the Model Evaluation Guidance Document published in the COST Action 732 by Britter and Schatzmann (2007).

In Japan, working groups of the Architectural Institute of Japan (AIJ) conducted extensive crosscomparisons between CFD simulation results and high-quality wind-tunnel measurements to support the development of guidelines for practical CFD applications. Part of these efforts were reported by Yoshie et al. (2007). In 2008, Tominaga et al. (2008a) published the "AIJ guidelines for practical applications of CFD to pedestrian wind environment around buildings", and Tamura et al. (2008) wrote the "AIJ guide for numerical prediction of wind loads on buildings". The guidelines by Tominaga et al. (2008a) focus on steady RANS simulations, while the guidelines by Tamura et al. (2008) also consider LES, given the importance of timedependent analysis for wind loading of buildings and structures.

More generic best practice advice was provided by Jakeman et al. (2006) in the article "Ten iterative steps in development and evaluation of environmental models", which were later on extended to development and evaluation of process-based biogeochemical models of estuaries by Robson et al. (2008) but also to CFD for environmental fluid mechanics (including CWE) by Blocken and Gualtieri (2012). Blocken et al. (2012) also provided a general decision framework for the analysis of PLW comfort and safety in urban areas.

These best practice guideline documents have been based on and/or reinforced by more basic guidelines and standards concerning verification and validation, as outlined in e.g. Roache (1994, 1997), AIAA ${ }^{8}$ (1998), Oberkampf et al. (2004), Roy (2005), Roy and Oberkampf (2010), $\operatorname{ASME}^{9}$ (2009), and others. It is interesting to note that the importance of numerical accuracy control is emphasised by the Journal of Fluids Engineering Editorial Policy (ASME 2011), incited by contributions by Roache et al. (1986) and Freitas (1993), which demand at least formally second-order accurate spatial discretisation.

In addition to these general guidelines, also some very specific guidelines were published. These include (1) consistent modelling of equilibrium atmospheric boundary layers in computational domains (e.g. Richards

\footnotetext{
${ }^{4}$ ERCOFTAC $=$ European Research Community on Flow, Turbulence and Combustion

${ }^{5}$ ECORA $=$ Evaluation of Computational Fluid Dynamic Methods for Reactor Safety Analysis

${ }^{6}$ QNET-CFD = Network for Quality and Trust in the Industrial Application of CFD

${ }^{7} \mathrm{COST}=$ European Cooperation in Science and Technology

${ }^{8} \mathrm{AIAA}=$ American Institute of Aeronautics and Astronautics

${ }^{9}$ ASME $=$ American Society of Mechanical Engineers
} 
and Hoxey 1993, Blocken et al. 2007a, 2007b, Hargreaves and Wright 2007, Franke et al. 2007, Di Sabatino et al. 2007, Gorlé et al. 2009, Yang et al. 2009, Parente et al. 2011, Richards and Norris 2011); (2) high-quality grid generation (e.g. Tucker and Mosquera, 2001, van Hooff and Blocken, 2010a) and (3) validation with field and laboratory data (e.g. Schatzmann et al., 1997, Schatzmann and Leitl, 2011). Note that most of the efforts in the first two areas were focused on steady RANS simulations.

The establishment of these guidelines has been an important step towards more accurate and reliable CFD simulations. Although several of the guideline documents mentioned above have been developed with focus on PLW conditions (Franke et al. 2004, Tominaga et al., 2008a, Blocken et al., 2012), most of the information is also applicable to other topics in CWE.

\section{CWE symposia: historical background and scope}

An excellent and very comprehensive overview of the history, progress and prospects of the IAWE and of the conferences in wind engineering has been provided by Solari (2007). He recalls the first Symposium on Wind Effects on Buildings and Structures in Teddington, 1963, organised by K. Scruton and his group, precisely 50 years before 6EACWE. This very successful conference incited a series of conferences: the second one in Ottawa, Canada, 1967, the third one in Tokyo, Japan, 1971, and the fourth one in London, UK, 1975. As mentioned by Solari (2007), these conferences "were destined to become milestones of modern wind engineering". At the fourth conference in London, the IAWE was founded. This incited the extension of the discipline of wind engineering beyond the study of wind effects on buildings and structures to a wider set of topics and also a wider community (Solari, 2007). Indeed, the fifth conference in Fort Collins, Colorado in 1979, did not only focus on wind effects on buildings and structures, but also included four innovative sections (Solari, 2007) that would later become main CWE topics: (1) Social and economic impact of wind storms; (2) Wind environment (wind erosion, natural ventilation, pedestrian wind comfort); (3) Physical and mathematical modelling (stack gas dispersion and snow drifting simulations in wind tunnels); and (4) Wind engineering applications (dispersion of chemical vapours and natural gas, siting of wind turbines, and train aerodynamics). It is important to note that this fifth conference was also the first International Conference on Wind Engineering (ICWE).

The later editions of the ICWE conference series saw an increasing growth of wind engineering activity and expertise in a wide range of topics. In the framework of CWE, it is important to mention the Eight ICWE held in London, Ontario, Canada, 1991 and chaired by A.G. Davenport (Davenport, 1991). Not only was this conference characterised by a very strong increase in the number of submitted and presented papers (with 264 presentations in 48 sessions, necessitating the use of parallel sessions), but it also introduced a series of new specific sessions, one of which was "Computational Fluid Dynamics (CFD)", chaired by T. Stathopoulos and R.J. Kind. As correctly pointed out by Solari (2007), the importance of this first session devoted to CFD by an ICWE cannot be overestimated.

Only one year later, a very strong impetus to CWE was provided by the organisation of a new symposium in 1992 by S. Murakami in Tokyo, Japan: the International Symposium on Computational Wind Engineering (CWE). The enormous success of this symposium was not only indicative of the potential of CFD for wind engineering, but it was also the very successful start of a new series of symposia, as indicated in Table 1. In 2005, the Executive Board of the IAWE, under presidency of G. Solari, made the important decision to manage these CWE symposia under the umbrella of the IAWE. As a result, since 2010, the CWE symposia are being held in a perfect temporal sequence and distribution of the most important conferences in the calendar of wind engineering (i.e. $\mathrm{ICWE}^{10}, \mathrm{ACWE}^{11}, \mathrm{APCWE}^{12}, \mathrm{EACWE}^{13}, \mathrm{BBAA}^{14}$ ) and also in a perfect rotation of conference venues among the different regions ${ }^{15}$ (Solari, 2007).

The success of the CWE conferences can be demonstrated in many ways, including number of presentations, number of participants, number of countries represented the conference and the resulting special issues in scientific journals. These numbers have continued to grow. There are several reasons for this. Certainly, the increasing availability of computational resources has played a main role. But at least equally important is the fact that each of these successive symposia has benefited immensely from the large success, strong reputation and excellent support of the preceding symposia and their organisers. The latest CWE symposium, CWE2010, hosted by Huber, Blocken and Stathopoulos, had 267 presentations including 6 keynote presentations and it had the pleasure of welcoming 299 participants from 30 countries. So far,

\footnotetext{
${ }^{10} \mathrm{ICWE}=$ International Conference on Wind Engineering

${ }^{11} \mathrm{ACWE}=$ American Conference on Wind Engineering

${ }^{12}$ APCWE $=$ Asia-Pacific Conference on Wind Engineering

${ }^{13}$ EACWE = European-African Conference on Wind Engineering

${ }^{14}$ BBAA = Bluff Body Aerodynamics and Applications

${ }^{15}$ The American, Asia-Pacific and European-African Region
} 
each of the five CWE symposia has also resulted in a Special Issue in either the JWEIA or the journal Wind and Structures. The growth of CWE is also demonstrated by the increasing number of research topics covered by these symposia over time, as shown in Table 2 that was prepared for the present paper. Two important comments concerning this Table are: (1) For CWE1992 and CWE1996, only selected papers of these symposia were compiled into the proceedings, and the classification in Table 2 pertains to these proceedings; (2) The topics in Table 2 are not mutually exclusive. Examples are bridges and wind-structure interaction; mesoscale modelling and meteorological phenomena; wind and thermal environment and pedestrian-level wind conditions, etc. Therefore, the comments below the Table detail the choices underlying this classification.

While many factors determine the type of contributions to a given symposium, Table 2 shows that the overall tendency is clearly towards a coverage of almost all traditional wind engineering topics by CWE. In particular, the following observations are made:

- A number of topics have been present from the very beginning. This holds in particular for the three general and fundamental topics: (1) ABL simulation, as an essential prerequisite for accurate windflow simulation around buildings and structures; (2) bluff body aerodynamics, which in this classification refers to studies with a clear focus on the application of CFD to explain fluid mechanical/physical processes of wind flow around buildings and structures; (3) turbulence modelling and numerical techniques, which in this classification refers to physical ${ }^{16}$ and numerical modelling (turbulence modelling, wall functions, grid generation, discretisation schemes, etc.), the related physical and numerical modelling errors and the resulting best practice guidelines.

- Also a very large number of applied topics, in spite of their complexity, was already present from the beginning: wind and thermal environment; pedestrian-level wind conditions; air pollutant dispersion; meteorological phenomena; flow over (complex) topography; sand, dust and snow transport; wind-driven rain; wind loads on generic obstacles and on buildings and structures; bridges; vibrations and/or wind-structure interactions; wind turbine rotor aerodynamics; computeraided experiments; and mesoscale modelling.

- $\quad \mathrm{New}^{17}$ topics at later CWE symposia were (1) surface convective heat transfer; (2) wind and acoustics; (3) wind energy site assessment, (4) wind-borne debris and (5) fires.

- Less represented topics were (1) wind energy in the built environment; and (2) sports aerodynamics. This can partly be explained by the fact that the wind energy community has its own and separate conference series, and that quite a lot of research on wind energy and sports aerodynamics is performed under contracts with confidentiality agreements, and is therefore not presented at conferences and symposia and also not published in conference and journal papers.

\section{An overview of CWE review papers published in scientific journals}

This section is limited to mentioning only a few contributions in detail and listing many others in Table 3 . This table applies the same categorisation as Table 2 in section 4 of this paper. Table 3 is limited to peer-reviewed journal papers, with one exception ${ }^{18}$. It contains the keynote and review papers published in the special issues of the previous CWE symposia, the CWE review papers published in the main wind engineering journals as well as several CWE review papers published in other journals. Many relevant CFD - but not CWE - review papers are not included, but do nevertheless constitute an important body of work on CFD.

Without wanting to detract from the excellent achievements by many CWE researchers, special attention in this section is given to a few papers by Murakami. In 1990, Murakami (1990b) provided what is - to the best of my knowledge - the first review paper in CWE. This review was very comprehensive, and, even though written more than 20 years ago, it is still very relevant. It addressed physical modelling errors, their reduction by improved turbulence modelling and wall boundary conditions, numerical errors and their assessment. It illustrated the power and potential of LES. It also contained a practical application of CWE to determine the pedestrian-level wind speed around four buildings to be located on an urban renewal site in a city near Tokyo

${ }^{16}$ The term "physical modelling" here refers to modelling of the physical processes by CFD and relates to the modelling of the object geometry and flow physics. It is associated with the specification of the equations to be solved and the boundary conditions for these equations. It is to be distinguished from numerical modelling, which is associated with the solution procedures of the equations. It is also to be distinguished from wind-tunnel testing, which is sometimes also termed physical modelling.

17 "New topics at CWE symposia" does not necessarily imply that these topics were dealt with for the first time at the CWE symposia, rather that they were not presented at previous CWE symposia.

${ }^{18}$ An exception is made for the extensive review paper by Meroney on "Wind tunnel and numerical simulation of pollution dispersion: a hybrid approach", presented at the Croucher Advanced Study Institute, Hong Kong University of Science and Technology, 6-10 December 2004. 
using steady RANS with the standard k- $\varepsilon$ model (Fig. 2a,b). A very remarkable part of this study is the detailed calculation of wind conditions at the balconies of one of these buildings, which also included the evaluation of a windbreak as remedial measure for strong winds (Fig. 2c-f). 20 years later, in the framework of revising the Dutch Wind Nuisance Standard NEN 8100, the Dutch Normalisation committee NEN asked the author of the present paper to investigate if any studies on wind comfort on balconies had been published in archival journals. This search did not yield any studies that went substantially past the pioneering work by Murakami (1990b). Recent CFD simulations for balconies were published by Montazeri and Blocken (2013) and Montazeri et al. (2013), but these simulations - although valuable - are definitely situated in the shadow of the achievements by Murakami (1990b), made 23 years earlier.

In his 1997 paper "Current status and future trends in computational wind engineering", Murakami (1997) outlines in detail why CWE is more difficult compared to some other areas in CFD. Next, this paper provides an impressive list of application examples, all of which are still intensively studied in CWE today (Fig. 3):

- Velocity and temperature fields around a human body (at the "real" human scale, i.e. the viscous sublayer at the body surface with $\mathrm{y}^{+}$values down to 3.3 , which is the layer that represents the largest resistance to heat and moisture transfer) (Fig. 3a,b);

- Velocity and pressure fields around a bluff body (bridge deck or building structure) (Fig. 3c,d);

- Coupled fluid-structure analysis;

- Pollutant dispersion around buildings;

- Pedestrian wind conditions around a high-rise building;

- Analysis of outdoor climate within city blocks (including air velocity, temperature, moisture and radiation);

- $\quad$ Mesoscale analysis of city and regional climates (Fig. 3e,f).

The paper continues by outlining "new trends in turbulence modelling for CWE applications", including the still very actual topic of inflow boundary conditions for LES, but too many to mention them all.

Table 3 provides a list of overview and review papers in CWE. It roughly indicates which topics have been extensively investigated and subsequently reviewed, and which topics might still be in need of a review paper. In particular, (additional) review papers are welcomed on CFD simulation of the neutral, stable and unstable atmospheric boundary layer, on wind and acoustics, on wind loads on solar panels, on wind energy in the built environment, on sports aerodynamics and on wind-borne debris. Note that a special issue in the JWEIA on wind loads on solar panels was established by G.A. Kopp (2013). Furthermore, in 2013, also two Virtual Special Issues in CWE were established, one on CFD simulation of micro-scale pollutant dispersion in the built environment in the journal Building and Environment (Blocken et al., 2013b) and one on CFD simulation of pedestrian-level wind conditions around buildings in the JWEIA (Blocken and Stathopoulos, 2013). In addition, note that papers by Castro and Robins (1977), Robins and Castro (1977a, 1977b), Huber and Snyder (1982), Li and Meroney (1983a, 1983b), Meroney et al. (1996), Tominaga et al. (1997), Gromke and Ruck $(2007,2008,2009,2012)$ and Gromke $(2011)$ have provided experimental data on pollutant dispersion that have been used extensively for the assessment and validation of numerical models (e.g. Li and Stathopoulos 1997, Selvam 1997, Tominaga and Stathopoulos 2007, 2009, 2010, Milliez and Carissimo 2007, 2008, Gromke et al. 2008, Blocken et al. 2008a, 2013b, Buccolieri et al. 2009, 2011, Balczo et al. 2009, Santiago et al. 2010, Dejoan et al. 2010, Salim et al. 2011a, 2011b, Di Sabatino et al. 2011, Gousseau et al. 2011b, 2012, Goricsan et al. 2011, Saloranta and Hellsten 2011, Buccolieri and Di Sabatino 2011, Baik et al. 2012, Moonen et al. 2013, Tominaga et al. 2013).

\section{Reduced-scale wind-tunnel testing and CWE: competing or complementary?}

As already mentioned in section 1, CWE is complementary to other, more traditional areas of wind engineering, such as full-scale on-site experimentation and reduced-scale wind-tunnel testing. Each approach has its specific advantages and disadvantages. CFD has some particular advantages over experimental (fullscale or reduced-scale) testing, especially the fact that it provides detailed information on the relevant flow variables in the whole calculation domain ("whole-flow field data"), under well-controlled conditions and without similarity constraints.

The following topics/processes have been reported to be very difficult or even impossible to study by reduced-scale wind-tunnel testing. It has been argued that they should be addressed by CWE:

1. Wind flow and related processes for study areas where relatively small flow features and dimensions are important, such as natural ventilation through relatively small openings, where scaling down could change the nature of the flow in these openings from turbulent to transitional or even laminar;

2. Wind flow and related processes over large areas that would require too large scaling factors, which include extensive (in terms of horizontal distances) microscale studies but certainly mesoscale studies;

3. Wind flow and related processes in atmospheric boundary layers with stable and unstable stratification;

4. Buoyant flows such as buoyancy-driven natural ventilation and air pollutant dispersion; 
5. Multiphase flow problems such as the transport and deposition of sand, dust, rain, hail and snow;

6. Meteorological phenomena such as tornadoes and downbursts.

That CWE can overcome the important problems in reduced-scale wind-tunnel testing and should be preferred is certainly true for topic (1) in situations where similarity would be strongly violated. This refers to similarity issues regarding the lowest range of spatial scales (e.g. van Hooff and Blocken 2010a, 2010b). Concerning topic (2) there are clearly concerns related to reduced-scale wind-tunnel testing (e.g. Bowen 2003) although for specific applications also successful wind-tunnel studies with large scaling factors have been reported. It should be noted that they require special preparation and care (e.g. Baker et al. 1985, Meroney 1980, 1990, Conan et al. 2012, Sanz Rodrigo et al. 2012). However, that CWE should be preferred over reduced-scale wind-tunnel testing is not really true for topics (3), (4) and (5), which present an almost equally large challenge to CWE as they do to wind-tunnel testing and where quite a number of important and successful wind-tunnel studies have been reported (e.g. Iversen 1981, Kothari et al. 1986, Meroney 1982, 1987a, 1987b, Meroney et al. 1984, Meroney and Neff 1986, Shin and Meroney 1988, Meroney and Meroney 1989, Isyumov and Mikitiuk 1990, Avissar et al. 1990, Da Matha Sant'Anna and Taylor 1990, Meroney and Melbourne 1992, Kwok et al. 1992, Smedley et al. 1993, Surry et al. 1994, Inculet and Surry 1994, Delpech et al. 1998, Inculet 2001, Sanz Rodrigo et al. 2012). Concerning topic (6), while many past studies have been numerical, also quite some experimental studies (e.g. Chay and Letchford 2002, Letchford and Chay 2002, Letchford et al. 2002, Mason et al. 2005, Xu and Hangan 2008, Tari et al. 2010) or combined numerical-experimental studies (Wood et al. 2001, Meroney 2003, Sengupta and Sarkar 2008, Sengupta et al. 2008) have been published. In addition, recently new facilities have been developed for enhanced reduced-scale testing of these and other phenomena (e.g. WindEEE Dome at the University of Western Ontario, Canada - UWO 2014).

In the past decades, often statements have been made that CFD would replace (reduced-scale) wind-tunnel testing and that it would become the "numerical wind tunnel". The label "numerical wind tunnel" was convincingly denounced by Castro and Graham in their paper "Numerical wind engineering: the way ahead?" (Castro and Graham 1999) and by Stathopoulos in his paper "The numerical wind tunnel for industrial aerodynamics: real or virtual in the new millennium?" (Stathopoulos 2002). The next section provides a series of quotes from computational wind engineers on the "numerical wind tunnel", systematically denouncing this label, however without recognising the important complementary value and potential of CWE.

The complementary aspects of wind-tunnel testing and CWE are multifold. Indeed, wind-tunnel testing can provide the indispensable high-quality validation data needed for CWE, and CWE can supplement wind-tunnel testing by providing whole-flow field data on all relevant parameters. Furthermore, Leitl and Meroney (1997) indicated the value of CFD to design wind-tunnel experiments:

"Using numerical codes ... can help to design and setup wind tunnel experiments; hence reducing the time required to optimize a physical model and expensive pre-runs in a wind tunnel. With a numerical simulation critical points like source design for dispersion simulation can be examined and boundary conditions can be modified."

Moonen et al. (2006) applied CFD to support the design and evaluation of wind tunnels. They developed a detailed methodology for numerically simulating the flow conditions in closed-circuit wind tunnels based on the method of characteristic lines. This effort was explicitly intended as a contribution to the general philosophy of incorporating CFD in wind-tunnel design and testing. They stated:

"The methodology developed in this paper and the accuracy obtained provide perspectives for the use of this methodology and of CFD in general as a tool in wind tunnel design and testing and for CFD validation studies when detailed boundary (inlet) conditions are not available."

Later, Moonen et al. (2007) developed a series of new indicators for wind-tunnel test section flow quality and applied CFD to illustrate the effectiveness of these indicators. The approach by Moonen et al. (2006) was adopted by Calautit et al. (2014) for further development of design methodologies of closed-loop subsonic wind tunnels.

\section{Some quotes}

This section lists some quotes, mainly by wind engineers, computational wind engineers and/or fluid mechanicians in the past decades. They give the reader a flavour of past discussions, concerns and trends, many of which are still equally valid today. This section is by no means intended to be complete - my incompleteness disclaimer also applies here. The quotes are provided without additional comments, to let them speak for themselves. 


\subsection{On verification and validation}

"The results of numerical simulation cannot be free from various types of numerical errors... Therefore it is indispensable that the accuracy of numerical simulation be examined by comparing the numerical results with those from wind tunnel tests or field experiments... Therefore the two different methods of research should proceed in concert and in cooperation with each other." (Murakami, 1990c)

"The frequently heard argument 'any solution is better than none' can be dangerous in the extreme. The greatest disaster one can encounter in computation is not instability or lack of convergence but results that are simultaneously good enough to be believable but bad enough to cause trouble.” (Ferziger, 1993c)

"Which model is best for which kind of flows (none is expected to be good for all flows) is not yet quite clear, partly due to the fact that in many attempts to answer this question numerical errors played a too important role so clear conclusions were not possible ... In most workshops held so far on the subject of evaluation of turbulence models, the differences between solutions produced by different authors using supposedly the same model were as large if not larger than the differences between the results of the same author using different models." (Ferziger and Peric, 1996)

"The very important point, independent of the semantics, is that use of a verified code is not enough. This point is probably well recognized by present readers, but it is not universally so. Especially in the commercial CFD arena, user expectations are often that the purchase and use of a 'really good code' will remove from the user the obligation of 'doing his homework', that is, the straightforward but tedious work of verification of calculations via systematic grid-convergence studies. This unrealistic hope is sometimes encouraged by advertising.” (Roache, 1997)

To simply compare model results with measured data is often inappropriate since data generated in field or laboratory experiments and those from model simulations exhibit systematic differences... In view of the remarks made above, it must be concluded that such a comparison often resembles the proverbial comparison of apples with oranges. (Schatzmann et al., 1997)

"Most practitioners are more concerned with obtaining results than with either the order of accuracy of their numerical schemes or the need to refine the grid until converged grid-independent solutions are obtained." (Stathopoulos, 1997)

"It appears that although CFD is definitely a good friend of wind engineering, it has not yet become a true ally." (Stathopoulos, 1997)

"In this paper, we have presented several applications of CFD analyses of outdoor climate ranging from human scale to urban scale. Comparisons of CFD results with measured data are also given when measured data are available. At this stage, the accuracy of CFD predictions is pretty good but not perfect. However, we do think that the comprehensive assessment based on the CFD method combining various factors seems to be the only approach for clarifying such complicated phenomena. Thus, further efforts are strongly required in this field." (Murakami et al, 1999)

"Good mental health in a fluid or CFD modeler is always indicated by the presence of a suspicious nature, cynicism and a 'show me' attitude. These are not necessarily the best traits for a life mate or a best friend, but they are essential if the integrity of the modeling process is to be maintained." (Meroney 2004)

“... verification is the assessment of the accuracy of the solution to a computational model, primarily by comparison with known solutions. Validation is the assessment of the accuracy of a computational simulation by comparison with experimental data. In verification, the relationship of the simulation to the real world is not an issue. In validation, the relationship between computation and the real world, ie, experimental data, is the issue. (Oberkampf et al., 2004)

" 'As Martin Jensen has reminded us the lack of full scale verification that has been tolerated is "embarrassing”. It is not characteristic of other technologies such as shipping, transportation or aeronautics.' The quote remains relevant and there is a continuing need for full-scale experimentation to 
validate loading data in codes, the use of wind tunnels and CFD.” (Baker, 2007, commenting on a quote by Davenport, 1999)

"In practice the quality of model output depends not only on the accuracy of the model itself and the model input, but also on the qualification of the person running a model. Numerical simulation is a knowledge-based activity. Appropriate knowledge can be transferred to users by recommendations concerning the proper use of models. For obstacle-resolving CFD codes such recommendations are not straightforward." (Schatzmann and Leitl, 2011)

"The judicial presumption of innocence does not hold in CFD. CFD results are wrong, until proven otherwise" (Blocken, 2014, this paper)

\subsection{On appropriate boundary conditions in CWE}

"In 1958 Jensen showed that in wind-tunnel testing it is just as important to correctly model the wind as it is to correctly model the building. This lesson must surely carry over into the relatively new field of computational wind engineering." (Richards and Hoxey, 1993)

"By setting appropriate profiles for wind velocity and the turbulence quantities at the inlet, it is often assumed that the boundary layer will be maintained up to the buildings or obstructions in the flow. This paper shows that this is not the case, even in the absence of obstructions, and that the velocity and turbulence profiles decay along the fetch under these default conditions.” (Hargreaves and Wright, 2007)

"The problems typically manifest themselves as unintended streamwise gradients in the vertical mean wind speed and turbulence profiles as they travel through the computational domain. These gradients can be held responsible - at least partly_for the discrepancies that are sometimes found between seemingly identical CFD simulations performed with different CFD codes and between CFD simulations and measurements."(Blocken et al., 2007a)

"[on LES inflow conditions] There is certainly scope for further development. For instance, the artificially generated turbulence may not be divergence free and this may have some downstream effects; this issue has rarely been addressed in the literature. A more general question, perhaps, relates to just how detailed should be the imposed statistics and, indeed, how many of the independent quantities need to be considered. Our feeling is that for general applicability it is important to model not only the turbulence stresses but also correlation scales in all three directions, as in the present method." (Xie and Castro, 2008)

“ 'Appropriate boundary conditions for computational wind engineering' was an issue addressed by Richards and Hoxey at the first Computational Wind Engineering Conference and is still a relevant issue today.” (Richards and Norris, 2011)

"In order to couple the LES with MMM [= Mesoscale Meteorological Models] successfully, several problems should be solved. One of the most significant issues to be solved from the viewpoint of CWE applications is the treatment of the turbulent velocity fluctuations imposed at the inflow as the boundary conditions." (Mochida et al., 2011)

"The inhomogeneous ABL has a significant effect on the prediction of the flow and dispersion fields, depending on the percentage deviation of the incident from the inlet conditions..." (Ai and Mak, 2013)

\subsection{On the "numerical wind tunnel"}

"The large majority of flows encountered in engineering, architectural and environmental applications are considerably more complex than those mentioned above... For these flows, the concept of a numerical wind tunnel generating quantitatively meaningful design data without careful case-related experimental validation may be decades away, if it is at all a sensible objective to pursue." (Leschziner, 1990)

"This [ = computer technology] evolution has given rise to the rather radical view - expressed predominantly among the US aerodynamics fraternity - that the wind tunnel is destined to become a 'convenient storage cabinet for computer output'. A moment's contemplation leads to the conclusion that 
this view reflects a rather narrow interpretation of CFD, focusing on the particular type of flows most relevant to high-speed external aerodynamics and some turbomachinery applications." (Leschziner, 1993)

"Using numerical codes like Fluent can help to design and setup wind tunnel experiments; hence reducing the time required to optimize a physical model and expensive pre-runs in a wind tunnel. With a numerical simulation critical points like source design for dispersion simulation can be examined and boundary conditions can be modified." (Leitl and Meroney, 1997)

"It is argued that although the potential is undoubtedly great and CFD is thus increasingly being used in industry (for assessment of wind loads, pollutant dispersion, etc.) there are significant dangers. Without a sound understanding of the fluid mechanics appropriate to the particular problem being attacked, an awareness of the extent to which the code being used has been validated for similar problems and a clear understanding of the sources of uncertainty and the accuracy levels actually needed, great caution is required in using CFD as an integral part of the design process." (Castro and Graham, 1999)

"It is true, of course, that even a highly accurate solution to the modelled equations may differ significantly from the actual flow that would occur given the same boundary conditions, because of inadequacies in the turbulence modelling. But this difference is often of secondary importance compared with those which arise because of 'bad' choices (or even plain user mistakes) in all the other areas." (Castro and Graham, 1999)

"Nevertheless, there seems to be an ever-increasing confidence in the results obtained by CFD codes and more and more papers propagate the idea that the numerical wind tunnel does exist today and produces results ready to be used by practitioners. In the author's opinion this is at best premature and at worst dangerous with the exception of very limited cases." (Stathopoulos, 2002)

"In spite of some interesting and visually impressive results produced with Computational Wind Engineering, the numerical wind tunnel is still virtual rather than real. Its potential however, is extremely high and its progress should be monitored carefully. Many more parallel studies - numerical and experimental - will be necessary in order to increase the present level of confidence in the computational results. Practitioners should be warned about the uncertainties of the numerical wind tunnel results and urged to exercise caution in their utilization. Finally, more effective efforts should be made in the numerical simulation of fluctuating flow field and the numerical evaluation of peak values of variables necessary for design." (Stathopoulos, 2002)

"Applications will become widespread in areas where wind velocities rather than surface pressures are required, such as the assessment of pedestrian comfort. These trends may well lead to the concentration of boundary layer wind tunnel testing for complex structures into a smaller number of institutions over the next few decades." (Baker, 2007)

"The biggest remaining challenge for CWE is the treatment of peak structural wind loads and peak cladding pressures on buildings. Continued hybrid use of wind tunnels and CFD with cross comparison validation between wind-tunnel (or full-scale) results will be essential to gain confidence in the methodology." (Cochran and Derickson, 2011)

"As demonstrated in this paper, inevitably, high quality CFD is often time consuming and costly. The validity of the level of expertise required and the time (cost) involved should be carefully evaluated on the basis of its purposes by comparing them with those of other assessment methods." (Tominaga and Stathopoulos, 2013)

\subsection{On Large Eddy Simulation versus RANS}

"[About LES] ... as the model formulation increases in complexity, the likelihood of degrading the model's performance due to input data and model parameter uncertainty increases as well." (Hanna, 1989)

"If it turns out that LES can be done on very coarse grids, it will be one of the few times that nature has been kind to us with regard to turbulent flows." (Ferziger, 1990) 
"In the event of peak wind and pressure loading having to be determined, a statistical framework is obviously inappropriate... In this case, the only alternative route is Large Eddy Simulation.” (Leschziner, 1993)

"At this stage, it is clear that dynamic LES gives the best results for many wind engineering applications. One disadvantage of using LES is that too much CPU time is required. However, rapid evolution of CPU hardware will surely overcome this restriction, and wide application of LES to CWE problems will certainly be realized in the near future." (Murakami, 1997)

"A major error source was found to be the stationary solution procedure that was chosen for all simulations. Since no vortex shedding at the building edges is calculated less turbulent mixing close to the building leads to stationary high concentration areas near the building edges. Less mixing observed for ground level releases might also have been caused by differences in turbulent structure close to the wall." (Leitl et al., 1997)

"It should be stressed however, that LES as a procedure of turbulence modeling is going to be truly useful only if it reaches the stage of producing peak instantaneous pressure coefficients, with some reasonable accuracy." (Stathopoulos, 2002)

"It is argued that RANS will further play an important role, especially in industrial and environmental computations, and that the further increase in the computing power will be used more to utilize advanced RANS models to shorten the design and marketing cycle rather than to yield the way to LES." (Hanjalic, 2004)

The CFD techniques that will prove to be of most use will be those that will faithfully model the turbulence structure within the atmospheric boundary layer, e.g. LES or DES techniques. The use of RANS based techniques will decrease over time, although their relative simplicity and economy will ensure their continued use for many applications.” (Baker, 2007)

"It should be noted that, in order to use CFD for wind load estimation, an accurate time-dependent analysis, such as LES, is definitely required, because it enables prediction of peak-type of quantities such as a peak pressure or maximum response of a building and a structure. Furthermore, consistency of inflow turbulence characteristics for various numerical models is very significant for appropriate wind load estimation.” (Tamura et al., 2008)

"Spatial distribution of the turbulent scalar flux inside building arrays has shown that inaccurate predictions of the effects of intermittency are the major cause for discrepancies between RANS and experimental results" (Di Sabatino et al., 2013)

\section{Application: CFD simulation of pedestrian-level wind conditions around buildings}

High-rise buildings can introduce high wind speed at pedestrian level, which can lead to uncomfortable or even dangerous conditions. Wind discomfort and wind danger can be detrimental to the success of new buildings. Wise (1970) reports about shops that are left untenanted because of the windy environment that discouraged shoppers. Lawson and Penwarden (1975) report the death of two old ladies due to an unfortunate fall caused by high wind speed at the base of a tall building. Today, many urban authorities only grant a building permit for a new high-rise building after a wind comfort study has indicated that the negative consequences for the pedestrian wind environment remain limited. Note that a wind comfort study is generally performed by a combination of three types of information/data: (1) statistical meteorological information; (2) aerodynamic information; and (3) a comfort criterion. CFD or wind-tunnel measurement data can be used to provide part of the aerodynamic information.

\subsection{CFD versus wind-tunnel measurements}

Wind comfort studies require the knowledge of at least the mean wind velocity vector field at pedestrian height $(\mathrm{z}=1.75$ or $2 \mathrm{~m})$. This information can be obtained by wind-tunnel modelling or by CFD. Wind-tunnel tests are generally point measurements with Hot-Wire Anemometry (HWA) or Hot-Film Anemometry (HFA) (e.g. Isyumov and Davenport 1975, Stathopoulos and Storms 1986, Uematsu et al. 1992, Blocken et al. 2008b), Irwin probes (Irwin 1981, Durgin 1992, Wu and Stathopoulos 1994, Monteiro and Viegas 1996, van Beeck et al. 2009, Tsang et al. 2012) or Laser-Doppler Anemometry (LDA) (e.g. van Beeck et al. 2009, Conan et al. 
2012). In the past, also area techniques such as sand erosion (Beranek and Van Koten, 1979, Beranek, 1982, 1984, Livesey et al., 1990, Richards et al., 2002, van Beeck et al., 2009, Conan et al., 2012) and infrared thermography (Yamada et al., 1996, Wu and Stathopoulos, 1997, Sasaki et al., 1997) have been used. They are however considered less suitable to obtain accurate quantitative information. Instead, they can be used as part of a two-step approach: first an area technique is used to qualitatively indicate the most important problem locations, followed by accurate point measurements at these most important locations (Blocken and Carmeliet, 2004b).

One of the main advantages of CFD in pedestrian-level wind comfort studies is avoiding this timeconsuming two-step approach by providing whole-flow field data. In spite of its deficiencies, steady RANS modelling with the k- $\varepsilon$ model or with other turbulence models has become the most popular CFD approach for pedestrian-level wind studies. Two main categories of CFD studies can be distinguished: (1) fundamental studies, which are typically conducted for simple, generic building configurations to obtain insight in the flow behaviour, for parametric studies and for CFD validation, and (2) applied studies, which provide knowledge of the wind environmental conditions in specific and often much more complex case studies. Fundamental CFD studies - beyond the case of the isolated building - were performed by several authors including Baskaran and Stathopoulos (1989), Bottema (1993), To and Lam (1995), Baskaran and Kashef (1996), Yoshie et al. (2007), Blocken et al. (2007b, 2008b), Blocken and Carmeliet (2008), Tominaga et al. (2008b) and Mochida and Lun (2008). Apart from these fundamental studies, also several CFD studies of pedestrian wind conditions in complex urban environments have been performed (Murakami, 1990b, Gadilhe et al., 1993, Takakura et al., 1993, Stathopoulos and Baskaran, 1996, Baskaran and Kashef, 1996, He and Song, 1999, Ferreira et al., 2002, Richards et al., 2002, Miles and Westbury, 2002, Westbury et al., 2002, Hirsch et al., 2002, Meroney et al. 2002, Blocken et al., 2004, Yoshie et al., 2007, Blocken and Carmeliet, 2008, Blocken and Persoon, 2009, Blocken et al. 2012, Janssen et al. 2013, Montazeri et al. 2013). Some of the computational grids and some typical presentations of results of these studies are shown in Figure 4. Almost all these studies focused on building groups, rather than isolated buildings, which is logical because unfavourable pedestrian-level wind conditions are often the specific result of the interaction of the wind-flow patterns around several buildings. Almost all these studies were also conducted with the steady RANS approach and a version of the k- $\varepsilon$ model. An exception is the study by He and Song (1999) who used LES.

\subsection{Accuracy of CFD}

Attempts to provide general statements about the accuracy of steady RANS CFD for pedestrian-level wind environment studies can easily be compromised by the presence of a combination of numerical errors and physical modelling errors. Statements on the accuracy of steady RANS with a certain turbulence model should therefore be based on CFD studies that have undergone solution verification, i.e. it should be proven that numerical errors are limited, so clear conclusions about the physical modelling errors can be made. Several studies have adopted this approach in their validation of CFD with wind-tunnel measurements and on-site measurements. A general observation from these studies is that the prediction accuracy is a pronounced function of the location in the flow pattern, and therefore of the wind direction. While several validation studies have been performed, at least two of those have provided conclusions on the accuracy of steady RANS CFD that can be generalised: the extensive validation study by Yoshie et al. (2007) for four different building and urban configurations and the validation study by Blocken and Carmeliet (2008). These two studies are discussed next.

In the framework of the development of the AIJ guideline for wind environment evaluation, Yoshie et al. (2007) reported validation studies for four different building and urban configurations (Figure 5): (1) an isolated square prism with ratio $\mathrm{L}: \mathrm{W}: \mathrm{H}=1: 1: 2$, (b) an idealized high-rise building surrounded by regularly spaced low-rise buildings, (c) building complexes in the actual urban area of Niigata, Japan, and (d) building complexes in the actual Shinjuku sub-central area in Tokyo, Japan. A view of the computational grids is also shown in Figure 5. In all four cases, the simulations were performed with steady RANS, combined with the standard k- $\varepsilon$ model or with revised k- $\varepsilon$ models, and compared with the results of wind-tunnel experiments. Note that the simulations included a grid-sensitivity analysis, careful application of the boundary conditions, higher-order discretisation schemes, a complete report of the computational settings and parameters and a detailed comparison with the wind-tunnel measurements, all of which are required in order to support the validity of the conclusions. The simulations for the isolated building were made with the standard k- $\varepsilon$ model and with two revised k- $\varepsilon$ models: the Launder-Kato k- $\varepsilon$ model (Kato and Launder, 1993) and the Renormalization Group (RNG) k- $\varepsilon$ model (Yakhot and Orszag, 1986). Comparison of the standard k- $\varepsilon$ model results with the wind-tunnel measurements showed that the amplification factor $\mathrm{U} / \mathrm{U}_{0}$ (which is the ratio of the local pedestrian-level wind speed $U$ to the wind speed $U_{0}$ that would occur at the same position without buildings) is generally predicted within an accuracy of $10 \%$ in the regions where $\mathrm{U} / \mathrm{U}_{0}>1$ (see Figure $6 \mathrm{a}$ ). In the wake region behind the building however, where $\mathrm{U} / \mathrm{U}_{0}<1$, the predicted wind speed is generally 
significantly underestimated, at some locations by a factor 5 or more (Figure 6a). The results of the other turbulence models showed a slight improvement in the high wind-speed regions, but worse results in the wake region (Figure $6 \mathrm{~b}$ ). The underestimations in the wake region are attributed to the underestimation of turbulent kinetic energy in the wake, due to the fact that steady RANS is not capable of reproducing the vortex shedding in the wake of buildings (Yoshie et al., 2007, Tominaga et al., 2008b).

The simulations for the idealized high-rise building surrounded by low-rise buildings were made with the standard k- $\varepsilon$ model and the RNG k- $\varepsilon$ model. In the high wind-speed regions, the standard k- $\varepsilon$ model underestimated the wind tunnel results by about $15 \%$. In the lower wind speed regions, differences up to a factor 4 were found. The results of the RNG k- $\varepsilon$ model showed improved performance in the high wind speed regions, but again a deteriorated performance in the lower wind speed regions. Similar conclusions on the different performance in high versus low wind speed regions were found in the CFD study for the actual urban area in Niigata: in high wind speed regions, the predictions are generally within $20 \%$ of the measurements, while the wind speed in low wind speed regions is generally significantly underestimated, at some positions with a factor 5 or more. The comparisons for the fourth configuration, the Shinjuku sub-central area, confirmed the findings for the other configurations. While for all four studies, large discrepancies are found in the low wind speed regions, it should be noted that the high wind speed regions are those of interest for pedestrianlevel wind studies. In these regions, steady RANS was shown to provide a good to very good accuracy (10$20 \%$ ).

Blocken and Carmeliet (2008) performed steady RANS CFD simulations with the realizable k- $\varepsilon$ model (Shih et al. 1995) for three configurations of parallel buildings and compared the results with the sand-erosion wind-tunnel experiments by Beranek (1982). Two of these comparisons are shown in Figure 7, yielding observations that are very similar to those by Yoshie et al. (2007): a close to very close agreement between $\mathrm{CFD}$ and wind-tunnel measurements in the region of high $\mathrm{U} / \mathrm{U}_{0}$ (about $10 \%$ accuracy) and significant underestimations in the regions of lower $\mathrm{U} / \mathrm{U}_{0}$. The regions of high $\mathrm{U} / \mathrm{U}_{0}$ are the corner streams and the areas between the buildings in which pressure short-circuiting occurs (Blocken and Carmeliet, 2008). Other results from the same study (not shown in Figure 7) indicate that also the high $\mathrm{U} / \mathrm{U}_{0}$ in the standing vortex is predicted with good accuracy by steady RANS CFD. Note that the standing vortex is only clearly visible for wind directions that are almost perpendicular to the long building facade. Regions of low $\mathrm{U} / \mathrm{U}_{0}$ do not only occur in the wake of the buildings, but are also found in the low-speed stagnation zone upstream of the buildings. Similar to the results by Yoshie et al. (2007), the underestimations in these regions can go up to a factor 5 or more. Note that also these simulations were based on grid-sensitivity analysis, careful application of the boundary conditions and higher order discretisation schemes. It should be noted that sand-erosion measurement results are generally considered to be less suitable for CFD validation, although in this study a very close agreement - both qualitatively and quantitatively - was found in the high $\mathrm{U} / \mathrm{U}_{0}$ region.

For assessing the accuracy of CFD for pedestrian-level wind studies, it is important to compare them not only with wind-tunnel measurements - where the boundary conditions are generally well-known - but also with on-site measurements. However, CFD pedestrian-level wind studies in complex urban environments including a comparison with on-site measurements are very scarce. To the knowledge of the author, only four such studies have been published: the study by Yoshie et al. (2007) for the Shinjuku Sub-central area in Tokyo (Figure 5d and 5h), the study by Blocken and Persoon (2009) for the area around the multifunctional ArenA stadium in Amsterdam (Figure 4e-f) and the studies by Blocken et al. (2012) and Janssen et al. (2013) for the Eindhoven University campus. Although these measurements were quite limited, overall, the comparisons confirmed the conclusions made earlier, albeit that the discrepancies in the high wind speed regions can slightly exceed $10 \%$.

\subsection{Practical applicability}

In spite of the very limited number of validation studies based on on-site measurements, CFD is gaining increasing acceptance as a tool for pedestrian-level wind studies. This has been confirmed by the publication of the Dutch Wind Nuisance Standard, NEN8100 (Wisse and Willemsen, 2003, NEN, 2006a, NEN, 2006b, Willemsen and Wisse, 2007) that specifically allows the user to choose between wind-tunnel testing and CFD for obtaining the aerodynamic part in the pedestrian-level wind comfort and wind safety assessment procedure. To the best of the author's knowledge, this standard is the first wind nuisance standard in the world. In addition, the option for the user to choose between wind-tunnel testing and CFD can be considered as a milestone in the acceptance process of CFD as a tool for the evaluation of wind comfort and wind safety in urban areas. However, it does not absolve the user from providing quality assurance. The decision to treat wind-tunnel experimentation and CFD as equals in the Dutch standard has not been made lightly and has indeed led to the specification of quality assurance requirements in the standard, both for CFD and for windtunnel testing. This reinforces the importance of best practice guidelines and their integration in wind comfort and wind safety studies. CFD solution verification and validation and complete reporting of the followed 
procedure are essential components of quality assurance. In practical situations and in case of complex urban environments, when measurements are often not available, CFD model validation should be performed for simpler configurations, the flow features of which show resemblance with those expected in the actual complex urban configuration (Oberkampf et al., 2004, Blocken et al., 2004, 2012, Franke et al., 2007, Yoshie et al., 2007, Blocken and Carmeliet, 2008, Tominaga et al., 2008a). For these simpler cases, wind-tunnel measurement data are generally available in the literature.

Steady RANS is the most commonly used method, while LES is still considered out of reach for practical pedestrian-level wind studies in actual urban environments (Yoshie et al. 2007). This is mainly attributed to the much larger computational cost of LES but also to the lack of best practice guidelines for LES. Indeed, as mentioned in section 3, most best practice guidelines focus on RANS. Concerning the computational cost, for pedestrian-level wind studies, simulations need to be performed for many (e.g. 12 or 16) wind directions, and this needs to be repeated for configurations with remedial measures implemented (Yoshie et al. 2007). Nevertheless, it is expected that the increase in computing power and speed together with the intrinsically superior potential of LES will render it increasingly more attractive in the years to come. While LES should be preferred over RANS for several CWE applications (especially wind loads), it is not yet fully clear whether this is the case for the practical assessment of pedestrian-level wind comfort and wind safety. There are quite some indications from recent studies supported by extensive solution verification and validation actions that steady RANS has a fairly high accuracy in predicting the mean wind speed at least for regions with high amplification factor (Yoshie et al., 2007, Blocken and Carmeliet, 2008, Blocken et al., $2011 \mathrm{a}$, Blocken et al., 2012, Janssen et al., 2013). It might turn out that - using the words by Ferziger (1990), pedestrian-level wind comfort is one of the few topics in CWE where nature is kind to us concerning turbulent flows.

\section{Application: CFD simulation of natural ventilation of buildings}

Natural ventilation is an important factor in the development of sustainable and healthy indoor environments (e.g. Finnegan et al. 1984, da Graça et al. 2002, Chang 2006, Chen et al. 2007, Chen 2009, Tablada et al. 2009, Heiselberg and Perino 2010, van Hooff and Blocken 2010a, 2012, 2013). It is driven by wind or buoyancy, or most often by a combination of both (e.g. Linden 1999, Hunt and Linden 1999, Li and Delsante 2001, Reichrath and Davies 2002, Tan and Glicksman 2005, Larsen and Heiselberg 2008). In the past decades, a lot of research efforts have contributed to the evaluation of the natural ventilation performance of buildings. A comprehensive review on methods for ventilation performance prediction for buildings was provided by Chen (2009). Other reviews were provided by, among others, Etheridge and Sandberg (1996), Reichrath and Davies (2002), Awbi (2003), Karava et al. (2004, 2006), Norton and Sun (2006), Norton et al. (2007), Etheridge (2011), Ramponi and Blocken (2012a) and Bjerg et al. (2013a, 2013b).

\subsection{CFD versus measurements}

Ventilation performance can be assessed by on-site and reduced-scale measurements, analytical and/or semiempirical formulae, simulations with zonal and multi-zone network models and CFD (Etheridge and Sandberg, 1996, Awbi, 2003, Chen, 2009, Etheridge 2011). As opposed to on-site measurements, reduced-scale windtunnel measurements offer the advantage that the boundary conditions can be carefully controlled. But windtunnel measurements also exhibit some particular problems, including incompatible similarity requirements especially when buoyancy is involved, and the scaling of the ventilation openings. Indeed, a specific problematic aspect of reduced-scale wind-tunnel measurements in natural ventilation is the scaling of the ventilation openings. It has been shown that the presence of surroundings buildings is very important to determine the natural ventilation of a given building (e.g. van Hooff and Blocken 2010b). This however imposes the need to include quite a large part of the urban surroundings in the wind-tunnel model, which in turns requires quite large scaling factors to be able to fit this urban model into the wind-tunnel test section. As a result, the ventilation openings can become so small that similarity is violated: the flow in these openings might change from turbulent at full scale to transitional or even laminar at reduced scale. In addition, the narrow ventilation openings in the scaled model might become impractically small (and nearly impossible to manufacture). CFD therefore has some clear advantages compared with on-site and reduced-scale measurements, the most important of which are that it provides whole-flow field data and that it avoids potentially incompatible similarity requirements because the simulations can be performed at full scale. In addition, CFD allows full control over the boundary conditions and easily and efficiently allows parametric studies to be performed to evaluate alternative design configurations. The latter is especially an advantage when the different configurations are all a priori embedded within the same computational domain and grid (see e.g. van Hooff and Blocken 2010a). Chen (2009) additionally mentions that CFD models are currently most popular and particularly suited for studying indoor air quality and natural ventilation, as these are difficult 
to predict with other models. For these reasons, many studies on evaluating and optimising the natural ventilation potential of buildings have employed CFD.

Two main categories of CFD studies can be distinguished: (1) fundamental studies, which are typically conducted for simple, generic building configurations to obtain insight in the flow behaviour, for parametric studies and for CFD validation, and (2) applied studies, which provide knowledge of the natural ventilation in specific and often much more complex case studies. In the remainder of this section, only natural crossventilation studies will be addressed. Fundamental studies on wind-induced cross-ventilation were performed by e.g. Kato et al. (1992), Straw et al. (2000), Kurabuchi et al. (2000), Bartzanas et al. (2002), Mistriotis and Briassoulis (2002), Shklyar and Arbel (2004), Hu et al. (2005, 2008), Lee et al. (2005), Evola and Popov (2006), Chang (2006), Wright and Hargreaves (2006), Asfour and Gadi (2007), Wang and Wong (2008, 2009), Kobayashi et al. (2009, 2010), Meroney (2009), Norton et al. (2010a), Nikas et al. (2010), Larsen et al. (2011), Cheung and Liu (2011), Ramponi and Blocken (2012a, 2012b), Shen et al. (2012), Stavridou and Prinos (2013), Bangalee et al. (2013), Chu and Chiang (2013). CFD studies of wind-induced cross-ventilation for specific buildings including those in complex urban environments were performed by e.g. Mistriotis et al. (1997a, 1997b), Jiang and Chen (2002), de Graça et al. (2002), Bartzanas et al. (2004, 2007), Tan and Glicksman (2005), Mochida et al. (2005, 2006), Fatnassi et al. (2006), Stavrakakis et al. (2008), Horan and Finn (2008), Teitel et al. (2008), Wang and Wong (2008), Norton et al. (2009, 2010a, 2010b), van Hooff and Blocken (2010a, 2010b, 2013), Wu et al. (2011), Wu et al. (2012), Lo et al. (2013) and Hajdukiewicz et al. (2013). A specific type of natural ventilation studies are those concerning specially designed roof constructions to drive natural ventilation of the building zones (e.g. Montazeri et al., 2010, Montazeri 2011, van Hooff et al., 2011a, Blocken et al., 2011b). Some of the computational grids and some typical presentations of results from CFD studies of natural cross-ventilation are shown in Figure 8. The large majority of CFD studies of natural cross-ventilation focused on an isolated building rather than on building groups. This is to some extent surprising given the potentially large impact of surrounding buildings (see e.g. van Hooff and Blocken 2010b). Most CFD studies of natural cross-ventilation were conducted with the steady RANS approach. Some exceptions are the studies by Kato et al. (1992), Kurabuchi et al. (2000), Jiang and Chen (2002), Hu et al. (2005, 2008), Meroney (2009) and Chu and Chiang (2013), who used LES, and the studies by Wright and Hargreaves (2006) and Meroney (2009) who used Detached Eddy Simulation (DES).

\subsection{Accuracy of CFD}

In CFD simulations of cross-ventilation involving large openings, a major issue of concern is the accurate modelling of the interaction between the outdoor wind flow around the buildings and the indoor air flow inside the buildings, which interact with each other at the ventilation openings. A distinction can be made between a coupled and a decoupled approach. In the coupled approach, there is a single computational geometry and computational domain, that includes both the outside and the inside environment of the building (Fig. 9a). In this approach, the ventilation openings are considered open, the outdoor wind flow and indoor air flow are solved within the same computational domain and the interaction (coupling) between the outdoor wind flow and indoor air flow is resolved in detail using the appropriate governing equations. Contrary to this, in the decoupled approach, there are two different computational geometries and two different computational domains: one for the outdoor environment and one for the indoor environment of the building (Fig. 9b). In this approach, the wind flow simulation is conducted for the building as a sealed body, i.e. the openings are "closed". This simulation yields the pressure coefficients at the positions of the openings and these coefficients are subsequently used as boundary conditions for the CFD simulation of the indoor air flow. A review of the literature indicates that, by far, most CFD research on wind-induced cross-ventilation has applied the coupled approach (Ramponi and Blocken 2012a).

The main reason for the extensive use of the coupled approach is the knowledge that, in case of large ventilation openings, the decoupled approach can introduce important errors. Indeed, the so-called sealed-body assumption in the decoupled approach implies that the pressure distribution on the building envelope is not affected by the presence of the openings (e.g. Murakami et al. 1991, Kato et al. 1992, Karava et al. 2007). It assumes that the turbulent kinetic energy is dissipated at the windward opening and that the effect of the dynamic pressure on the air flow passing through the opening is negligible (Murakami et al. 1991, Etheridge and Sandberg 1996, Seifert et al. 2006, Karava et al. 2007, 2011, Kobayashi et al. 2010). However, Murakami et al. (1991), Kato et al. (1992), Sandberg (2004), Karava et al. (2006, 2011) and Kobayashi et al. (2009, 2010) correctly pointed out that in case of wind flow through large ventilation openings, the turbulent kinetic energy is rather preserved and the sealed-body assumption is therefore no longer valid. A virtual stream-tube model was introduced to explain the direct connection between the inlet and outlet openings (Murakami 1991, Kato et al. 1992, Sandberg 2004, Kobayashi et al. 2009, 2010).

Many CFD studies of natural cross-ventilation have included a comparison with either wind-tunnel measurements or on-site measurements, or both. Given the importance of solution verification including grid- 
convergence analysis, this paper will only highlight a very small sample of the RANS studies that included a grid-convergence analysis, as well as a particular study performed with LES.

Bartzanas et al. (2004) applied 3D steady RANS with the standard k-E model to analyse the effect of the ventilation configuration of a tunnel greenhouse with crop on airflow and temperature patterns. The simulations were based on grid-sensitivity analysis yielding a grid with 76,800 cells. Validation was performed with on-site measurements of local velocity and ventilation rate data from $\mathrm{N}_{2} \mathrm{O}$ tracer gas measurements. For wind direction parallel to the ridge of the tunnel greenhouse, deviations in local wind speed varied between 10 and $35 \%$, while deviations in ventilation rate were only $12-15 \%$, which is considered a very good agreement for this rather complex study.

Evola and Popov (2006) applied 3D steady RANS with the standard and RNG k- $\varepsilon$ model to analyse crossventilation for the isolated cubic building model that was previously studied by Jiang et al. (2003) (Fig. 10a). The grid-sensitivity analysis yielded a grid of 676,000 control volumes. The wind direction was perpendicular to the ventilation openings. The CFD results were compared with the wind-tunnel measurements by Jiang et al. (2003) along 5 vertical lines (Fig. 10b). The results in Fig. 10c indicate that the RNG k- $\varepsilon$ model outperforms the standard k- $\varepsilon$ model at some locations, while the opposite is true at other locations. Comparing the ventilation rates obtained by both models with the LES results by Jiang et al. (2003), the deviation by the standard $\mathrm{k}-\varepsilon$ model is $9 \%$, while that for the RNG k- $\varepsilon$ model is only $3 \%$.

Meroney (2009) was the first to perform a very extensive CFD study of cross-ventilation for the isolated building model that was experimentally studied by Karava et al. (2011) and Karava and Stathopoulos (2012). This study was published prior to the actual publication of the experimental data. It included a detailed evaluation of steady RANS with the standard k- $\varepsilon$ model, the realizable k- $\varepsilon$ model, the RNG k- $\varepsilon$ model, the standard k- $\omega$ model (Wilcox 1998) and the Reynolds Stress Model (RSM) (Launder et al. 1975), DetachedEddy Simulation (DES) and Large-Eddy Simulation (LES). A remarkable result from this study was that despite the obvious transient nature of separation and reattachment flows some of the RANS models performed just as well as the LES or DES models.

Ramponi and Blocken (2012a) applied 3D steady RANS for the isolated building by Karava et al. (2011) and Karava and Stathopoulos (2012) (Fig. 11a). The turbulence models included the standard k- $\varepsilon$ model, the realizable k- $\varepsilon$ model, the RNG k- $\varepsilon$ model, the standard k- $\omega$ model, the shear-stress transport (SST) k- $\omega$ model (Menter 1994) and the Reynolds Stress Model (RSM). The study also investigated the impact of various other computational parameters on the accuracy of the outdoor and indoor mean velocity ratios, including the size of the computational domain, the resolution of the computational grid, the inlet turbulent kinetic energy profile of the atmospheric boundary layer, the order of the discretisation schemes and the iterative convergence criteria. The grid-sensitivity analysis yielded a grid with 575,247 control volumes (Fig. 11b). The best agreement with the PIV wind-tunnel measurements by Karava et al. (2011) was obtained by the SST k- $\omega$ model (Fig. 11c,d) followed by the RNG k- $\varepsilon$ model. The other models were insufficiently capable of reproducing the magnitude and position of the standing vortex upstream of the building facade, and of the resulting direction of the jet through the ventilation opening. Apart from the area close to the ventilation openings, where the accuracy of the PIV measurements suffered from reflections, the differences between measurements and simulations are generally less than $20 \%$, and less than $10 \%$ in the central part of the building.

Jiang and Chen (2002) compared results from LES with the Smagorinsky subgrid-scale model with experimental data from Katayama et al. (1992), who performed on-site measurements and wind-tunnel tests for both outdoor and indoor airflows on a building site (Fig. 12a,b). In particular, Jiang and Chen (2002) focused on the effect of wind-direction fluctuations on the wind-velocity patterns. Indeed, the natural wind is highly variable in both speed and direction, which cannot easily be generated in a wind tunnel. In a conventional wind tunnel, the wind direction is fixed. Therefore using a tunnel-generated wind to simulate real wind may cause significant errors. Jiang and Chen (2002) successfully demonstrated that LES can simulate both cases by fixing or changing the incoming wind direction. For the wind-tunnel case, LES with a constant wind direction was applied. For the on-site case, LES simulated the wind with either a normal or a uniform distribution depending on the magnitude of the incoming wind speed. The results in Figure $12 \mathrm{c}$ and $12 \mathrm{~d}$ show that the wind-tunnel data present a deep, thin and high velocity core in the north room (upper room) of building A and that the LES results with fixed wind direction show a similar flow pattern. The results in Figure 12e and $12 \mathrm{f}$ show that the on-site measurements present a shallower and wider high-speed region in both rooms which is clearly reproduced by LES with the varied wind direction.

For assessing the accuracy of CFD for natural cross-ventilation studies, it is important to not only perform solution verification and validation studies for isolated buildings, but also for buildings in building groups and in complex urban environments. Such studies however are scarce. Some exceptions are the study by Jiang and Chen (2002) that was mentioned above and the studies by Mochida et al. (2005, 2006), Fatnassi et al. (2006), Teitel et al. (2008) and van Hooff and Blocken (2010a, 2010b, 2013). However, many more of these studies are needed to arrive at definite conclusions concerning the accuracy of CFD for natural cross-ventilation. 


\subsection{Practical applicability}

The application of CFD for natural ventilation studies of buildings in practice - and especially for buildings situated in complex urban environments - has up to now remained rather limited. On the one hand, this is surprising because CFD provides some clear practical advantages compared to wind-tunnel testing. It does not suffer from potentially incompatible similarity requirements related to buoyancy effects and scaling of the ventilation openings because the simulations can be conducted at full scale. In addition, the coupled approach in CFD allows resolving the interaction between the outdoor wind flow and the indoor airflow. Also, CFD allows taking into account the natural variability in wind directions, which was shown to be important by Jiang and Chen (2002). On the other hand, it is not so surprising. For natural ventilation studies with the coupled approach in complex urban environments, it is important to accurately resolve the wind flow in the urban area, the flow through the ventilation openings and the indoor airflow. The large differences in spatial scales (from the extent of the urban area down to the size of the ventilation openings) puts quite high demands on the development of a high-resolution and high-quality computational grid, which in turn translates into relatively large numbers of cells and therefore a high computational cost.

Also for natural ventilation, solution verification and validation of the CFD simulations are indispensable. Although many solution verification and validation studies have been performed for isolated buildings, there is a clear lack of such studies for buildings in generic or more complex (real) urban areas. As a result, there is also a lack of specific guidelines for such simulations. This imposes the need for detailed solution verification and validation for every new case study. In practical situations and in case of complex urban environments, when onsite measurements or wind-tunnel measurements are often not available and/or not possible, CFD model validation should be performed for simpler configurations, the flow features of which show resemblance with those expected in the actual practical or complex urban configuration. For these simpler cases, wind-tunnel measurement data should be collected to allow this validation.

Steady RANS is by far the commonly used method. This is mainly attributed to the much larger computational cost of LES but also to the lack of best practice guidelines for LES. Nevertheless, it is expected that the increase in computing power and speed together with the intrinsically superior potential of LES will render it increasingly more attractive in the future. Irrespective of this expected development, future detailed validation studies for practical and complex situations should indicate in which cases steady RANS simulations can be sufficient, and in which cases the more complex LES approach should be applied. This is important because, as stated by Hanna (1989): “... as the model formulation increases in complexity, the likelihood of degrading the model's performance due to input data and model parameter uncertainty increases as well."

\section{Application: CFD simulation of wind-driven rain on building facades}

Wind-driven rain (WDR) is one of the most important moisture sources affecting the hygrothermal performance and durability of building facades. Consequences of its destructive properties can take many forms. Moisture accumulation in porous materials can lead to rain water penetration, frost damage, moisture induced salt migration, discolouration by efflorescence, structural cracking due to thermal and moisture gradients, to mention just a few. WDR impact and runoff is also responsible for the appearance of surface soiling patterns on facades that have become characteristic for so many of our buildings. Assessing the intensity of WDR on building facades is complex, because it is influenced by a wide range of parameters: building geometry, environment topography, position on the building facade, wind speed, wind direction, turbulence intensity, rainfall intensity and raindrop-size distribution (e.g. Choi 1993, 1994a, 1994b, Etyemezian et al., 2000, Blocken and Carmeliet, 2002, 2004a, Tang and Davidson, 2004).

\subsection{CFD versus measurements and semi-empirical formulae}

Three categories of methods exist for the assessment of WDR on building facades: measurements, semiempirical methods and numerical methods based on Computational Fluid Dynamics (CFD). An extensive literature review of each of these categories has been provided by Blocken and Carmeliet (2004a).

Measurements have always been the primary tool in WDR research, although a systematic experimental approach in WDR assessment is not feasible. Different reasons are responsible for this, the most important of which is the fact that WDR measurements can easily suffer from large errors (Högberg et al. 1999, van Mook 2002, Blocken and Carmeliet 2005, 2006a). Recently, guidelines that should be followed for selecting accurate and reliable WDR data from experimental WDR datasets have been proposed (Blocken and Carmeliet 2005, 2006a). The strict character of these guidelines, however, implies that only very few rain events in a WDR dataset are accurate and reliable and hence suitable for WDR studies. Other drawbacks of WDR measurements are the fact that they are time-consuming and the fact that measurements on a particular building site have very limited application to other sites. These limitations drove researchers to establish semi-empirical relationships 
between the intensity of WDR and the influencing meteorological parameters wind speed, wind direction and horizontal rainfall intensity (i.e., the rainfall intensity through a horizontal plane, as measured by a traditional rain gauge). The advantage of semi-empirical methods is their ease-of-use; their main disadvantage is that only rough estimates of the WDR exposure can be obtained (Blocken and Carmeliet 2004a, 2010). Given the drawbacks associated with measurements and semi-empirical methods, researchers realised that further achievements were to be found by employing numerical methods. CFD can be a valuable alternative to avoid time-consuming and expensive on-site or reduced-scale experiments, and provide more detailed and accurate information than (semi-)empirical formulae (Blocken et al. 2010, 2011c). To the knowledge of the author, the first CFD simulations of WDR on buildings were made by Souster (1979). Choi (1991, 1993, 1994a, 1994b) developed and applied a steady-state simulation technique for WDR. It consists of solving the wind-flow pattern and calculating the trajectories of raindrops in this pattern by solving their equation of motion (Lagrangian particle tracking). This technique allows determining the spatial distribution of WDR on building facades for given (fixed) values of the wind speed, the wind direction and the horizontal rainfall intensity. Later, Choi's simulation technique was extended into the time domain by Blocken and Carmeliet (2002, 2007a). Choi's technique (with and without the extension) has been applied by many researchers to assess the WDR exposure of building facades (e.g. Lakehal et al. 1995, Choi 1997, Hangan 1999, Etyemezian et al. 2000, van Mook 2002, Blocken et al. 2002, 2004a, 2006b, 2007b, 2010, 2011c, Tang and Davidson 2004). A particular application of CFD WDR simulations for buildings concerns the wetting of stands in football stadia (Persoon et al. 2008, van Hooff et al. 2011b). The large majority of CFD WDR studies focused on isolated buildings rather than on building groups. Most CFD WDR studies were based on the steady RANS approach with a k- $\varepsilon$ turbulence model to provide closure.

\subsection{Accuracy of CFD}

Although validation is an essential part of CFD WDR simulations, up to now, only a few validation attempts have been made. Hangan (1999) compared his CFD simulations with the WDR wind-tunnel tests by Inculet and Surry (1994). CFD validation with on-site full-scale WDR measurements was performed by van Mook (2002), Blocken and Carmeliet (2002, 2004a, 2006b, 2007b), Tang and Davidson (2004), Abuku et al. (2009), Briggen et al. (2009), Huang and Li (2010) and Kubilay et al. (2013). While some authors found significant discrepancies between simulations and measurements, others indicated a fair to good agreement. Three examples are given below.

Validation studies of CFD simulations of WDR for a low-rise building were first performed by Blocken and Carmeliet in 2002 and later extended by the same authors in 2006 and 2007 (Blocken and Carmeliet 2002, 2006b, 2007b). WDR measurements were made at 9 positions on the facade of the low-rise VLIET test building during 1997-1999 and at 24 facade positions during 2002 (Figure 13a). Figure 13b illustrates contours of the catch ratio on the south-west facade after a rain event with south-west wind direction. The catch ratio is the ratio of the WDR sum at a certain position at the facade to the horizontal rainfall sum measured by a traditional rain gauge (i.e. the unobstructed rainfall sum falling on the ground). The three separate validation studies in (Blocken and Carmeliet 2007b) indicate deviations between CFD results and measurements that are $20 \%$ on average, but that can locally go up to $50 \%$ and more. Considering the complexity of turbulent wind flow around a building and WDR deposition on building surfaces, $20 \%$ is considered very good agreement. Several remarks are made here: (1) The CFD simulations were made on grids based on grid-sensitivity analysis, with second-order discretisation schemes and specific care was given to specification of the boundary conditions; (2) The measurement data for validation were carefully selected to minimise measurement errors; (3) A good to very good qualitative agreement (wetting patterns) was obtained; (4) The error percentages mentioned do not include the values on the west corner of the building that was in reality influenced by a row of trees that was not included in the CFD model.

Tang et al. (2004) and Tang and Davidson (2004) performed measurements and CFD simulations of WDR on the facades of the Cathedral of Learning in Pittsburg, US, to explain the surface soiling patterns on the facades (Figure 13c-d). WDR measurements were made at 16 locations for a period of 21 months. The CFD simulations were performed using the extended simulation method by Blocken and Carmeliet (2002). The deviations were on average $25 \%$. The higher deviations compared to the study by Blocken and Carmeliet (2007b) can be attributed to the larger geometrical complexity of the building and its high-rise character, as will be explained below. Figure 13e shows the catch ratio distribution for different reference wind speeds. For this type of building, $25 \%$ is considered a very good agreement.

Briggen et al. (2009) conducted WDR measurements and CFD simulations for the south-west facade of the monumental building Hunting Lodge Saint Hubertus in the Netherlands, to provide the boundary conditions for numerical BE-HAM transfer models to analyse the moisture related damage to the facades (Figure 13f). The grid was based on grid-sensitivity analysis, specific care was given to the boundary conditions and the measurement data for validation were carefully selected following the guidelines by Blocken and Carmeliet 
(2005). In spite of these efforts, very large discrepancies were found at the lower part of the south-west facade (up to more than a factor 2), while a fair to good agreement was found at the upper part (20\% on average). One set of results is shown in Figure 13g. The most likely reason for these discrepancies is the role of the turbulent dispersion of raindrops, which was neglected in these studies. The effect of turbulent dispersion can be very different depending on the building geometry and the position on the building (Briggen et al., 2009). It can be especially important for the bottom part of high-rise buildings and when the reference wind speed is low. The reason is that in this case, the raindrop trajectories (without turbulent dispersion) close to the windward facade are almost vertical and parallel to the bottom part of the windward facade, and do not always impinge on the facade. Turbulent dispersion in the streamwise direction can cause these raindrops to deviate from their "mean" trajectory and to hit the facade anyway. This means that, when including turbulent dispersion, more rain will impinge on the lower part of the facade in reality than calculated with the CFD model. This statement is corroborated by an earlier study by Lakehal et al. (1995) who found that turbulent dispersion is an important factor increasing WDR on vertical walls in cases with weak upstream wind flow, such as in a street canyon.

For assessing the accuracy of CFD for WDR studies, it is important to not only perform validation studies for isolated buildings, but also for buildings in building groups and in complex urban environments. Such studies however are very scarce, but they are needed to arrive at definite conclusions concerning the accuracy of CFD for WDR.

\subsection{Practical applicability}

In spite of quite some research efforts, the application of CFD for WDR studies in practice has up to now remained very limited. A few authors provided specific guidelines for CFD WDR simulation (Choi, 1994a, 1994b, Blocken and Carmeliet, 2002, 2004a, 2006b, Briggen et al., 2009). It should be noted that the guidelines mentioned in section 4 also apply for CFD WDR studies, as accurate calculation of the wind-flow pattern is the first step for successful WDR simulations. There are two main reasons for the current limited practical use of CFD for WDR studies: (1) the very time-consuming character of Lagrangian particle tracking of raindrops, in which the entire building facade needs to be covered by a large number of raindrops.

Lagrangian particle tracking implies solving the equation of motion of individual raindrops within the windflow field. Note that this wind-flow field is generally obtained with an Eulerian approach, i.e. not focusing on individual particles but on fixed positions in space. Lagrangian tracking needs to be performed for a large number of combinations of reference wind speed, wind direction and raindrop diameter. (2) The fact that steady RANS generally does not allow accurate modelling of turbulence fields around buildings, and therefore also not of turbulent dispersion of raindrops, which is important for calculating WDR intensities at the lower part of high-rise building facades. Accurate turbulent dispersion modelling would require transient simulations with LES or hybrid URANS/LES, which would require even more intensive Lagrangian particle tracking efforts. To alleviate these problems, it might be necessary to abandon the traditional "Eulerian-Lagrangian" framework in CFD WDR simulations, and to resort to "Eulerian-Eulerian" modelling instead, in which not only the wind-flow pattern, but also the WDR intensities are computed with an Eulerian approach. This implies that the rain phase, like the air phase, is treated as a continuum. This approach has been followed by Huang and $\mathrm{Li}$ (2010) and Kubilay et al. (2013) and is expected to become the preferred approach in the future.

\section{Summary and future perspectives}

In the past 50 years, Computational Wind Engineering (CWE) has undergone a successful transition from an emerging field into an increasingly established field in wind engineering research, practice and education. This paper addressed three key illustrations of the success of CWE: (1) the establishment of CWE as an individual research and application area in wind engineering with its own successful conference series under the umbrella of the International Association of Wind Engineering (IAWE); (2) the increasing range of topics covered in CWE; and (3) the history of related review papers published in scientific journals.

CWE and CFD offer some particular advantages compared with on-site measurements and reduced-scale wind tunnel measurements. They can provide detailed information on the relevant flow variables in the whole calculation domain ("whole-flow field data"), under well-controlled conditions and without similarity constraints. However, the accuracy and reliability of CFD are of concern and solution verification and validation studies are imperative. This requires high-quality full-scale or reduced-scale measurements, which in turn should satisfy important quality criteria. In addition, it is widely recognised that the results of CFD simulations can be very sensitive to the wide range of computational parameters that have to be set by the user. This expresses the need for best practice guidelines for CWE.

CWE is complementary to other, more traditional areas of wind engineering, such as full-scale on-site experimentation and reduced-scale wind-tunnel testing. But it cannot replace them. Although several claims concerning the establishment of the "numerical wind tunnel" have been made, mainly by non-wind engineers, 
the CWE community has systematically and throughout the past decades, up to the present day, denounced this label and has continued to warn that many CWE problems are too complex to be tackled by CFD alone. Instead, exploiting the synergy between experiments and CFD simulations is promoted.

Care for high quality and reliability of CFD simulations is crucial. Poor quality in CWE can easily spread, contaminate and damage the field - the further development of CWE requires the opposite. In a personal communication with Robert N. Meroney, Emeritus Professor of Civil and Environmental Engineering at Colorado State University, USA, he expressed his important concerns based on his 50 years of expertise and experience in computational and experimental wind engineering as follows:

"Many go directly to using commercial CFD codes without ever taking a course in fundamental numerical methods. This has and will continue to lead to inappropriate designs and decisions. A similar situation occurred during the 1960's when D. Bruce Turner published his famous "Workbook of Atmospheric Dispersion Estimates", EPA, 1969. He was horrified to find that many engineering firms were handing the workbook to young hirees, and telling them to apply it to stack plume calculations to real situations. The result was that the methodology was applied frequently "outside the box" of validation or intention. Often the applications were so distorted from the intended use that the results had no relation to reality. He told me personally that he wished he never wrote the document." (Meroney, 2014)

Indeed, the increasing availability of (commercial) CFD codes with user-friendly graphical user interfaces and the related increased accessibility - combined with the increasing availability of computational power has strongly increased the use of CFD in Environmental and Structural Wind Engineering. This is both a blessing and a curse. A blessing because it has allowed CWE to develop into the strong field in wind engineering that it is today. A curse because it is precisely the increased availability and accessibility that, far too often, has led, is leading and will continue to lead to the use of CFD for CWE without the required basic knowledge. Present and future evaluation of such studies will be unforgiving. There is no substitute for thorough knowledge of fluid mechanics and numerical methods. There is no substitute for detailed literature study of CFD and CWE literature and for the systematic and strenuous application of published best practice guidelines.

Care for high quality and reliability of CFD simulations is crucial. Therefore, building further on the many research efforts made in the past decades, present and future CWE simulations should demonstrate their quality and reliability by:

- Demonstrated assessment of numerical and physical modelling errors. Discretisation errors, based on at least second order schemes, should be assessed by spatial and temporal sensitivity analyses, with Richardson extrapolation and preferably reported using the convergence index by Roache (1997). After assessment of the numerical modelling errors, physical modelling errors should be estimated by comparison with high-quality wind-tunnel or on-site measurement data. If such data are not available, the validation should be performed for simpler configurations, the flow features of which show resemblance with those expected in the case under study.

- Demonstrated adherence to general best practice guidelines in CWE, such as those by Franke et al. (2007, 2011), Britter and Schatzmann (2007), Tominaga et al. (2008a), Tamura et al. (2008) and Blocken and Gualtieri (2012) and to specific best practice guidelines such as those by Richards and Hoxey (1993), Blocken et al. (2007a), Hargreaves and Wright (2007), Di Sabatino et al. (2007) and others. Note however that most best practice guidelines for CFD focus on steady RANS rather than on LES and that the development of specific guidelines for LES in CWE is an important task for the future.

It has been shown that the steady RANS approach in CWE has several important limitations, although it appears to be rather successful for pedestrian-level wind conditions, at least when high-quality and highresolution grids are applied and when focusing on areas with high amplification factors, which are often the areas of primary interest in those studies. In this respect, it might turn out that - using the words by Ferziger (1990), pedestrian-level wind conditions is one of the few topics in CWE where nature is kind to us concerning turbulent flows.

In addition, steady RANS has also been used successfully for studies of natural cross-ventilation of buildings and wind-driven rain on building facades, although by far most of these studies only considered isolated buildings. Future studies should analyse the capabilities of steady RANS when applied to buildings in both generic and realistic urban environments. On the other hand, steady RANS is clearly deficient when mean and especially peak values of pollutant concentration or surface pressure are needed. LES is intrinsically capable of providing this information, on condition of sufficient computational resources, accurate initial and boundary conditions and sufficiently high spatial and temporal resolution. Particular challenges for the future are exploring the boundaries of coarse-grid LES and LES with efficient time- 
stepping and the establishment of best practice guidelines for LES in CWE. Important achievements here would open up a wide range of additional opportunities and applications for CWE.

Past research efforts have shown the application of CFD to many areas of wind engineering. Nevertheless, some areas appear still fairly unexploited - or at least unpublished - and might represent fertile ground for new CWE developments and related publications: (1) Surface convective heat transfer; (2) Wind and acoustics; (3) Wind-borne debris; (4) Wind energy in the built environment; (5) Sports aerodynamics.

CWE has come a long way. While there is still a long way to go, many problems to be tackled, many research questions to be addressed and many challenges to overcome, the strong progress established in the past 50 years provides a promising outlook for its future.

\section{Acknowledgements}

This paper is an extended version of the keynote paper by the author at the $6^{\text {th }}$ European-African Conference on Wind Engineering (6EACWE) in Cambridge, UK, July 7-11, 2013. The author is very grateful to the organisers for the kind invitation to deliver a keynote lecture, and for their efforts in making this conference a great success. 6EACWE was organised by Dr. John Owen, Prof.dr. Mark Sterling, Dr. David Hargreaves, Prof.dr. Chris Baker, Dr. Hassan Hemida and Dr. Andrew Quinn.

The author is deeply indebted to his mentor in (computational) wind engineering, Prof.dr. Ted Stathopoulos, whose group at Concordia University, Montreal, he joined in 2004-2005, thanks to a fellowship from the Research Fund of Flanders (FWO-Vlaanderen) in Flanders, Belgium. He is also very grateful to his mentors in building physics, Prof.dr. Jan Carmeliet, previously full professor at Leuven University in Belgium and now Chair of Building Physics at ETH Zurich, Switzerland, and Prof.dr. Hugo Hens, emeritus full professor at Leuven University.

The author is a member of the Dutch-Flemish Wind Engineering Association, which is part of the IAWE, and as such he expresses his gratitude to his colleagues in this Association, in particular Prof. Jacob Wisse (founding member of the Association), Prof.dr. Chris Geurts, Carine van Bentum, Eddy Willemsen and Prof.dr. Jeroen van Beeck.

In 2010, the author had the opportunity to contribute to the organisation of CWE2010 in Chapel Hill, North Carolina, as chair of the scientific committee under the excellent chairmanship of Dr. Alan Huber and in close collaboration with Prof.dr. Ted Stathopoulos and Prof.dr. Robert Meroney. In 2011, the author assisted in the organisation of ICWE13 in Amsterdam, as chair of the scientific committee, under the excellent chairmanship of Prof.dr. Chris Geurts. Many thanks are due to both conference organising committees for the very enjoyable and successful collaboration in support of the activities of the IAWE.

The author expresses his great appreciation to the Executive Board of the IAWE, in particular to Prof.dr. Giovanni Solari, previous IAWE president, and to Prof.dr. Yukio Tamura, present IAWE president, for their extensive and very successful efforts in building the future of wind engineering in the framework of the IAWE.

The author thanks his national and international colleagues, many of which are cited in this paper. A very special acknowledgement is given to Prof.dr. Robert N. Meroney for his many invaluable comments to this paper based on his 50 years of expertise and experience in computational and experimental wind engineering. Special thanks also go both Prof.dr. Robert N. Meroney and Prof.dr. Shuzo Murakami for their pioneering achievements in CWE that have shaped the past of CWE and will continue to shape its future. Thanks also go to Prof.dr. Y. Tominaga and Prof.dr. R. Yoshie, for the kind permission to reproduce some of their figures in this paper.

Finally, last but certainly not least, a warm and sincere acknowledgement is given to the postdocs and $\mathrm{PhD}$ students in my group, whose youthful motivation, hard work and inspiration keep us going every day: Postdocs Dr. Twan van Hooff and Dr. Christof Gromke, and PhD students Dr. Rubina Ramponi (who received her PhD between submission and revision of this paper), Hamid Montazeri, Wendy Janssen, Okke Bronkhorst, Yasin Toparlar, Adelya Khayrullina, Jorge Isaac Peren Montero, Katarina Kosutova, Raffaele Vasaturo, Samy Iousef and Alessandro Pizzoferrato. The same warm acknowledgement is given to the previous PhD students that I supervised: Dr. Thijs Defraeye and Dr. Pierre Gousseau. And to the current visiting and/or external PhD students in the group: Thijs van den Brande, Aytac Kubilay, Antonio Castillo Torres and Alessio Ricci. 


\section{References}

Abuku M, Blocken B, Nore K, Thue JV, Carmeliet J, Roels S. 2009. On the validity of numerical wind-driven rain simulation on a rectangular low-rise building under various oblique winds. Building and Environment 44(3): 621-632.

Ai, Z.T., Mak, C.M. 2013. CFD simulation of flow and dispersion around an isolated building: Effect of inhomogeneous ABL and near-wall treatment. Atmospheric Environment 77: 568-578.

AIAA, 1998. Guide for the verification and validation of computational fluid dynamics simulations, American Institute of Aeronautics and Astronautics, AIAA, AIAA-G-077-1998, Reston, VA.

AMS. 2014. Meteorological Glossary. American Meteorological Society. http://glossary.ametsoc.org/wiki/Mesoscale. Retrieved on March 4, 2014.

Asfour, O.S., Gadi, M.B. 2007. A comparison between CFD and Network models for predicting wind-driven ventilation in buildings. Build Environ 42: 4079-85.

ASME, 2009. Standard for verification and validation in Computational Fluid Dynamics and heat transfer. ASME VandV 20-2009, The American Society of Mechanical Engineers.

ASME, 2011. http://journaltool.asme.org/Templates/JFENumAccuracy.pdf. Retrieved on 30 July 2011.

Avissar, R., Moran, M.D., Wu, G., Meroney, R.N., Pielke, R.A. 1990. Operating rages of mesoscale numerical models and meteorological wind tunnels for the simulation of sea and land breezes. Boundary-Layer Meteorology 50: 227-275.

Awbi, H.B. 2003. Ventilation of buildings. London: New York: Spon Press.

Ayotte, K. 2008. Computational modelling for wind energy assessment. Journal of Wind Engineering and Industrial Aerodynamics, 96, 10-11, 1571-1590.

Baetke, F., Werner, H., Wengle, H. 1990. Numerical simulation of turbulent flow over surface-mounted obstacles with sharp edges and corners. Journal of Wind Engineering and Industrial Aerodynamics, 35 (13), 129-147.

Baik, J.-J., Kwak, K.-H., Park, S.-B., Ryu, Y.-H. 2012: Effects of building roof greening on air quality in street canyons. Atmospheric Environment 61, 48-55.

Baker, C.J., Wood, C.J., Gawthorpe, R.G. 1985. Strong winds in complicated hilly terrain - field measurements and wind-tunnel study. Journal of Wind Engineering and Industrial Aerodynamics 18(1), 126.

Baker, C.J. 2000. Foreword. Proceedings of the $3^{\text {rd }}$ International Symposium on Computational Wind Engineering, Birmingham, UK, 4-7 September, 2000.

Baker C.J., 2007. Wind engineering - Past, present and future. Journal of Wind Engineering and Industrial Aerodynamics 95(9-11), 843-870.

Baker C.J. 2010. The flow around high speed trains. Journal of Wind Engineering and Industrial Aerodynamics 98(6-7), 277-298.

Balczo, M., Gromke, C., Ruck, B. 2009. Numerical modelling of flow and pollutant dispersion in street canyons with tree planting. Meteorologische Zeitschrift 18(2): 197-206.

Balczo, M., Balogh, M., Goricsan, I., Nagel, T., Suda, J.M., Lajos, T. 2011. Air quality around motorway tunnels in complex terrain - computational fluid dynamics modeling and comparison to wind tunnel data. IDOJARAS 115, 3, 179-204.

Bangalee, M.Z.I., Miau, J.J., Lin, S.Y., Yang, J.H. 2013. Flow visualization, PIV measurement and CFD calculation for fluid-driven natural cross-ventilation in a scale model. Energy and Buildings 66: 306-314.

Bartzanas, T., Boulard, T., Kittas, C. 2002. Numerical simulation of the airflow and temperature distribution in a tunnel greenhouse equipped with insect-proof screen in the openings. Comput Electron Agric 34: $207-$ 21.

Bartzanas, T., Boulard, T., Kittas, C. 2004. Effect of vent arrangement on windward ventilation of a tunnel greenhouse. Biosystems Eng 88: 479-90.

Bartzanas, T., Kittas, C., Sapounas, A.A., Nikita-Martzopoulou, C. 2007. Analysis of airflow through experimental rural buildings: Sensitivity to turbulence models. Biosystems Eng 97: 229-39.

Bartzis, J.G., Vlachogiannis, D., Sfetsos, A. 2004. Thematic area 5: Best practice advice for environmental flows. The QNET-CFD Network Newsletter, 2 (4), 34-39.

Bartzis, J.G. 2006. Turbulence modelling in the atmospheric boundary layer: a review and some recent developments. WIT Transactions on Ecology and the Environment: Air Pollution XIV: 86: 3-12.

Baskaran, A., Kashef, A. 1996. Investigation of air flow around buildings using computational fluid dynamics techniques. Engineering Structures 18 (11), 861-873.

Baskaran, A., Stathopoulos, T. 1989. Computational evaluation of wind effects on buildings. Building and Environment, 24 (4), 325-333.

Baskaran, A., Stathopoulos, T. 1992. Influence of computational parameters on the evaluation of wind effects on the building envelope. Building and Environment, 27 (1), 39-49. 
Beranek, W.J. 1982. Beperken van windhinder om gebouwen, deel 2, Stichting Bouwresearch no. 90, Kluwer Technische Boeken BV, Deventer (in Dutch).

Beranek, W.J. 1984. Wind environment around single buildings of rectangular shape, Heron, 29 (1), 4-31.

Beranek, W.J., Van Koten, H. 1979. Beperken van windhinder om gebouwen, deel 1, Stichting Bouwresearch no. 65, Kluwer Technische Boeken BV, Deventer (in Dutch).

Bitsuamlak, G., Stathopoulos, T., Bédard, C. 2004. Numerical evaluation of wind flow over complex terrain: review. Journal of Aerospace Engineering 17(4), 135-145.

Bjerg, B., Liberati, P., Marucci, A., Zhang, G., Banhazi, T., Bartzanas, T., Cascone, G., Lee, I.B., Norton, T., 2013a. Modelling of ammonia emissions from naturally ventilated livestock buildings. Part 2: Air change modelling. Biosystems Engineering 116: 246-258.

Bjerg, B., Cascone, G., Lee, I.B., Bartzanas, T., Norton, T., Hong, S.W., Seo, I.H., Banhazi, T., Liberati, P., Marucci, A., Zhang, G., 2013b. Modelling of ammonia emissions from naturally ventilated livestock buildings. Part 3: CFD modelling. Biosystems Engineering 116: 259-275.

Blocken B, Carmeliet J. 2002. Spatial and temporal distribution of driving rain on a low-rise building. Wind and Structures 5(5): 441-462.

Blocken, B., Carmeliet, J. 2004a. A review of wind-driven rain research in building science. Journal of Wind Engineering and Industrial Aerodynamics, 92 (13), 1079-1130.

Blocken, B., Carmeliet, J, 2004b. Pedestrian wind environment around buildings: Literature review and practical examples. Journal of Thermal Envelope and Building Science, 28 (2), 107-159.

Blocken, B., Roels, S., Carmeliet, J. 2004. Modification of pedestrian wind comfort in the Silvertop Tower passages by an automatic control system. Journal of Wind Engineering and Industrial Aerodynamics, 92 (10), 849-873.

Blocken B, Carmeliet J. 2005. High-resolution wind-driven-rain measurements on a low-rise building experimental data for model development and model validation. Journal of Wind Engineering and Industrial Aerodynamics 93(12): 905-928.

Blocken B, Carmeliet J. 2006a. On the accuracy of wind-driven rain measurements on buildings. Building and Environment 41(12): 1798-1810.

Blocken B, Carmeliet J. 2006b. The influence of the wind-blocking effect by a building on its wind-driven rain exposure.Journal of Wind Engineering and Industrial Aerodynamics 94(2): 101-127.

Blocken B, Carmeliet J. 2007a. On the errors associated with the use of hourly data in wind-driven rain calculations on building facades. Atmospheric Environment 41(11): 2335-2343.

Blocken B, Carmeliet J. 2007b. Validation of CFD simulations of wind-driven rain on a low-rise building. Building and Environment 42(7): 2530-2548.

Blocken, B., Carmeliet, J. 2008. Pedestrian wind conditions at outdoor platforms in a high-rise apartment building: generic sub-configuration validation, wind comfort assessment and uncertainty issues, Wind and Structures, 11 (1), 51-70.

Blocken, B., Stathopoulos, T., Carmeliet, J, 2007a. CFD simulation of the atmospheric boundary layer: wall function problems. Atmospheric Environment, 41 (2), 238-252.

Blocken, B., Carmeliet, J., Stathopoulos, T. 2007b. CFD evaluation of wind speed conditions in passages between parallel buildings - effect of wall-function roughness modifications for the atmospheric boundary layer flow. Journal of Wind Engineering and Industrial Aerodynamics, 95 (9-11), 941-962.

Blocken B, Stathopoulos T, Saathoff P, Wang X. 2008a. Numerical evaluation of pollutant dispersion in the built environment: comparisons between models and experiments. Journal of Wind Engineering and Industrial Aerodynamics 96(10-11): 1817-1831.

Blocken, B., Stathopoulos, T., Carmeliet, J. 2008b. Wind environmental conditions in passages between two long narrow perpendicular buildings. Journal of Aerospace Engineering - ASCE 21(4): 280-287.

Blocken, B., Moonen, P., Stathopoulos, T., Carmeliet, J. 2008c. A numerical study on the existence of the Venturi-effect in passages between perpendicular buildings. Journal of Engineering Mechanics - ASCE, 134 (12), 1021-1028.

Blocken, B., Persoon, J. 2009. Pedestrian wind comfort around a large football stadium in an urban environment: CFD simulation, validation and application of the new Dutch wind nuisance standard. Journal of Wind Engineering and Industrial Aerodynamics, 97 (5-6), 255-270.

Blocken, B, Carmeliet J. 2010. Overview of three state-of-the-art wind-driven rain assessment models and comparison based on model theory. Building and Environment, 45 (3), 691-703.

Blocken B, Deszö G, van Beeck J, Carmeliet J. 2010. Comparison of calculation methods for wind-driven rain deposition on building facades. Atmospheric Environment 44(14): 1714-1725.

Blocken, B., Stathopoulos T, Carmeliet, J., Hensen, J.L.M. 2011a. Application of CFD in building performance simulation for the outdoor environment: an overview. Journal of Building Performance Simulation 4(2), 157-184. 
Blocken B, van Hooff T, Aanen L, Bronsema B. 2011b. Computational analysis of the performance of a venturi-shaped roof for natural ventilation: venturi-effect versus wind-blocking effect. Computers and Fluids 48(1): 202-213.

Blocken B, Abuku M, Nore K, Briggen PM, Schellen HL, Thue JV, Roels S, Carmeliet J. 2011 c. Intercomparison of wind-driven rain deposition models based on two case studies with full-scale measurements. Journal of Wind Engineering and Industrial Aerodynamics 99(4): 448-459.

Blocken, B., Gualtieri, C. 2012. Ten iterative steps for model development and evaluation applied to Computational Fluid Dynamics for Environmental Fluid Mechanics. Environmental Modelling and Software 33: 1-22.

Blocken, B., Janssen, W.D., van Hooff, T. 2012. CFD simulation for pedestrian wind comfort and wind safety in urban areas: General decision framework and case study for the Eindhoven University campus. Environmental Modelling and Software 30, 15-34.

Blocken, B., Derome, D., Carmeliet, J. 2013a. Rainwater runoff from building facades: a review. Building and Environment 60: 339-361.

Blocken, B., Tominaga, Y., Stathopoulos, T. 2013b. Editorial to virtual special issue: CFD simulation of micro-scale pollutant dispersion in the built environment. Building and Environment 64: 225-230.

Blocken, B., Stathopoulos, T. 2013. Editorial to virtual special issue: CFD simulation of pedestrian-level wind conditions around buildings: past achievements and prospects. Journal of Wind Engineering and Industrial Aerodynamics 121: 138-145.

Bottema, M. 1993. Wind climate and urban geometry. PhD thesis, Eindhoven University of Technology, 212 p.

Bournet, P.E., Boulard, T. 2010. Effect of ventilator configuration on the distributed climate of greenhouses: A review of experimental and CFD studies. Computers and Electronics in Agriculture 74, 2, 195-217.

Bowen, A.J. 2003. Modelling of strong wind flows over complex terrain at small geometric scales. Journal of Wind Engineering and Industrial Aerodynamics 91(12-15), 1859-1871.

Briggen PM, Blocken B, Schellen HL. 2009. Wind-driven rain on the facade of a monumental tower: numerical simulation, full-scale validation and sensitivity analysis. Building and Environment 44(8): $1675-1690$.

Britter, R., Schatzmann, M. (Eds.). 2007. Model Evaluation Guidance and Protocol Document COST Action 732. COST Office Brussels, ISBN 3-00-018312-4.

Buccolieri, R., Gromke, C., Di Sabatino, S., Ruck, B. 2009. Aerodynamic effects of trees on pollutant concentration in street canyons. Science of the Total Environment 407(19): 5247-5256.

Buccolieri, R., Salim, S.M., Leo, L.S., Di Sabatino, S., Chan, A.D., Ielpo, P., de Gennaro, G., Gromke, C. 2011. Analysis of local scale tree-atmosphere interaction on pollutant concentration in idealized street canyons and application to a real urban junction. Atmospheric Environment 45(9): 1702-1713.

Buccolieri, R., Di Sabatino, S. 2011. MUST experiment simulations using CFD and integral models. International Journal of Environment and Pollution 44(1-4): 376-384.

Calautit, J.K., Chaudry H.N., Hughes, B.R., Sim, L.F. 2014. A validated design methodology for a closed-loop subsonic wind tunnel. Journal of Wind Engineering and Industrial Aerodynamics 125: 180194.

Canepa, E. 2004. An overview about the study of downwash effects on dispersion of airborne pollutants. Environmental Modelling and Software 19, 12, 1077-1087.

Casey, M., Wintergerste, T. 2000. Best Practice Guidelines, ERCOFTAC Special Interest Group on Quality and Trust in Industrial CFD, ERCOFTAC, Brussels.

Castro, I.P., Graham, J.M.R. 1999. Numerical wind engineering: the way ahead? Proceedings of the Institution of Civil Engineers - Structures and Buildings, 134, 3, 275-277.

Castro, I.P., Robins, A.G. 1977. Flow around a surface-mounted cube in uniform and turbulent streams. Journal of Fluid Mechanics 79, 307-.

Cermak, J.E. 1975. Applications of fluid mechanics to wind engineering - A Freeman Scholar Lecture. J. Fluids Engng., ASME, March, 9-38.

Chang, W.R. 2006. Effect of porous hedge on cross ventilation of a residential building. Build Environ 41: 549-56.

Chapman S. 1965. Introduction to Dover edition of weather prediction by numerical process.

Chay, M.T., Letchford, C.W. 2002. Pressure distributions on a cube in a simulated thunderstorm downburst Part A: stationary downburst observations. Journal of Wind Engineering and Industrial Aerodynamics 90(7): 711-732.

Charney, J.G. 1955. The use of the primitive equations of motion in numerical prediction. Tellus 7: 22-26.

Charney, J.G., Fjortoft, R., von Neumann, J. 1950. Numerical integration of the barotropic vorticity equation. Tellus 2: 237-254. 
Chen, Q., Glicksman, L.R., Lin, J., Scott, A. 2007. Sustainable urban housing in China. J Harbin Inst Tech (New Series) 14: 6-9.

Chen, Q. 2009. Ventilation performance prediction for buildings: A method overview and recent applications. Building and Environment 44(4): 848-858.

Cheung, J.O.P., Liu, C.H. 2011. CFD simulations of natural ventilation behaviour in high-rise buildings in regular and staggered arrangements at various spacings. Energy Build 43: 1149-58.

Choi, E.C.C. 1991. Numerical simulation of wind-driven rain falling onto a 2-D building, in: Asia Pacific Conf. on Computational Mechanics, Hong Kong, 1721-1728.

Choi, E.C.C., 1993. Simulation of wind-driven rain around a building. Journal of Wind Engineering and Industrial Aerodynamics 46\&47, 721-729.

Choi, E.C.C. 1994a. Determination of wind-driven rain intensity on building faces. Journal of Wind Engineering and Industrial Aerodynamics 51, 55-69.

Choi, E.C.C. 1994b. Parameters affecting the intensity of wind-driven rain on the front face of a building. Journal of Wind Engineering and Industrial Aerodynamics 53: 1-17.

Choi, E.C.C. 1997. Numerical modelling of gust effect on wind-driven rain. Journal of Wind Engineering and Industrial Aerodynamics 72: 107-116.

Chu C.R., Chiang B.F., 2013. Wind-driven cross ventilation with internal obstacles. Energy and Buildings 67 : 201-209.

Cochran, L., Derickson R. 2011. A physical modeler's view of Computational Wind Engineering. Journal of Wind Engineering and Industrial Aerodynamics 99(4): 139-153.

Conan, B., van Beeck, J., Aubrun, S., 2012. Sand erosion technique applied to wind resource assessment. $J$ Wind Eng Ind Aerodyn 104-106: 322-329.

Cowan, I.R., Castro, I.P., Robins, A.G, 1997. Numerical considerations for simulations of flow and dispersion around buildings, Journal of Wind Engineering and Industrial Aerodynamics, 67 and 68: 535-545.

da Graça, G., Chen, Q., Glicksman, L.R., Norford, L.K. 2002. Simulation of wind-driven ventilative cooling systems for an apartment building in Beijing and Shanghai. Energy Build 34: 1-11.

Da Matha Sant'Anna, F., Taylor, D.A. 1990. Snow drifts on flat roofs: wind tunnel tests and field measurements. Journal of Wind Engineering and Industrial Aerodynamics 34(3): 223-250.

Dalgliesh, W.A., Surry, D. 2003. BLWT, CFD and HAM modelling vs. the real world: Bridging the gaps with full-scale measurements. Journal of Wind Engineering and Industrial Aerodynamics 91: 1651-1669.

Davenport, A.G., 1991. Preface to the Proceedings of the 8th International Conference on Wind Engineering, London, Ontario.

Davenport, A.G., 1999. The missing links. Proceedings of the 10th International Conference on Wind Engineering, Copenhagen, pp. 3-15.

Deaves, D.M. 1975. Wind over hills: A numerical approach. Journal of Wind Engineering and Industrial Aerodynamics 1: 371-391.

Defraeye, T., Blocken, B., Derome, D., Nicolai, B., Carmeliet, J. 2012. Convective heat and mass transfer modelling at air-porous material interfaces: Overview of existing methods and relevance. Chemical Engineering Science 74, 49-58.

Defraeye, T., Verboven, P., Ho, Q.T., Nicolai, B. 2013. Convective heat and mass exchange predictions at leaf surfaces: Applications, methods and perspectives. Computers and Electronics in Agriculture 96: 180-201.

Dejoan, A., Santiago, J.L., Martilli, A., Martin, F., Pinelli, A. 2010. Comparison between Large-Eddy Simulation and Reynolds-Averaged Navier-Stokes computations for the MUST field experiment. Part II: Effects of incident wind angle deviation on the mean flow and plume dispersion. Boundary-Layer Meteorology 135(1): 133-150.

Delage, Y., Taylor, P.A. 1970. Numerical studies of heat island circulations. Boundary-Layer Meteorology 1: 201-226.

Delpech, Ph., Palier, P., Gandemer, J. 1998. Snowdrifting simulation around Antartic buildings. J Wind Eng Ind Aerodyn. 74-76: 567-576.

Derickson, R.G., Meroney, R.N. 1977. A simplified physics airflow model for evaluating wind power sites in complex terrain. Summer Computer Simulation Conference, July 18-20, 1977, Hyatt Regency, Chicago, Illinois.

Di Sabatino, S., Buccolieri, R., Pulvirtenti, B., Britter, R. 2007. Simulations of pollutant dispersion within idealised urban-type geometries with CFD and integral models. Atmospheric Environment 41: 8316-8329.

Di Sabatino S., Buccolieri R., Olesen H. R., Ketzel M., Berkowicz R., Franke J., Schatzmann M., Schlünzen H., Leitl B., Britter R., Borrego C., Costa A. M., Trini Castelli S., Reisin T., Hellsten A., Saloranta J., Moussiopoulos N., Barmpas F., Brzozowski K., Goricsan I., Balczò M., Bartzis J., Efthimiou G., Santiago J. L., Martilli A., Piringer M., Hirtl M., Baklanov A., Nuterman R., Starchenko A., 2011. COST 732 in practice: the MUST model evaluation exercise. Int. J. Environment and Pollution 44, 403-418. 
Di Sabatino, S., Buccolieri, R., Salizzoni, P. 2013. Recent advancements in numerical modelling of flow and dispersion in urban areas: a short review. Int. J. Environment and Pollution 52, 3-4: 172-191.

Durgin, F.H., 1992. Pedestrian level wind studies at the Wright brothers facility. J Wind Eng Ind Aerodyn. 44(1-3): 2253-2264.

Estoque, M.A. 1961. A theoretical investigation of the sea breeze. Quart. J. Roy. Metorol. Soc. 87: 136-146.

Estoque, M.A. 1962. The sea breeze as a function of the prevailing synoptic situation. J. Atmospheric Sci. 19: 244-250.

Estoque, M.A., Bhumralkar C.M. 1969. Flow over a localized heat source. Monthly Weather Review 97: 850859.

Etheridge, D.W., Sandberg, M., 1996. Building ventilation: theory and measurement. Chichester, New York: John Wiley \& Sons.

Etheridge DW. 2011. Natural ventilation of buildings. Theory, measurement and design. Wiley, $454 \mathrm{p}$.

Etyemezian, V., Davidson, C.I., Zufall, M., Dai, W., Finger, S., Striegel, M. 2000. Impingement of rain drops on a tall building. Atmospheric Environment, 34 (15), 2399-2412.

Evola, G., Popov, V. 2006. Computational analysis of wind driven natural ventilation in buildings. Energy Build 38: 491-501.

Fatnassi, H., Boulard, T., Poncet, C., Chave, M. 2006. Optimisation of greenhouse insect screening with computational fluid dynamics. Biosystems Eng 93: 301-12.

Fernando, H.J.S., Zajic, D., Di Sabatino, S., Dimitrova, R., Hedquist, B., Dallman, A. 2010. Flow, turbulence and pollutant dispersion in urban atmospheres. Physics of Fluids 22(5): 051301

Ferreira, A.D., Sousa, A.C.M., Viegas, D.X. 2002. Prediction of building interference effects on pedestrian level comfort. Journal of Wind Engineering and Industrial Aerodynamics, 90, 4-5, 305-319.

Ferziger, J.H. 1990. Approaches to turbulent flow computation: applications to flow over obstacles. Journal of Wind Engineering and Industrial Aerodynamics 35: 1-19.

Ferziger, J.H. 1993a. A computational fluid dynamicist's view of CWE. Journal of Wind Engineering and Industrial Aerodynamics, 46-47, 879-880.

Ferziger, J.H. 1993b. Simulation of complex turbulent flows: recent advances and prospects in wind engineering. Journal of Wind Engineering and Industrial Aerodynamics, 46-47, 195-212.

Ferziger, J.H. 1993c. Estimation and reduction of numerical error. FED vol. 158, Symposium on Quantification of Uncertainty in Computational Fluid Dynamics, ASME Fluid Engineering Division, Summer Meeting, Washington DC, June 20-24, pp. 1-8.

Ferziger, J.H., Peric, M. 1996. Computational methods for fluid dynamics. Springer Berlin, 356p.

Finnegan, M.J., Pickering, C.A., Burge, P.S. 1984. The sick building syndrome: prevalence studies. Br Med J (Clin Res Ed) 289: 1573-5.

Fisher, E.L. 1961. A theoretical study of the sea breeze. Journal of Meteorology 18: 216-233.

Fosberg, M.A. 1967. Numerical analysis of convective motions over a mountain ridge. Journal of Applied Meteorology 6: 889-904.

Fosberg, M.A. 1969. Airflow over a heated coastal mountain. Journal of Applied Meteorology 8: 436-442.

Franke, J., Hirsch, C., Jensen, A.G., Krüs, H.W., Schatzmann, M., Westbury, P.S., Miles, S.D., Wisse, J.A., Wright, N.G. 2004. Recommendations on the use of CFD in wind engineering. In: van Beeck, J.P.A.J. (Ed.), Proceedings of the International Conference on Urban Wind Engineering and Building Aerodynamics. COST Action C14, Impact of Wind and Storm on City Life Built Environment. Von Karman Institute, Sint-Genesius-Rode, Belgium, 5-7 May 2004.

Franke, J., Hellsten, A., Schlünzen, H., Carissimo, B. (Eds.). 2007. Best practice guideline for the CFD simulation of flows in the urban environment. COST Office Brussels, ISBN 3-00-018312-4.

Franke, J., Hellsten, A., Schlünzen, H., Carissimo, B. 2011. The COST 732 best practice guideline for CFD simulation of flows in the urban environment - A summary. International Journal of Environmental Pollution 44(1-4): 419-427.

Freitas, C.J. 1993. Journal of Fluids Engineering editorial policy statement on the control of numerical accuracy. Journal of Fluids Engineering, 115, 339-340.

Frost, W., Maus, J.R., Fichtl, G.H. 1974. A boundary-layer analysis of atmospheric motion over a semielliptical surface obstruction. Boundary-Layer Meteorology 7: 165-184.

Fujii, K. 2005. Progress and future prospects of CFD in aerospace-Wind tunnel and beyond. Progress in Aerospace Sciences 41, 6, 455-470.

Gadilhe, A., Janvier, L., Barnaud, G. 1993. Numerical and experimental modelling of the three-dimensional turbulent wind flow through an urban square. Journal of Wind Engineering and Industrial Aerodynamics, 46-47: 755-763.

Ge, Y.J., Xiang, H.F. 2008. Recent development of bridge aerodynamics in China. Journal of Wind Engineering and Industrial Aerodynamics, 96, 6-7, 736-768. 
Goricsan, I., Balczo, M., Balogh, M., Czader, K., Rakai, A., Tonko, C. 2011. Simulation of flow in an idealised city using various CFD codes. International Journal of Environment and Pollution 44(1-4): 359-367.

Gorlé, C., van Beeck, J., Rambaud, P., Van Tendeloo, G. 2009. CFD modelling of small particle dispersion: the influence of the turbulence kinetic energy in the atmospheric boundary layer. Atmospheric Environment, 43 (3), 673-681.

Gosman, A.D. 1999. Developments in CFD for industrial and environmental applications in wind engineering. Journal of Wind Engineering and Industrial Aerodynamics 81(1-3): 21-39.

Gousseau P, Blocken B, Stathopoulos T, van Heijst GJF. 2011. CFD simulation of near-field pollutant dispersion on a high-resolution grid: a case study by LES and RANS for a building group in downtown Montreal. Atmospheric Environment 45(2): 428-438.

Gousseau P, Blocken B, van Heijst GJF. 2011. CFD simulation of pollutant dispersion around isolated buildings: On the role of convective and turbulent mass fluxes in the prediction accuracy. Journal of Hazardous Materials 194: 422-434.

Gousseau, P., Blocken, B., van Heijst, G.J.F. 2012. Large-Eddy Simulation of pollutant dispersion around a cubical building: analysis of the turbulent mass transport mechanism by unsteady concentration and velocity statistics. Environmental Pollution 167: 47-57.

Gromke, C., Ruck, B. 2007. Influence of trees on the dispersion of pollutants in an urban street canyon Experimental investigation of the flow and concentration field. Atmospheric Environment 41(16): $3287-$ 3302.

Gromke, C., Buccolieri, R., Di Sabatino, S., Ruck, B. 2008. Dispersion study in a street canyon with tree planting by means of wind tunnel and numerical investigations - Evaluation of CFD data with experimental data. Atmospheric Environment 42(37): 8640-8650.

Gromke, C., Ruck, B. 2008. Aerodynamic modelling of trees for small-scale wind tunnel studies. Forestry 81(3): 243-258

Gromke, C., Ruck, B. 2009. On the impact of trees on dispersion processes of traffic emissions in street canyons. Boundary-Layer Meteorology 131(1): 19-34.

Gromke, C., Ruck, B. 2012. Pollutant concentrations in street canyons of different aspect ration with avenues of trees for various wind directions. Boundary-Layer Meteorology 144(1): 41-64.

Gromke, C. 2011. A vegetation modeling concept for building and environmental aerodynamics wind tunnel tests and its application in pollutant dispersion studies. Environmental Pollution 159(8-9): 2094-2099.

Hajdukiewicz, M., Geron, M., Keane, M.M. 2013. Calibrated CFD simulation to evaluate thermal comfort in a highly-glazed naturally ventilated room. Building and Environment 70: 73-89.

Hall, R.C. (ed.). 1997. Evaluation of modelling uncertainty. CFD modelling of near-field atmospheric dispersion. Project EMU final report, European Commission Directorate-General XII Science, Research and Development Contract EV5V-CT94- 0531. Surrey: WS Atkins Consultants Ltd.

Haltiner, G.J., Williams, R.T. 1980. Numerical prediction and dynamic meteorology. Wiley, 477 p.

Hangan, H., 1999. Wind-driven rain studies. A C-FD-E approach. Journal of Wind Engineering and Industrial Aerodynamics, 81: 323-331.

Hanjalic, K., 2004. Will RANS survive LES? A view of perspectives. Journal of Fluids Engineering Transactions of the ASME 127, 5, 831-839.

Hanjalic, K., Kenjeres, S. 2008. Some developments in turbulence modeling for wind and environmental engineering. Journal of Wind Engineering and Industrial Aerodynamics,96(10-11): 1537-1570.

Hanna, S.R., 1989. Plume dispersion and concentration fluctuations in the atmosphere. Encyclopedia of environmental control technology. In: Air Pollution Control, Vol. 2. Houston, TX: Gulf Publishing Company, 547-582.

Hansen, M.O.L., Sørensen, J.N., Voutsinas, S., Sørensen, N., Madsen, H.A. 2006. State of the art in wind turbine aerodynamics and aeroelasticity. Progress in Aerospace Sciences 42, 4, 285-330.

Hanson, T., Summers D.M., Wilson, C.B. 1986. Validation of a computer simulation of wind flow over a building model. Building and Environment, 21: 97-111.

Hargreaves, D.M., Wright, N.G. 2007. On the use of the $\mathrm{k}-\varepsilon$ model in commercial CFD software to model the neutral atmospheric boundary layer. Journal of Wind Engineering and Industrial Aerodynamics, 95 (5), 355-369.

He, J., Song, C.C.S. 1999. Evaluation of pedestrian winds in urban area by numerical approach. Journal of Wind Engineering and Industrial Aerodynamics, 81, 295-309.

Heiselberg, P., Perino, M. 2010. Short-term airing by natural ventilation-implication on IAQ and thermal comfort. Indoor Air 20: 126-40.

Hess, J.L., Smith, A.M.O. 1967. Calculation of potential flow about arbitrary bodies. Progress in Aeronautics Sciences 8: 1-138. 
Hirsch, C., Bouffioux, V., Wilquem, F. 2002. CFD simulation of the impact of new buildings on wind comfort in an urban area. Workshop Proceedings, Cost Action C14, Impact of Wind and Storm on City Life and Built Environment, Nantes, France.

Hirt, C.W., Cook, J.L. 1972. Calculating three-dimensional flows around structures and over rough terrain. Journal of Computational Physics 10: 324-340.

Högberg, A.B., Kragh, M.K., van Mook, F.J.R. 1999. A comparison of driving rain measurements with different gauges. Proceedings of the fifth symposium of building physics in the Nordic Countries, Gothenburg; p. 361-8.

Holmes, N.S., Morawska, L. 2006. A review of dispersion modelling and its application to the dispersion of particles: An overview of different dispersion models available. Atmospheric Environment, 40, 30, 59025928.

Horan, J.M., Finn, D.P. 2008. Sensitivity of air change rates in a naturally ventilated atrium space subject to variations in external wind speed and direction. Energy Build 40: 1577-85.

Hu, C.H., Kurabuchi, T., Ohba, M. 2005. Numerical study of cross-ventilation using two-equation RANS turbulence models. Int $J$ Vent 4: 123-32.

Hu, C.H., Ohba, M., Yoshie, R. 2008. CFD modelling of unsteady cross ventilation flows using LES. $J$ Wind Eng Ind Aerodyn 96: 1692-706.

Huang, S.H., Li, Q.S., 2010. Numerical simulations of wind-driven rain on building envelopes based on Eulerian multiphase model. Journal of Wind Engineering and Industrial Aerodynamics, 98(12), 843-857.

Huber, A.H., Snyder, W.H. 1982. Wind tunnel investigation of the effects of a rectangular-shaped building on dispersion of effluents from short adjacent stacks. Atmospheric Environment 16(12): 2837-2848.

Huber, A., Blocken, B. 2011. Preface to the Special Issue of the $5^{\text {th }}$ Symposium on Computational Wind Engineering. Journal of Wind Engineering and Industrial Aerodynamics 99(4): vii-ix.

Hucho, W.H., Sovran, G. 1993. Aerodynamics of road vehicles. Annual Review of Fluid Mechanics 25, $485-$ 537.

Hughes, T.J.R, Jansen, K., 1993. Finite element methods in wind engineering. Journal of Wind Engineering and Industrial Aerodynamics, 46-47, 297-313.

Hunt, G.R., Linden, P.F. 1999. The fluid mechanics of natural ventilation - displacement ventilation by buoyancy-driven flows assisted by wind. Build Environ 34: 707-20.

Inculet, D., Surry, D. 1994. Simulation of wind-driven rain and wetting patterns on buildings, BLWTLSS301994, Final report.

Inculet, D.R. 2001. The design of cladding against wind-driven rain. Ph.D. thesis, The University of Western Ontario, London, Canada, 297 p.

Irwin HPAH. 1981. A simple omnidirectional sensor for wind-tunnel studies of pedestrian-level winds. $J$ Wind Eng Ind Aerodyn. 7(3): 219-239.

Isyumov N, Davenport AG. 1975. Comparison of full-scale and wind tunnel wind speed measurements in the commerce court plaza. J Wind Eng Ind Aerodyn 1: 201-212.

Isyumov, N., Mikitiuk, M. 1990. Wind tunnel model tests of snow drifting on a two-level flat roof. Journal of Wind Engineering and Industrial Aerodynamics 36(2): 893-904.

Iversen, J.D. 1981. Comparison of wind-tunnel model and full-scale snow fence drifts. Journal of Wind Engineering and Industrial Aerodynamics 8(3): 231-249.

Yamada, T., Meroney, R.N. 1972. Numerical and wind tunnel simulation of airflow over an obstacle. National Conference on Atmospheric Waves, American Meteorological Society, Salt Lake City, October 12-15, 1971.

Jakeman, A.J., Letcher, R.A., Norton, J.P. 2006. Ten iterative steps in development and evaluation of environmental models. Environmental Modelling and Software 21(5), 602-614.

Janssen WD, Blocken B, van Hooff T. 2013. Pedestrian wind comfort around buildings: comparison of wind comfort criteria based on whole-flow field data for a complex case study. Building and Environment 59: 547-562.

Jiang, Y., Chen, Q. 2002. Effect of fluctuating wind direction on cross natural ventilation in buildings from large eddy simulation. Build Environ 37: 379-86.

Jiang Y, Alexander D, Jenkins H, Arthur R, Chen Q. 2003. Natural ventilation in buildings: measurement in a wind tunnel and numerical simulation with large-eddy simulation. $J$ Wind Eng Ind Aerodyn 91:331-353.

Jiru T.E., Bitsuamlak, G.T. 2010. Application of CFD in modelling wind-induced natural ventilation of buildings - a review. International Journal of Ventilation, 9, 2, 131-147.

Jones, W., Launder, B. 1972. The prediction of laminarization with a two-equation model of turbulence. Int $J$ Heat Mass Transfer 15:301-14.

Karava, P., Stathopoulos, T., Athienitis, A.K., 2004. Wind driven flow through openings-a review of discharge coefficients. Int J Vent 3: 255-66. 
Karava, P., Stathopoulos, T., Athienitis, A.K., 2006. Impact of internal pressure coefficients on wind-driven ventilation analysis. Int J Vent 5: 53-66.

Karava, P., Stathopoulos, T., Athienitis, A.K. 2007. Wind-induced natural ventilation analysis. Sol Energy 81: 20-30.

Karava, P., Stathopoulos, T., Athienitis, A.K. 2011. Airflow assessment in cross-ventilated buildings with operable facade elements. Build Environ 46:266-79.

Karava P, Stathopoulos T. 2012. Wind-induced internal pressures in buildings with large façade openings. $J$ Eng Mech 138(4): 358-370

Kareem, A., 2008. Numerical simulation of wind effects: A probabilistic perspective. Journal of Wind Engineering and Industrial Aerodynamics, 96(10-11), 1472-1497.

Kasahara, A., Washington, W.M., 1967. NCAR global general circulation model of the atmosphere, Mon. Weather Rev. 95: 389-402.

Kasahara, A. 1974. Various vertical coordinate systems used for numerical weather prediction. Mon. Weather Rev. 102(7): 509-522.

Katayama, T., Tsutsumi, J., Ishii, A. 1992. Full-scale measurements and wind tunnel tests on cross-ventilation. Journal of Wind Engineering and Industrial Aerodynamics, 41-44: 2553-2562.

Kato, S., Murakami, S., Mochida, A., Akabayashi, S., Tominaga, Y. 1992. Velocity-pressure field of cross ventilation with open windows analyzed by wind tunnel and numerical simulation. J Wind Eng Ind Aerodyn 44: 2575-86.

Kato, M., Launder, B.E. 1993. The modelling of turbulent flow around stationary and vibrating square cylinders. Nineth Symposium on Turbulent Shear Flows, pp. 10-14.

Katz, J. 2006. Aerodynamics of race cars. Annual Review of Fluid Mechanics 38, 27-63.

Kimura, R. 2002. Numerical weather prediction. Journal of Wind Engineering and Industrial Aerodynamics, 90: 1403-1414.

Kobayashi, T., Sagara, K., Yamanaka, T., Kotani, H., Takeda, S., Sandberg, M. 2009. Stream tube based analysis of problems in prediction of cross-ventilation rate. Int $J$ Vent 7: 321-34.

Kobayashi, T., Sandberg, M., Kotani, H., Claesson, L. 2010. Experimental investigation and cfd analysis of cross-ventilated flow through single room detached house model. Build Environ 45: 2723-34.

Kothari, K.M, Peterka, J.A., Meroney, R.N. 1986. Perturbation analysis and measurements of building wakes in a stably stratified turbulent boundary layer. Journal of Wind Engineering and Industrial Aerodynamics, 25(1): 49-74.

Kopp G.A. 2013. Guest editorial for SI: Solar array and wind loads. Journal of Wind Engineering and Industrial Aerodynamics, 123, 191.

Kubilay A, Derome D, Blocken B, Carmeliet J. 2013. CFD simulation and validation of wind-driven rain on a building facade with an Eulerian multiphase model. Building and Environment 61: 69-81.

Kurabuchi, T., Ohba, M., Arashiguchi, A., Iwabuchi, T., 2000. Numerical study of airflow structure of a cross ventilated model building. In: Air Distribution in Rooms: Ventilation for Health and Sustainable Environment 313-8.

Kwok, K.C.S., Kim, D.H., Smedley, D.J., Rohde, H.F. 1992. Snowdrift around buildings for antartic environment. J Wind Eng Ind Aerodyn. 44(1-3): 2797-2808.

Lakehal, D., Mestayer, P.G., Edson, J.B., Anquetin, S., Sini, J.F., 1995. Eulero-Lagrangian simulation of raindrop trajectories and impacts within the urban canopy. Atmospheric Environment, 29 (23), 3501-3517.

Larsen, T.S., Heiselberg, P. 2008. Single-sided natural ventilation driven by wind pressure and temperature difference. Energy Build 40: 1031-40.

Larsen, T.S., Nikolopoulos, N., Nikolopoulos, A., Strotos, G., Nikas, K.S. 2011. Characterization and prediction of the volume flow rate aerating a cross ventilated building by means of experimental techniques and numerical approaches. Energy Build 43: 1371-81.

Launder BE, Reece GJ, Rodi W. 1975. Progress in the development of a Reynolds-stress turbulence closure. $J$ Fluid Mech 68:537-66.

Lawson, T.V., Penwarden, A.D. 1975. The effects of wind on people in the vicinity of buildings, Proceedings 4th International Conference on Wind Effects on Buildings and Structures, Cambridge University Press, Heathrow, pp. 605-622.

Lee, I., Lee, S., Kim, G., Sung, J., Sung, S., Yoon, Y. 2005. PIV verification of greenhouse ventilation air flows to evaluate CFD accuracy. Trans ASAE (Am Soc Agric Eng) 48: 2277-88.

Lee, I.-B, Bitog, J.P.P., Hong, S.-W., Seo, I.-H., Kwon, K.-S., Bartzanas, T., Kacira, M. 2013. The past, present and future of CFD for agro-environmental applications. Computers and Electronics in Agriculture, 93, 168-183.

Lee, R.L., Albritton, J.R., Ermak, D.L., Kim, J. 1997. Computational fluid dynamics modeling for emergency preparedness and response. Environmental Modelling and Software, 12, 1, 43-50. 
Lee, I.B., Bitog, J.P.P., Hong, S.-W., Seo, I.H., Kwon, K.S., Bartzanas, T., Kacira, M., 2013. The past, present and future of CFD for agro-environmental applications. Computers and Electronics in Agriculture 93: 168-183.

Leitl, B.M., Kastner-Klein, P., Rau, M., Meroney, R.N. 1997. Concentration and flow distributions in the vicinity of U-shaped buildings: wind-tunnel and computational data. Journal of Wind Engineering and Industrial Aerodynamics, 67\&68, 745-755.

Leitl, B.M., Meroney, R.N. 1997. Car exhaust dispersion in a street canyon. Numerical critique of a wind tunnel experiments. Journal of Wind Engineering and Industrial Aerodynamics, 67\&68, 293-304.

Leschziner M.A. 1993. Computational modelling of complex turbulent flow - expectations, reality and prospects. Journal of Wind Engineering and Industrial Aerodynamics 46-47, 37-51.

Leschziner, M.A. 1990. Modelling engineering flows with Reynolds stress turbulence closure. Journal of Wind Engineering and Industrial Aerodynamics 35: 21-47.

Letchford, C.W., Chay, M.T. 2002. Pressure distributions on a cube in a simulated thunderstorm downburst. Part B: moving downburst observations. Journal of Wind Engineering and Industrial Aerodynamics 90(7): 733-753.

Letchford, C.W., Mans, C., Chay, M.T. 2002. Thunderstorms - their importance in wind engineering (a case for the next generation wind tunnel). Journal of Wind Engineering and Industrial Aerodynamics 90(1215): 1415-1433.

Leung, D.YC., Yang, Y. 2012. Wind energy development and its environmental impact: A review. Renewable and Sustainable Energy Reviews 16, 1, 1031-1039.

Li, W.W., Meroney, R.N. 1983a. Gas dispersion near a cubical model building. Part II. Concentration fluctuation measurements. Journal of Wind Engineering and Industrial Aerodynamics, 12, 1, 35-47.

Li, W.W., Meroney, R.N. 1983b. Gas dispersion near a cubical model building. Part I. Mean concentration measurements. Journal of Wind Engineering and Industrial Aerodynamics, 12, 1, 15-33.

Li, Y., Stathopoulos, T. 1997. Numerical evaluation of wind-induced dispersion of pollutants around a building, J.Wind Eng. Ind. Aerodyn. 67\&68: 757-766.

Li, X.X., Liu, C.H., Leung, D.Y.C., Lam, K.M. 2006. Recent progress in CFD modelling of wind field and pollutant transport in street canyons. Atmospheric Environment, 40, 29, 5640-5658.

Li, Y.G., Delsante, A. 2001. Natural ventilation induced by combined wind and thermal forces. Build Environ 36: 59-71.

Linden, P.F. 1999. The fluid mechanics of natural ventilation. Annu Rev Fluid Mech 31: 201-38.

Livesey, F., Inculet, D., Isyumov, N., Davenport, A.G. 1990. A scour technique for evaluation of pedestrian winds, Journal of Wind Engineering and Industrial Aerodynamics, 36, 779-789.

Livingstone, I., Wiggs, G.F.S., Weaver, C.M. 2007. Geomorphology of desert sand dunes: A review of recent progress. Earth-Science Reviews 80(3-4): 239-257.

Lo, L.J., Banks, D., Novoselac, A. 2013. Combined wind tunnel and CFD analysis for indoor airflow prediction of wind-driven cross-ventilation. Building and Environment 60: 12-23.

Lynch, P. 2006. The emergence of numerical weather prediction: Richardson's dream. Cambridge University Press, Cambridge, UK, pp. 1-27.

Lynch, P. 2008. The origins of computer weather prediction and climate modelling. Journal of Computational Physics 227: 3431-3444.

Magata, M. 1965. A study of the sea breeze by numerical experimentation. Papers Meteor. Geophys. Tokyo 16: 23-36.

Mason, M.S., Letchford, C.W., James, D.L. 2005. Pulsed wall jet simulation of a stationary thunderstorm downburst: part A: Physical structure and flow field characterization. Journal of Wind Engineering and Industrial Aerodynamics 93(7): 557-580.

Mehta, R.D. 1985. Aerodynamics of sports balls. Annual Review of Fluid Mechanics, 17, 151-189.

Menter, F., Hemstrom, B., Henrikkson, M., Karlsson, R., Latrobe, A., Martin, A., Muhlbauer, P., Scheuerer, M., Smith, B., Takacs, T., Willemsen, S. 2002. CFD Best Practice Guidelines for CFD Code Validation for Reactor-Safety Applications, Report EVOLECORA-D01, Contract No. FIKS-CT-2001-00154, 2002.

Menter, F.R. 1994. Two-equation eddy-viscosity turbulence models for engineering applications. AIAA J 32:1598-605.

Meroney, B.N., Meroney, R.N. 1989. Snow control with vortex and blower fences. Proc. of Conf. on A Multidisciplinary Approach to Snow Engineering, Santa Barbara, California, 10-15 July 1988.

Meroney, R.N., Yamada, T. 1971. Wind tunnel and numerical experiments of two-dimensional stratified airflow over a heated island. Winter Annual Meeting of ASME, Nov. 28-Dec. 2, Washington DC.

Meroney, R.N., Yamada, T. 1972. Numerical and physical simulation of a stratified airflow over a series of heated islands. Proceedings of Summer Simulation Conference, June 13-16, 1972, San Diego, California.

Meroney, R.N. 1980. Wind-tunnel simulation of the flow over hills and complex terrain. Journal of Industrial Aerodynamics 5: 297-321. 
Meroney, R.N. 1982. Wind-tunnel experiments on dense gas dispersion. Journal of Hazardous Materials 6(12): $85-106$.

Meroney, R.N., Neff, D.E., Heskestad, G. 1984. Wind-tunnel simulation of field dispersion tests (by the U.K. Health and Safety Executive) of water-spray curtains. Boundary-Layer Meteorology 28: 107-119.

Meroney, R.N. 1987a. Validation of fluid modelling techniques for assessing hazards of dense gas cloud dispersion. Journal of Hazardous Materials 15(3): 377-417.

Meroney, R.N. 1987b. Guidelines for fluid modelling of dense gas cloud dispersion. Journal of Hazardous Materials 17(1): 23-46.

Meroney, R.N., Neff, D.E. 1986. Heat transfer effects during cold dense gas dispersion: wind-tunnel simulation of cold gas spills. Journal of Heat Transfer 108: 9-16.

Meroney, R.N. 1990. Fluid dynamics of flow over hills and mountains: insights obtained through physical modelling. Chapter 7 of AMS Monograph on Current Directions in Atmospheric Processes over Complex Terrain, AMS Monograph Vol. 23, Nr. 45, Jne 1990, pp. 145-172.

Meroney, R.N., Melbourne W.H. 1992. Operating ranges of meteorological wind tunnels for the simulation of convective boundary layer (CBL) phenomena. Boundary-Layer Meteorology 61: 145-174.

Meroney, R.N., Pavageau, M., Rafailidis, S., Schatzmann, M. 1996. Study of line source characteristics for 2$\mathrm{D}$ physical modelling of pollutant dispersion in street canyons. Journal of Wind Engineering and Industrial Aerodynamics, 62, 1, 37-56.

Meroney, R.N. 1997. Preface to Special Issue of Second International Symposium on Computational Wind Engineering (CWE-96), Journal of Wind Engineering and Industrial Aerodynamics 67-68: vii-viii.

Meroney, R.N., Neff, D.E., Chang, C.H. 2002. Diagnosis of a sick building by the wind doctors. Proc. of the $2^{\text {nd }}$ International Symposium on Advances in Wind and Structures (AWAS '02), 21-23 August 2002, Pusan Convention Center, Pusan, Korea.

Meroney, R.N. 2003. Fire whirls, fire tornadoes and firestorms: physical and numerical modelling. Proc. of PHYSMOD2003: International Workshop on Physical Modelling of Flow and Dispersion Phenomena, 3-5 September 2003, Prato, Italy.

Meroney, R.N. 2004. Wind tunnel and numerical simulation of pollution dispersion: a hybrid approach. Paper for Invited Lecture at the Croucher Advanced Study Institute, Hong Kong University of Science and Technology, 6-10 December 2004.

Meroney, R.N. 2009. CFD prediction of airflow in buildings for natural ventilation. Proceedings 11th Americas Conference on Wind Engineering, San Juan, Puerto Rico 1-11.

Meroney, R.N. 2014. Personal commucation, March 7, 2014.

Miles, S.D., Westbury, P.S. 2002. Assessing CFD as a tool for practical wind engineering applications. Proceedings Fifth UK Conference on Wind Engineering, September.

Miller, A., Chang, B., Issa, R., Chen, G. 2013. Review of computer-aided numerical simulation in wind energy. Renewable \& Sustainable Energy Reviews 25: 122-134.

Milliez, M., Carissimo, B. 2007. Numerical simulations of pollutant dispersion in an idealized urban area, for different meteorological conditions. Boundary-Layer Meteorology 122(2): 321-342.

Milliez, M., Carissimo, B. 2008. Computational fluid dynamical modelling of concentration fluctuations in an idealized urban area. Boundary-Layer Meteorology 127(2): 241-259.

Mistriotis, A., Arcidiacono, C., Picuno, P., Bot, G.P.A., Scarascia-Mugnozza, G. 1997. Computational analysis of ventilation in greenhouses at zero-and low-wind-speeds. Agric For Meteorol 88: 121-35.

Mistriotis, A., Bot, G., Picuno, P., Scarascia-Mugnozza, G. 1997. Analysis of the efficiency of greenhouse ventilation using computational fluid dynamics. Agric For Meteorol 85: 217-28.

Mistriotis, A., Briassoulis, D. 2002. Numerical estimation of the internal and external aerodynamic coefficients of a tunnel greenhouse structure with openings. Comput Electron Agric 34: 191-205.

Mochida, A., Iizuka, S., Tominaga, Y., Lun, I.Y.F. 2011. Up-scaling CWE models to include mesoscale meteorological influences. Journal of Wind Engineering and Industrial Aerodynamics 99, 4, 187-198.

Mochida, A., Lun, I.Y.F. 2008. Prediction of wind environment and thermal comfort at pedestrian level in urban area. Journal of Wind Engineering and Industrial Aerodynamics, 96 (10-11), 1498-1527.

Mochida, A., Murakami, S., Shoji, M., Ishida, Y. 1993. Numerical simulation of flow field around Texas Tech Building by Large Eddy Simulation. Journal of Wind Engineering and Industrial Aerodynamics, 46-47, 455-460.

Mochida, A., Tabata, Y., Iwata, T., Yoshino, H. 2008. Examining tree canopy models for CFD prediction of wind environment at pedestrian level. Journal of Wind Engineering and Industrial Aerodynamics, 96, 1011, 1667-1677.

Mochida, A., Tominaga, Y., Murakami, S., Yoshie, R., Ishihara, T., Ooka, R. 2002. Comparison of various k-E models and DSM applied to flow around a high-rise building-report on AIJ cooperative project for CFD prediction of wind environment. Wind and Structures, 5 (2-4), 227-244. 
Mochida, A., Yoshino, H., Takeda, T., Kakegawa, T., Miyauchi, S. 2005. Methods for controlling airflow in and around a building under cross-ventilation to improve indoor thermal comfort. $J$ Wind Eng Ind Aerodyn 93: 437-49.

Mochida, A., Yoshino, H., Miyauchi, S., Mitamura, T. 2006. Total analysis of cooling effects of crossventilation affected by microclimate around a building. Sol Energy 80: 371-82.

Montazeri, H., Montazeri, F., Azizian, R., Mostafavi, S. 2010. Two-sided wind catcher performance evaluation using experimental, numerical and analytical modeling. Renewable Energy 35(7): 1424-1435.

Montazeri, H. 2011. Experimental and numerical study on natural ventilation performance of various multiopening wind catchers. Building and Environment 46(2): 370-378.

Montazeri H, Blocken B. 2013. CFD simulation of wind-induced pressure coefficients on buildings with and without balconies: validation and sensitivity analysis. Building and Environment, 60: 137-149.

Montazeri H, Blocken B, Janssen WD, van Hooff T. 2013. CFD evaluation of new second-skin facade concept for wind comfort on building balconies: Case-study for the Park Tower in Antwerp. Building and Environment 68: 179-192.

Monteiro, J.P., Viegas, D.X., 1996. On the use of Irwin and Preston wall shear stress probes in turbulent incompressible flows with pressure gradients. $J$ Wind Eng Ind Aerodyn 64(1): 15-29.

Moonen P, Blocken B, Roels S, Carmeliet J. 2006. Numerical modeling of the flow conditions in a low-speed closed-circuit wind tunnel. Journal of Wind Engineering and Industrial Aerodynamics 94(10): 699-723.

Moonen P, Blocken B, Carmeliet J. 2007. Indicators for the evaluation of wind tunnel test section flow quality and application to a numerical closed-circuit wind tunnel. Journal of Wind Engineering and Industrial Aerodynamics 95(9-11): 1289-1314.

Moonen, P., Defraeye, T., Dorer, V., Blocken, B., Carmeliet, J. 2012. Urban Physics: Effect of the microclimate on comfort, health and energy demand. Frontiers of Architectural Research, 1, 3, 197-228.

Moonen, P., Gromke, C., Dorer, V. 2013. Performance assessment of Large Eddy Simulation (LES) for modeling dispersion in an urban street canyon with tree planting. Atmospheric Environment 75: 66-76

Moussiopoulos, N., Schlünzen, K.H., Louka, P., 2003. Modelling urban air pollution (Chap. 6). In: Moussiopoulos, N. (Ed.), Air Quality in Cities. SpringerVerlag, Berlin, pp.121-154.

Mueller, T.J., DeLaurier, J.D. 2003. Aerodynamics of small vehicles. Annual Review of Fluid Mechanics, 35 , 89-111.

Murakami, S., Mochida, A., Hayashi, Y. 1990. Examining the k- $\varepsilon$ model by means of a wind tunnel test and large-eddy simulation of the turbulence structure around a cube. Journal of Wind Engineering and Industrial Aerodynamics, 35, 87-100.

Murakami, S. 1990a. Preface to Special Issue on Computational Wind Engineering. Journal of Wind Engineering and Industrial Aerodynamics 35(1): ix-xi.

Murakami, S. 1990b. Computational Wind Engineering. Journal of Wind Engineering and Industrial Aerodynamics 36(1): 517-538.

Murakami, S. 1990c. Numerical simulation of turbulent flowfield around cubic model: current status and applications of k-e model and LES. Journal of Wind Engineering and Industrial Aerodynamics, 33 (1-2), 139-152.

Murakami, S., Kato, S., Akabayashi, S., Mizutani, K., Kim, Y. 1991. Wind tunnel test on velocity-pressure field of cross-ventilation with open windows. ASHRAE Trans 97:525-538.

Murakami, S. 1993a. Preface to the First International Symposium on Computational Wind Engineering (CWE92). Journal of Wind Engineering and Industrial Aerodynamics, 46-47: 1-2.

Murakami, S. 1993b. Comparison of various turbulence models applied to a bluff body. Journal of Wind Engineering and Industrial Aerodynamics, 46 and 47: 21-36.

Murakami, S. 1997. Current status and future trends in computational wind engineering. Journal of Wind Engineering and Industrial Aerodynamics 67 and 68: 3-34.

Murakami, S. 1998. Overview of turbulence models applied in CWE-1997. Journal of Wind Engineering and Industrial Aerodynamics 74-76: 1-24.

Murakami, S., Matsumoto, M., Tamura, Y. 2008. Preface to the Special Issue of the Fifth Symposium on Computational Wind Engineering. Journal of Wind Engineering and Industrial Aerodynamics 96, 10-11, 1449-1450.

Murakami, S., Mochida, A. 1988. 3-D numerical simulation of airflow around a cubic model by means of the k- $\varepsilon$ model. Journal of Wind Engineering and Industrial Aerodynamics, 31 (2-3), 283-303.

Murakami, S., Mochida, A., Hibi, K. 1987. Three-dimensional numerical simulation of airflow around a cubic model by means of large eddy simulation. Journal of Wind Engineering and Industrial Aerodynamics, 25: 291-305.

Murakami, S., Mochida, A. 1989. Three-dimensional numerical simulation of turbulent flow around buildings using the $\mathrm{k}-\varepsilon$ turbulence model. Building and Environment 24 (1), 51-64. 
Murakami, S., Mochida, A., Hayashi, Y., Sakamoto, S. 1992. Numerical study on velocity-pressure field and wind forces for bluff bodies by k- $\varepsilon$, ASM and LES. Journal of Wind Engineering and Industrial Aerodynamics, 44 (1-3), 2841-2852

Murakami, S., Ooka, R., Mochida, A., Yoshida, S., Kim, S. 1999. CFD analysis of wind climate from human scale to urban scale. Journal of Wind Engineering and Industrial Aerodynamics, 81(1-3), 57-81.

NEN, 2006a. Wind comfort and wind danger in the built environment, NEN 8100 (in Dutch) Dutch Standard.

NEN, 2006b. Application of mean hourly wind speed statistics for the Netherlands, NPR 6097:2006 (in Dutch). Dutch Practice Guideline.

Nicholls, M., Pielke, R., Meroney, R. 1993. Large eddy simulation of microburst winds flowing around a building. Journal of Wind Engineering and Industrial Aerodynamics, 46-47, 229-237.

Nikas, K.S., Nikolopoulos, N., Nikolopoulos, A. 2010. Numerical study of a naturally cross-ventilated building. Energy Build 42: 422-34.

Nore K, Blocken B, Thue JV. 2010. On CFD simulation of wind-induced airflow in narrow ventilated facade cavities: coupled and decoupled simulations and modelling limitations. Building and Environment 45(8): 1834-1846.

Norton, T., Sun, D.W., 2006. Computational fluid dynamics (CFD) - an effective and efficient design and analysis tool for the food industry: a review. Trends in Food Science \& Technology 17: 600-620.

Norton, T., Sun, D.W., Grant, J., Fallon, R., Dodd, V. 2007. Applications of computational fluid dynamics (CFD) in the modelling and design of ventilation systems in the agricultural industry: A review. Bioresource Technology, 98, 12, 2386-2414.

Norton, T., Grant, J., Fallon, R., Sun, D.W. 2009. Assessing the ventilation effectiveness of naturally ventilated livestock buildings under wind dominated conditions using computational fluid dynamics. Biosystems Eng 103: 78-99.

Norton, T., Grant, J., Fallon, R., Sun, D.W. 2010a. Optimising the ventilation configuration of naturally ventilated livestock buildings for improved indoor environmental homogeneity. Build Environ 45: 983-95.

Norton, T., Grant, J., Fallon, R., Sun, D.W. 2010b. Improving the representation of thermal boundary conditions of livestock during CFD modelling of the indoor environment. Comput Electron Agric 73: 1736.

Oberkampf, W. L., Trucano, T. G., Hirsch, C. 2004. Verification, validation, and predictive capability in computational engineering and physics. Applied Mechanics Reviews, 57 (5), 345 - 384.

Orlanski, I. 1975. A rational subdivision of scales for atmospheric processes. Bull. Amer. Meteor. Soc.. 56. 527-530.

Parente, A., Gorlé, C., van Beeck, J., Benocci, C. 2011. Improved k- $\varepsilon$ model and wall function formulation for the RANS simulation of ABL flows. Journal of Wind Engineering and Industrial Aerodynamics, 99(4), 267-278.

Paterson, D.A., Apelt C.J. 1986. Computation of wind flows over three-dimensional buildings. Journal of Wind Engineering and Industrial Aerodynamics, 24, 192-213.

Paterson, D.A., Apelt, C.J. 1989. Simulation of wind flow around three-dimensional buildings. Building and Environment, 24, 39-50.

Paterson, D.A., Apelt, C.J. 1990. Simulation of flow past a cube in a turbulent boundary layer. Journal of Wind Engineering and Industrial Aerodynamics, 35, 149-176.

Pearce, R.P. 1955. The calculation of the sea breeze circulation in terms of the differential heating across the coast line. Quart. J. Roy. Meteorol. Soc. 81: 351-381.

Persoon J, van Hooff T, Blocken B, Carmeliet J, de Wit MH. 2008. Impact of roof geometry on rain shelter in football stadia. Journal of Wind Engineering and Industrial Aerodynamics 96(8-9): 1274-1293.

Phillips, N.A. 1956. The general circulation of the atmosphere: a numerical experiment. Q. J. Roy. Meteorol. Soc. 82: 123-164.

Phillips, N.A. 1960. On the problem of initial data for the primitive equations. Tellus 12: 121-126.

Pielke, R.A., Nicholls, M.E. 1997. Use of meteorological models in computational wind engineering. Journal of Wind Engineering and Industrial Aerodynamics, 67-68, 363-372.

Platzman, G.W. 1979. The ENIAC computations of 1950 - gateway to numerical weather prediction. Bull. Am. Met. Soc. 60: 302-312.

Porté-Agel, F., Wu, Y.T., Lu, H., Conzemius, R.J. 2011. Large-eddy simulation of atmospheric boundary layer flow through wind turbines and wind farms. Journal of Wind Engineering and Industrial Aerodynamics, 99, 4, 154-168.

Ramponi, R., Blocken, B. 2012a. CFD simulation of cross-ventilation for a generic isolated building: impact of computational parameters. Building and Environment, 53, 34-48.

Ramponi R, Blocken B. 2012b. CFD simulation of cross-ventilation flow for different isolated building configurations: validation with wind tunnel measurements and analysis of physical and numerical diffusion effects. Journal of Wind Engineering and Industrial Aerodynamics 104-106: 408-418. 
Randerson, D., 1976. An overview of regional-scale numerical models. Bull. Am. Met. Soc. 57, $797-804$.

Reichrath, S., Davies, T.W., 2002. Using CFD to model the internal climate of greenhouses: past, present and future. Agronomie 22: 3-19.

Richards, P.J., Hoxey, R.P. 1993. Appropriate boundary conditions for computational wind engineering models using the k- $\varepsilon$ turbulence model. Journal of Wind Engineering and Industrial Aerodynamics, 46\&47, 145-153.

Richards, P.J., Mallison, G.D., McMillan, D., Li, Y.F. 2002. Pedestrian level wind speeds in downtown Auckland. Wind and Structures, 5(2-4), 151-164.

Richards, P.J., Norris, S.E. 2011. Appropriate boundary conditions for computational wind engineering models revisited. Journal of Wind Engineering and Industrial Aerodynamics, 99(4), 257-266.

Richardson, L.F. 1922. Weather prediction by numerical process. Cambridge, The University Press.

Roache, P.J. 1994. Perpective - a method for uniform reporting of grid refinement studies. Journal of Fluids Engineering - Transactions of the ASME, 116, 3, 405-413.

Roache, P.J. 1997. Quantification of uncertainty in computational fluid dynamics. Annual Reviews in Fluid Mechanics, 29, 123-160.

Roache, P.J., Chia, K.N., White, F. 1986. Editorial policy statement on the control of numerical accuracy. Journal of Fluids Engineering, 108:2

Robins, A. 2003. Wind tunnel dispersion modelling some recent and not so recent achievements. Journal of Wind Engineering and Industrial Aerodynamics, 91, 12-15, 1777-1790.

Robins, A.G., Castro, I.P. 1977a. Wind-tunnel investigation of plume dispersion in vicinity of a surface mounted cube. 1. Flow field. Atmospheric Environment, 11(4), 291-297.

Robins, A.G., Castro, I.P. 1977b. Wind-tunnel investigation of plume dispersion in vicinity of a surface mounted cube. 2. Concentration field. Atmospheric Environment, 11(4), 299-311.

Rodi, W. 1997. Comparison of LES and RANS calculations of the flow around bluff bodies. Journal of Wind Engineering and Industrial Aerodynamics, 69-71, 55-75.

Robson, B.J., Hamilton, D.P., Webster, I.T., Chan, T. 2008. Ten steps applied to development and evaluation of process-based biogeochemical models of estuaries. Environmental Modelling \& Software, 23, 4, 369384.

Roy, C.J, Oberkampf, W.L. 2010. A complete framework for verification, validation, and uncertainty quantification in scientific computing. 48th AIAA Aerospace Sciences Meeting Including the New Horizons Forum and Aerospace Exposition 4 - 7 January 2010, Orlando, Florida.

Roy, C.J. 2005. Review of code and solution verification procedures for computational simulation. Journal of Computational Physics 205, 1, 131-156.

Roy, S., Saha, U.K. 2013. Review on the numerical investigations into the design and development of Savonius wind rotors. Renewable and Sustainable Energy Reviews 24, 73-83.

Salim, S.M., Cheah, S.C., Chan, A. 2011a. Numerical simulation of dispersion in urban street canyons with avenue-like tree plantings: comparison between RANS and LES. Building and Environment 46(9): 17351746.

Salim, S. M., Buccolieri, R., Chan, A., Di Sabatino, S. 2011: Numerical simulation of atmospheric pollutant dispersion in an urban street canyon: Comparison between RANS and LES. Journal of Wind Engineering and Industrial Aerodynamics 99, 103-113.

Saloranta, J., Hellsten, A. 2011. Evaluation of a general CFD-solver for a micro-scale urban flow. International Journal of Environment and Pollution 44(1-4): 368-375.

Sandberg, M. 2004. An alternative view on the theory of cross-ventilation. Int J Vent 4:409-418.

Sanderse, B., van der Pijl, S.P., Koren, B. 2011. Review of computational fluid dynamics for wind turbine wake aerodynamics. Wind Energy 14, 7, 799-819.

Santiago, J..L., Dejoan, A., Martilli, A., Martin, F., Pinelli, A. 2010. Comparison between Large-Eddy Simulation and Reynolds-Averaged Navier-Stokes computations for the MUST field experiment. Part I: Study of the flow for an incident wind directed perpendicularly to the front array of containers. BoundaryLayer Meteorology 135(1): 109-132.

Sanz Rodrigo, J., van Beeck, J., Buchlin, J.M. 2012. Wind engineering in the integrated design of princess Elisabeth Antarctic base. Building and Environment 52: 1-18.

Sasaki, R, Uematsu, Y, Yamada, M, Saeki, H. 1997. Application of infrared thermography and a knowledgebased system to the evaluation of the pedestrian-level wind environment around buildings. Journal of Wind Engineering and Industrial Aerodynamics, 67-68, 873-883.

Sawyer, J.S. 1960. Numerical calculation of the displacements of a stratified airstream crossing a ridge. Quart. J. Roy. Meteorol. Soc. 86, 326-345.

Scaperdas, A., Gilham, S. 2004. Thematic Area 4: Best practice advice for civil construction and HVAC, The QNET-CFD Network Newsletter, 2 (4), 28-33. 
Schatzmann, M., Rafailidis, S., Pavageau, M. 1997. Some remarks on the validation of small-scale dispersion models with field and laboratory data. Journal of Wind Engineering and Industrial Aerodynamics 67and68. 885-893.

Schatzmann, M., Leitl, B. 2011. Issues with validation of urban flow and dispersion CFD models. Journal of Wind Engineering and Industrial Aerodynamics, 99, 169-186

Schlünzen, K.H., 1996. Validierung hochauflösender Regionalmodelle. Ber. aus dem Zentrum f. Meeres- und Klimaforschung, Meteorologisches Institut, Universität Hamburg, A23, 184. >http://www.bis.zmaw.de/fileadmin/Bib/Voll texte/ZMK-A23.pdf>

Schlünzen, K.H., Grawe, D., Bohnenstengel, S.I., Schlüter, I., Koppmann, R. 2011. Joint modelling of obstacle induced and mesoscale changes - Current limits and challenges. Journal of Wind Engineering and Industrial Aerodynamics, 99, 4, 217-225.

Sengupta, A., Sarkar, P.P. 2008. Experimental measurement and numerical simulation of an impinging jet with application to thunderstorm microburst winds. Journal of Wind Engineering and Industrial Aerodynamics 96(3): 345-365.

Sengupta, A., Haan, F.L., Sarkar, P.P., Balaramudu, V. 2008. Transient loads on buildings in microburst and tornado winds. Journal of Wind Engineering and Industrial Aerodynamics 96(10-11): 2137-2187.

Selvam, R.P. 1997. Numerical simulation of pollutant dispersion around a building using FEM. J. Wind Eng. Ind. Aerodyn. 67\&68: 805-814.

Shah, K.B., Ferziger, J.H. 1997. A fluid mechanicians view of wind engineering: Large eddy simulation of flow past a cubic obstacle. Journal of Wind Engineering and Industrial Aerodynamics, 67-68, 211-224.

Seifert, J., Li, Y., Axley, J., Rösler, M. 2006. Calculation of wind-driven cross ventilation in buildings with large openings. J Wind Eng Ind Aerodyn 94:925-47.

Shen, X., Zhang, G., Bjerg, B. 2012. Comparison of different methods for estimating ventilation rates through wind driven ventilated buildings. Energy and Buildings 54: 297-306.

Shih, T.H., Liou, W.W., Shabbir, A., Yang, Z., Zhu, J. 1995. A new k- $\varepsilon$ eddy viscosity model for high Reynolds number turbulent flows. Computers \& Fluids; 24 : 227-238.

Shin, S.H., Meroney, R.N. 1988. Surface pattern comparability of wind-tunnel simulations of the Thorney Island dense gas dispersion trials. $17^{\text {th }}$ NATO/COMS International Technical Meeting on Air Pollution Modelling and its Application. Cambridge, UK, 19-22 Sept. 1988, Downing College, Cambridge University.

Shklyar, A., Arbel, A. 2004. Numerical model of the three-dimensional isothermal flow patterns and mass fluxes in a pitched-roof greenhouse. J Wind Eng Ind Aerodyn 92: 1039-59.

Shuman, F.G., Hovermale, J. 1968. An operational six-layer primitive equation model. J. Appl. Meteor. 7: 525-547.

Shuman, F.G. 1989. History of numerical weather prediction at the National Meteorological Center, Weather Forecast 4: 286-296.

Smagorinsky, J., 1953. The dynamical influence of large-scale heat sources and sinks on the quasi-stationary mean motions of the atmosphere. Quarterly Journal of the Royal Meteorological Society, 79, 342-366.

Smagorinsky, J., 1958. On the numerical integration of the primitive equations of motion for baroclinic flow in a closed region. Mon. Weather Rev. 86(12): 457-466.

Smagorinsky, J. 1963. General Circulation experiments with the primitive equations I. The basic experiment. Monthly Weather Review, 91(3), 99-164.

Smagorinsky, J., 1969. Problems and promises of deterministic extended range forecasting. Bulletin of the American Meteorological Society, 50(5), 286-311.

Smedley, D.J., Kwok, K.C.S., Kim, D.H. 1993. Snowdrifting simulation around Davis Station workshop, Antartica. J Wind Eng Ind Aerodyn. 50: 153-162.

Snel, H. 2003. Review of aerodynamics for wind turbines. Wind Energy 6, 3, 203-211.

Solari, G. 2007. The International Association for Wind Engineering (IAWE): Progress and prospects. Journal of Wind Engineering and Industrial Aerodynamics 95: 813-842.

Sorensen, J.N. 2011. Aerodynamic aspects of wind energy conversion. Annual Review of Fluid Mechanics 43, 427-448.

Souster, C., 1979. A theoretical approach to predicting snow loads and driving rain deposition on buildings, Ph.D. Thesis, University of Sheffield, UK, 1979.

Squires, K.D., Krishnan, V., Forsythe, J.R. 2008. Prediction of the flow over a circular cylinder at high Reynolds number using detached-eddy simulation. Journal of Wind Engineering and Industrial Aerodynamics, 96, 10-11, 1528-1536.

Stathopoulos, T. 1997. Computational Wind Engineering: Past achievements and future challenges. Journal of Wind Engineering and Industrial Aerodynamics 67-68: 509-532.

Stathopoulos, T. 2002. The numerical wind tunnel for industrial aerodynamics: real or virtual in the new millennium? Wind and Structures, 5 (2-4), 193-208. 
Stathopoulos, T. 2003. Wind loads on low buildings: in the wake of Alan Davenport's contributions. Journal of Wind Engineering and Industrial Aerodynamics 91 (12-15), 1565-1585.

Stathopoulos, T. 2006. Pedestrian level winds and outdoor human comfort. Journal of Wind Engineering and Industrial Aerodynamics 94(11), 769-780.

Stathopoulos, T., Storms, R., 1986. Wind environmental conditions in passages between buildings. J Wind Eng Ind Aerodyn 24(1): 19-31.

Stathopoulos, T., Baskaran, A. 1990. Boundary treatment for the computation of 3D turbulent conditions around buildings. Journal of Wind Engineering and Industrial Aerodynamics, 35: 177-200.

Stathopoulos, T., Baskaran, A. 1996. Computer simulation of wind environmental conditions around buildings. Engineering Structures, 18 (11), 876-885.

Stathopoulos, T. 2013. Personal communication, 9 May 2013.

Stavrakakis, G.M., Koukou, M.K., Vrachopoulos, M.G., Markatos, N.C. 2008. Natural cross-ventilation in buildings: Building-scale experiments, numerical simulation and thermal comfort evaluation. Energy Build 40: $1666-81$.

Stavridou, A.D., Prinos, P.E. 2013. Natural ventilation of buildings due to buoyancy assisted by wind: investigating cross ventilation with computational and laboratory simulation. Building and Environment 66: 104-119.

Straw, M.P., Baker, C.J., Robertson, A.P. 2000. Experimental measurements and computations of the windinduced ventilation of a cubic structure. J Wind Eng Ind Aerodyn 88: 213-30.

Sumner, J., Watters, C.S., Masson, C. 2010. CFD in wind energy: the virtual, multiscale wind tunnel. Energies 3: 989-1013.

Surry, D., Inculet, D.R., Skerlj, P.F., Lin, J-X., Davenport, A.G. 1994. Wind, rain and the building envelope: a status report of ongoing research at the University of Western Ontario. J. Wind Eng. Ind. Aerodyn., 53, 19-36

Tablada, A., De Troyer, F., Blocken, B., Carmeliet, J., Verschure, H., 2009. On natural ventilation and thermal comfort in compact urban environments-the Old Havana case. Build Environ 44: 1943-58.

Tabor, G.R., Baba-Ahmadi, M.H. 2010. Inlet conditions for large eddy simulation: A review. Computers and Fluids 39, 4, 553-567.

Taddei, D., Bontempi, F. 2003. A reference framework for the aerodynamic and aeroelastic analysis of long span bridges with Computational Fluid Dynamic. System-Based Vision for Strategic and Creative Design, $1-3,2511-2516$.

Takagi, M. 1990. Application of computers to automobile aerodynamics. Journal of Wind Engineering and Industrial Aerodynamics, 33, 1-2, 419-428.

Takakura, S, Suyama, Y, Aoyama, M. 1993. Numerical simulation of flowfield around buildings in an urban area. Journal of Wind Engineering and Industrial Aerodynamics, 46-47, 765-771.

Tamura, T. 2008. Towards practical use of LES in wind engineering. Journal of Wind Engineering and Industrial Aerodynamics 96(10-11): 1451-1471.

Tamura, T., Kawai, H., Kawamoto, S., Nozawa, K., Sakamoto, S., Ohkuma, T. 1997. Numerical prediction of wind loading on buildings and structures - Activities of AIJ cooperative project on CFD. Journal of Wind Engineering and Industrial Aerodynamics, 67-68, 671-685.

Tamura, T., Nozawa, K., Kondo, K. 2008. AIJ guide for numerical prediction of wind loads on buildings. Journal of Wind Engineering and Industrial Aerodynamics, 96 (10-11), 1974-1984.

Tamura, T. 1999. Reliability on CFD estimation for wind-structure interaction problems. Journal of Wind Engineering and Industrial Aerodynamics, 81, 117-143.

Tamura, Y., Matsui, M. 2002. Recent topics in wind engineering focusing on monitoring techniques Advances in Building Technology, I, 65-74.

Tan, G., Glicksman, L.R. 2005. Application of integrating multi-zone model with CFD simulation to natural ventilation prediction. Energy Build 37: 1049-57.

Tang, W., Davidson, C.I., Finger, S., Vance, K., 2004. Erosion of limestone building surfaces caused by winddriven rain: 1. Field measurements. Atmospheric Environment 38(33), 5589-5599.

Tang, W., Davidson, C.I., 2004. Erosion of limestone building surfaces caused by wind-driven rain. 2. Numerical modelling. Atmospheric Environment 38(33), 5601-5609.

Tari, P.H., Gurka, R., Hangan, H. 2010. Experimental investigation of tornado-like vortex dynamics with swirl ratio: the mean and turbulent flow fields. Journal of Wind Engineering and Industrial Aerodynamics 98(12): 936-944.

Taylor, P.A., Gent, P.R. 1974. A model of atmospheric boundary-layer flow above an isolated twodimensional 'hill'; an example of flow above 'gentle topography'. Boundary-Layer Meteorology 7: 349362.

Teitel M, Ziskind G, Liran O, Dubovsky V, Letan R. 2008. Effect of wind direction on greenhouse ventilation rate, airflow patterns and temperature distributions. Biosystems Eng 101:351-369. 
Tezduyar, T.E. 1999. CFD methods for three-dimensional computation of complex flow problems. Journal of Wind Engineering and Industrial Aerodynamics 81, 1-3, 97-116.

Tyagi, S.K., Pandey, A.K., Pant, P.C., Tyagi, V.V. 2012. Formation, potential and abatement of plume from wet cooling towers: A review. Renewable \& Sustaintable Energy Reviews: 16(5): 3409-3429.

To, A.P., Lam, K.M. 1995. Evaluation of pedestrian-level wind environment around a row of tall buildings using a quartile-level wind speed descripter. Journal of Wind Engineering and Industrial Aerodynamics, 54-55, 527-541.

Tominaga, Y., Murakami, S., Mochida, A. 1997. CFD prediction of gaseous diffusion around a cubic model using a dynamics mixed SGS model based on composite grid technique. Journal of Wind Engineering and Industrial Aerodynamics, 67-68, 827-841.

Tominaga, Y., Stathopoulos, T. 2007. Turbulent Schmidt numbers for CFD analysis with various types of flowfield. Atmospheric Environment, 41 (37), 8091-8099.

Tominaga Y, Stathopoulos T., 2009. Numerical simulation of dispersion around an isolated cubic building: Comparison of various types of k- $\varepsilon$ models. Atmospheric Environment, 43 (20), 3200-3210.

Tominaga, Y, Stathopoulos T., 2010. Numerical simulation of dispersion around an isolated cubic buildings: Model evaluation of RANS and LES. Building and Environment 45(10): 2231-2239.

Tominaga, Y., Stathopoulos, T. 2013. CFD simulation of near-field pollutant dispersion in the urban environment: A review of current modelling techniques. Atmospheric Environment, 79, 716-730.

Tominaga, Y., Mochida, A., Yoshie, R., Kataoka, H., Nozu, T., Yoshikawa, M., Shirasawa, T. 2008a. AIJ guidelines for practical applications of CFD to pedestrian wind environment around buildings. Journal of Wind Engineering and Industrial Aerodynamics 96(10-11), 1749-1761.

Tominaga, Y., Mochida, A., Murakami, S., Sawaki, S. 2008b. Comparison of various revised k- $\varepsilon$ models and LES applied to flow around a high-rise building model with 1:1:2 shape placed within the surface boundary layer. Journal of Wind Engineering and Industrial Aerodynamics 96(4) 389-411.

Tominaga, Y., Okaze, T., Mochida, A. 2011. CFD modeling of snowdrift around a building: An overview of models and evaluation of a new approach. Building and Environment, 46(4), 899-910.

Tominaga, Y., Iizuka, S., Imano, M., Kataoka, H., Mochida, A., Nozu, T., Ono, Y., Shirasawa, T., Tsuchiya, N., Yoshie, R. 2013. Cross comparisons of CFD results of wind and dispersion fields for MUST experiment: evaluation exercises by AIJ. Journal of Asian Architecture and Building Engineering 12(1): 117-124.

Tsang, C.W., Kwok, K.C.S., Hitchcock, P.A., 2012. Wind tunnel study of pedestrian level wind environment around tall buildings: Effects of building dimensions, separation and podium. Build Environ 49: 167-181.

Tucker, P.G., Mosquera, A. 2001. NAFEMS introduction to grid and mesh generation for CFD. NAFEMS CFD Working Group, R0079, 56 pp.

Uematsu, Y., Yamada, M., Higashiyama, H., Orimo, T., 1992. Effects of the corner shape of high-rise buildings on the pedestrian-level wind environment with consideration for mean and fluctuating wind speeds. J Wind Eng Ind Aerodyn 44(1-3): 2289-2300.

UWO. 2014. http://www.eng.uwo.ca/windeee/facilities.html. University of Western Ontario. Retrieved on March 4, 2014.

Van Beeck, J.P.A.J., Dezsö, G., Planquart, P., 2009. Microclimate assessment by sand erosion and Irwin probes for atmospheric boundary layer wind tunnels. PHYSMOD 2009, Von Karman Institute (VKI), Sint-Genesius-Rode, Belgium.

van Hooff, T, Blocken, B. 2010a. Coupled urban wind flow and indoor natural ventilation modelling on a highresolution grid: A case study for the Amsterdam ArenA stadium. Environmental Modelling and Software, $25(1), 51-65$.

van Hooff T, Blocken B, 2010b. On the effect of wind direction and urban surroundings on natural ventilation of a large semi-enclosed stadium. Computers and Fluids 39: 1146-1155.

van Hooff T, Blocken B, Aanen L, Bronsema B. 2011a. A venturi-shaped roof for wind-induced natural ventilation of buildings: wind tunnel and CFD evaluation of different design configurations. Building and Environment 46(9): 1797-1807.

van Hooff T, Blocken B, van Harten M. 2011b. 3D CFD simulations of wind flow and wind-driven rain shelter in sports stadia: influence of stadium geometry. Building and Environment 46(1): 22-37

van Hooff T, Blocken B. 2012. Full-scale measurements of indoor environmental conditions and natural ventilation in a large semi-enclosed stadium: possibilities and limitations for CFD validation. Journal of Wind Engineering and Industrial Aerodynamics 104-106: 330-341.

van Hooff T, Blocken B. 2013. CFD evaluation of natural ventilation of indoor environments by the concentration decay method: $\mathrm{CO}_{2}$ gas dispersion from a semi-enclosed stadium. Building and Environment 61: 1-17.

van Mook, F.J.R., 2002. Driving rain on building envelopes, Ph.D. thesis, Building Physics and Systems, Technische Universiteit Eindhoven, Eindhoven University Press, Eindhoven, The Netherlands, 198 p. 
Vardoulakis, S., Fisher, B.E.A., Pericleous, K., Gonzalez-Flesca, N. 2003. Modelling air quality in street canyons: a review. Atmospheric Environment, 37, 2, 155-182.

Vasilic-Melling, D. 1977. Three dimensional turbulent flow past rectangular bluff bodies, Ph.D. Thesis, Imperial College of Science and Technology, London.

Vermeer, L.J., Sørensen, J.N., Crespo, A. 2003. Wind turbine wake aerodynamics. Progress in Aerospace Sciences, 39, 6-7, 467-510.

Wallington, C.E., Portnall, J. 1958. A numerical study of the wavelength and amplitude of lee waves', Quart. J. Roy. Meteorol. Soc. 84, 38-45.

Wang, L., Wong, N.H. 2008. Coupled simulations for naturally ventilated residential buildings. Autom Constr 17: 386-98.

Wang, L., Wong, N.H. 2009. Coupled simulations for naturally ventilated rooms between building simulation (BS) and computational fluid dynamics (CFD) for better prediction of indoor thermal environment. Build Environ 44: 95-112.

Westbury, P.S., Miles, S.D., Stathopoulos, T. 2002. CFD application on the evaluation of pedestrian-level winds. Workshop on Impact of Wind and Storm on City Life and Built Environment, Cost Action C14, CSTB, June 3-4, Nantes, France.

Wilcox, D.C. 1998. Turbulence modeling for CFD. La Canada, California: DCW Industries, Inc.

Willemsen, E., Wisse, J.A. 2007. Design for wind comfort in The Netherlands: Procedures, criteria and open research issues. Journal of Wind Engineering and Industrial Aerodynamics, 95 (9-11), 1541-1550.

Wise, A.F.E. 1970. Wind effects due to groups of buildings. Royal Society Symposium Architectural Aerodynamics, London.

Wisse, J.A., Willemsen, E. 2003. Standardization of wind comfort evaluation in the Netherlands. $11^{\text {th }}$ International Conference on Wind Engineering (11ICWE), Lubbock, Texas.

Wood, N. 2000. Wind flow over complex terrain: a historical perspective and the prospect for large-eddy modelling. Boundary-Layer Meteorology 96: 11-32.

Wood, G.D., Kwok, K.C.S., Motteram, N.A., Fletcher, D.F. 2001. Physical and numerical modelling of thunderstorm downbursts. Journal of Wind Engineering and Industrial Aerodynamics 89(6): 535-552.

Wright, N.G., Easom, G.J., Hoxey, R.J. 2001. Development and validation of a non-linear k-epsilon: model for flow over a full-scale building. Wind and Structures, 4 (3), 177-196.

Wright, N.G., Hargreaves, D.M. 2006. Unsteady CFD Simulations for natural ventilation. Int J Vent 5: 13-20.

Wu, H., Stathopoulos, T., 1994. Further experiments on Irwin's surface wind sensor. J Wind Eng Ind Aerodyn 53(3): 441-452.

$\mathrm{Wu}$, H.Q., Stathopoulos, T. 1997. Application of infrared thermography for pedestrian wind evaluation, Journal of Engineering Mechanics - ASCE, 123 (10), 978-985.

Wu, G., Higuchi, K., Meroney, R.N. 1992. Applications of digital image processing in wind engineering. Journal of Wind Engineering and Industrial Aerodynamics, 42(1-3), 999-1010.

Wu, Y.C., Yang, A.S., Tseng, L.Y., Liu, C.L. 2011. Myth of ecological architecture designs: comparison between design concept and computational analysis results of natural-ventilation for tjibaou cultural center in new caledonia. Energy Build 43: 2788-97.

Wu, W., Zhai, J., Zhang, G., Nielsen, P.V. 2012. Evaluation of methods for determining air exchange rate in a naturally ventilated dairy cattle building with large openings using computational fluid dynamics (CFD). Atmospheric Environment 63: 179-188.

Yakhot, V., Orszag, S.A. 1986. Renormalization group analysis of turbulence. Journal of Scientific Computing, $1(1), 3-51$.

Yamada, M, Uematsu, Y, Sasaki, R. 1996. A visual technique for the evaluation of the pedestrian-level wind environment around buildings by using infrared thermography. Journal of Wind Engineering and Industrial Aerodynamics, 65 (1-3), 261-271.

Yamada, T., Katsuyuki, K. 2011. Downscaling mesoscale meteorological models for computational wind engineering applications. Journal of Wind Engineering and Industrial Aerodynamics, 99 (4), 199-216.

Yamada,T., Meroney, R.N. 1972. Numerical and wind tunnel simulation of airflow over an obstacle. National Conference on Atmospheric Waves, American Meteorological Society, Salt Lake City, October 12-15, 1971.

Yang, Y., Gu, M., Chen, S., Jin, X. 2009. New inflow boundary conditions for modelling the neutral equilibrium atmospheric boundary layer in computational wind engineering. Journal of Wind Engineering and Industrial Aerodynamics, 97 (2), 88-95.

Yoshie, R., Mochida, A., Tominaga, Y., Kataoka, H., Harimoto, K., Nozu, T., Shirasawa, T. 2007. Cooperative project for CFD prediction of pedestrian wind environment in the Architectural Institute of Japan. Journal of Wind Engineering and Industrial Aerodynamics, 95(9-11), 1551-1578.

Xie, Z.-T., Castro, I.P. 2008. Efficient generation of inflow conditions for large eddy simulation of street-scale flows. Flow, Turbulence and Combustion 81, 449-470. 
Xu, Z., Hangan, H. 2008. Scale, boundary and inlet condition effects on impinging jets. Journal of Wind Engineering and Industrial Aerodynamics 96(12): 2383-2402. 
Table 1: Overview of CWE symposia, with acronym, location, date, chair(s) and special issue.

\begin{tabular}{llllll}
\hline Nr & Acronym & Location & Date & Chair(s) & Special Issue \\
\hline 1 & CWE1992 & Tokyo, Japan & $\begin{array}{l}\text { August 21-23, } \\
1992\end{array}$ & Murakami & $\begin{array}{l}\text { JWEIA 1993, } \\
\text { vol. 46-47 }\end{array}$ \\
\hline 2 & CWE1996 & $\begin{array}{l}\text { Fort Collins, } \\
\text { Colorado, USA }\end{array}$ & $\begin{array}{l}\text { August 4-8, } \\
1996\end{array}$ & Meroney, Bienkiewicz & $\begin{array}{l}\text { JWEIA 1997, } \\
\text { vol. 67-68 }\end{array}$ \\
\hline 3 & CWE2000 & Birmingham, UK & $\begin{array}{l}\text { September 4-7, } \\
2000\end{array}$ & Baker & WAS 2002, \\
& & & & vol. 5 \\
\hline 4 & CWE2006 & Yokohama, Japan & July 16-19, & Murakami, & JWEIA 2008, \\
& & 2006 & Matsumoto, Tamura & vol. 96(10-11) \\
\hline 5 & CWE2010 & Chapel Hill, North & May 23-27, & Huber, Blocken, & JWEIA 2011, \\
& & Carolina, USA & 2010 & Stathopoulos & vol. 99(4) \\
\hline 6 & CWE2014 & Hamburg, & June 8-13, 2014 & Schlünzen, Höffer, & \\
& & & Leitl & \\
\hline
\end{tabular}


Table 2: Overview of scope and type of contributions in CWE conference proceedings.

\begin{tabular}{|c|c|c|c|c|c|}
\hline $\mathrm{C}$ & CWE1992 (a) & CWE1996 ${ }^{(\mathrm{a})}$ & CWE2000 & CWE2006 & CWE2010 \\
\hline Review and overview papers & $\mathrm{x}$ & $\mathrm{x}$ & $\mathrm{x}$ & $\mathrm{x}$ & $\mathrm{x}$ \\
\hline \multicolumn{6}{|l|}{ General topics } \\
\hline Atmospheric boundary layer simulation ${ }^{(\mathrm{c})}$ & $\mathrm{x}$ & $\mathrm{x}$ & - & $\mathrm{x}$ & $\mathrm{x}$ \\
\hline Bluff body aerodynamics ${ }^{(d)}$ & $\mathrm{x}$ & $\mathrm{x}$ & $\mathrm{x}$ & $\mathrm{x}$ & $\mathrm{x}$ \\
\hline $\begin{array}{l}\text { Turbulence modelling \& numerical } \\
\text { techniques }\end{array}$ & $\mathrm{x}$ & $\mathrm{x}$ & $\mathrm{x}$ & $\mathrm{x}$ & $\mathrm{x}$ \\
\hline \multicolumn{6}{|l|}{ Environmental wind engineering ${ }^{(b)}$} \\
\hline Wind and thermal environment ${ }^{(\mathrm{f})}$ & $\mathrm{x}$ & - & $\mathrm{x}$ & $\mathrm{x}$ & $\mathrm{x}$ \\
\hline Pedestrian-level wind conditions ${ }^{(\mathrm{g})}$ & $\mathrm{x}$ & - & $\mathrm{x}$ & $\mathrm{x}$ & $\mathrm{x}$ \\
\hline Air pollutant dispersion ${ }^{(h)}$ & $\mathrm{x}$ & $\mathrm{x}$ & $\mathrm{x}$ & $\mathrm{x}$ & $\mathrm{x}$ \\
\hline Meteorological phenomena & $\mathrm{x}$ & $\mathrm{x}$ & - & $\mathrm{x}$ & $\mathrm{x}$ \\
\hline Fire & - & - & - & - & $\mathrm{x}$ \\
\hline Flow over (complex) topography ${ }^{(i)}$ & $\mathrm{x}$ & $\mathrm{x}$ & $\mathrm{x}$ & $\mathrm{x}$ & $\mathrm{x}$ \\
\hline $\begin{array}{l}\text { (Natural) ventilation of buildings and } \\
\text { vehicles } \mathrm{j} \text { ) }\end{array}$ & - & $\mathrm{x}$ & - & $\mathrm{x}$ & $\mathrm{x}$ \\
\hline Sand, dust and snow transport & $\mathrm{x}$ & - & $\mathrm{x}$ & $\mathrm{x}$ & $\mathrm{x}$ \\
\hline Wind-driven rain & $\mathrm{x}$ & $\mathrm{x}$ & - & $\mathrm{x}$ & $\mathrm{x}$ \\
\hline Surface convective heat transfer ${ }^{(\mathrm{k})}$ & - & - & - & $\mathrm{x}$ & $\mathrm{x}$ \\
\hline Acoustics & - & - & - & $\mathrm{x}$ & - \\
\hline \multicolumn{6}{|l|}{ Structural wind engineering ${ }^{(b)}$} \\
\hline Wind loads on generic obstacles ${ }^{(1)}$ & $\mathrm{x}$ & $\mathrm{x}$ & $\mathrm{x}$ & $\mathrm{x}$ & $\mathrm{x}$ \\
\hline Wind loads on buildings and structures ${ }^{(\mathrm{m})}$ & $\mathrm{x}$ & $\mathrm{x}$ & $\mathrm{x}$ & $\mathrm{x}$ & $\mathrm{x}$ \\
\hline Wind loads on solar panels & - & - & - & - & $\mathrm{x}$ \\
\hline Bridges & $\mathrm{x}$ & $\mathrm{x}$ & $\mathrm{x}$ & $\mathrm{x}$ & $\mathrm{x}$ \\
\hline Vibrations / wind-structure interactions & $\mathrm{x}$ & $\mathrm{x}$ & $\mathrm{x}$ & $\mathrm{x}$ & $\mathrm{x}$ \\
\hline \multicolumn{6}{|l|}{ Wind energy } \\
\hline Wind energy siting assessment ${ }^{(\mathrm{n})}$ & - & - & - & $\mathrm{x}$ & $\mathrm{x}$ \\
\hline Wind energy in the built environment & - & - & $\mathrm{x}$ & - & $\mathrm{x}$ \\
\hline Wind turbine rotor aerodynamics & $\mathrm{x}$ & - & $\mathrm{x}$ & $\mathrm{x}$ & - \\
\hline \multicolumn{6}{|l|}{ Other topics } \\
\hline Vehicle aerodynamics $^{(0)}$ & - & $\mathrm{x}$ & $\mathrm{x}$ & $\mathrm{x}$ & $\mathrm{x}$ \\
\hline Sports aerodynamics & - & $\mathrm{x}$ & - & - & - \\
\hline Windborne debris & - & - & - & $\mathrm{x}$ & $\mathrm{x}$ \\
\hline Computer-aided experiments ${ }^{(\mathrm{p})}$ & $\mathrm{x}$ & $\mathrm{x}$ & - & $\mathrm{x}$ & $\mathrm{x}$ \\
\hline Experiments for CFD validation & - & $\mathrm{x}$ & $\mathrm{x}$ & $\mathrm{x}$ & $\mathrm{x}$ \\
\hline Mesoscale modelling $^{(\mathrm{q})}$ & $\mathrm{x}$ & $\mathrm{x}$ & $\mathrm{x}$ & $\mathrm{x}$ & $\mathrm{x}$ \\
\hline Total number of topics & 18 & 18 & 17 & 25 & 26 \\
\hline
\end{tabular}

(a) Only selected papers of these symposia were compiled into the proceedings; the indications in the table pertain to these proceedings.

(b) Excluding aerodynamics of vehicles and sports.

${ }^{(c)}$ Includes inflow boundary conditions for RANS and LES.

(d) Focus on fluid mechanical and physical aspects of wind flow around buildings and structures.

(e) Focus on physical and numerical modelling such as turbulence modelling, wall functions, grid generation/discretisation, assessment of physical and numerical modelling errors, sensitivity studies and best practice guidelines.

(f) Includes outdoor thermal comfort and urban heat island effect.

(g) Isothermal studies of pedestrian-level wind conditions around buildings.

(h) Also includes urban ventilation studies that do not explicitly model the dispersion of a scalar.

(i) Excludes studies of wind flow around bluff bodies and bluff body groups, which are contained in the category "Bluff body aerodynamics".

(i) Only includes studies on ventilation of indoor environments, ventilation of outdoor environments is part of category "Air pollutant dispersion".

(k) High-resolution modelling of surface convective heat transfer including the thin viscous sublayer that represents the largest thermal resistance.

(1) Circular or square cylinders, often in smooth approach flow.

(m) Generic or real surface-mounted buildings and structures, in turbulent boundary layer approach flow.

(n) Off-shore or on-shore, but natural terrain, not built environment. 
(o) Including wind loads, therefore different from the topics in "Structural wind engineering".

(p) Includes the use of CFD for wind-tunnel design and evaluation.

(q) Mesoscale modelling alone or coupled mesoscale-microscale modelling. 
Table 3: Overview of CWE review and overview papers published in archival journals

\begin{tabular}{l}
\hline Topic \\
\hline General topics \\
\hline $\begin{array}{l}\text { Atmospheric boundary layer } \\
\text { simulation }\end{array}$ \\
\hline $\begin{array}{l}\text { Bluff body aerodynamics, turbulence } \\
\text { modelling \& numerical techniques }\end{array}$
\end{tabular}

Author(s) (year) of publication

Franke et al. (2004, 2007), Tominaga et al. (2008a), Tamura (2008),

Tamura et al. (2008), Tabor \& Baba-Ahmadi (2010)

Murakami (1990b,1993b,1997,1998,1999), Roache (1994,1997),

Ferziger (1990,1993a,1993b), Leschziner (1990,1993), Hughes \& Jansen

(1993), Shah \& Ferziger (1997), Stathopoulos (1997,2002), Rodi (1997),

Tamura et al. (1997,2008), Gosman (1999), Castro \& Graham (1999),

Tezduyar (1999), Franke et al. (2004,2007,2011), Fujii (2005), Norton

\& Sun (2006), Bartzis (2006), Baker (2007,2010), Tamura (2008),

Hanjalic \& Kenjeres (2008), Tominaga et al. (2008a), Squires et al.

(2008), Tabor \& Baba-Ahmadi (2010), Cochran \& Derickson (2011),

Blocken \& Gualtieri (2012), Lee et al. (2013)

IAWE Solari (2007)

Environmental wind engineering

Wind and thermal environment

Murakami et al. (1999), Stathopoulos (2006), Mochida \& Lun (2008),

Mochida et al. (2008), Moonen et al. (2012), Lee et al. (2013)

Pedestrian-level wind conditions $\quad$ Blocken \& Carmeliet (2004b), Stathopoulos (2006), Yoshie et al. (2007),

Mochida \& Lun (2008), Blocken et al. (2011a, 2012), Moonen et al.

(2012), Blocken \& Stathopoulos (2013)

Air pollutant dispersion $\quad$ Lee et al. (1997), Vardoulakis et al. (2003), Meroney (2004), Canepa

(2004), Li et al. (2006), Holmes \& Morawska (2006), Tominaga \&

Stathopoulos (2007, 2013), Fernando et al. (2010), Blocken et al. (2011a,

2013b), Gousseau et al. (2011), Balczo et al. (2011), Tyagi et al. (2012),

Lee et al. (2013), Di Sabatino et al. (2013)

\begin{tabular}{l}
\hline Meteorological phenomena \\
\hline Fire \\
\hline Flow over (complex) topography \\
$\begin{array}{l}\text { (Natural) ventilation of buildings and } \\
\text { vehicles }\end{array}$
\end{tabular}

\begin{tabular}{ll}
\hline Sand, dust and snow transport & Livingstone et al. (2007), Tominaga et al. (2011) \\
\hline Wind-driven rain & Blocken \& Carmeliet (2004a, 2010), Blocken et al. (2011a, 2013a) \\
\hline Surface convective heat transfer & Blocken et al. (2011a), Defraeye et al. (2012, 2013) \\
\hline Acoustics & - \\
\hline Structural wind engineering & \\
\hline Wind loads on generic obstacles & - \\
\hline Wind loads on buildings and & Stathopoulos (1997,2003), Kareem (2008) \\
structures & \\
\hline Wind loads on solar panels & - \\
\hline Bridges & Taddei \& Bontempi (2003), Ge \& Xiang (2008) \\
\hline Vibrations and/or wind-structure & Tamura (1999) \\
interactions & \\
\hline Wind energy & \\
\hline Wind energy siting assessment & Ayotte (2008), Sumner et al. (2010), Porté-Agel et al. (2011), Sanderse \\
& et al. (2011), Sorensen (2011), Leung \& Yang (2012), Miller et al. \\
& (2013) \\
\hline Wind energy in the built environment & - \\
\hline Wind turbine rotor aerodynamics & Vermeer et al. (2003), Snel (2003), Hansen et al. (2006), Sumner et al. \\
& $(2010)$, Sorensen (2011), Porté-Agel et al. (2011), Roy \& Saha (2013), \\
& Miller et al. (2013) \\
\hline Other topics & Takagi (1990), Hucho \& Sovran (1993), Mueller \& DeLaurier (2003), \\
\hline Vehicle aerodynamics & Katz (2006), Baker (2010) \\
\hline Sports aerodynamics & Mehta (1985) \\
\hline Windborne debris & - \\
\hline Computer-aided experiments & Wu et al. (1992), Tamura \& Matsui (2002), Meroney (2004) \\
\hline Experiments for CFD validation & Robins (2003), Schatzmann et al. (1997), Dalgliesh \& Surry (2003), \\
& Meroney (2004), Schatzmann \& Leitl (2011) \\
\hline Mesoscale (and macroscale) & Platzman (1979), Shuman (1989), Pielke \& Nicholls (1997), Kimura \\
modelling & (2002), Lynch (2008), Mochida et al. (2011), Yamada \& Katsuyuki, \\
& $(2011)$, Schlünzen et al. (2011) \\
\hline & \\
\hline
\end{tabular}




\section{FIGURES}

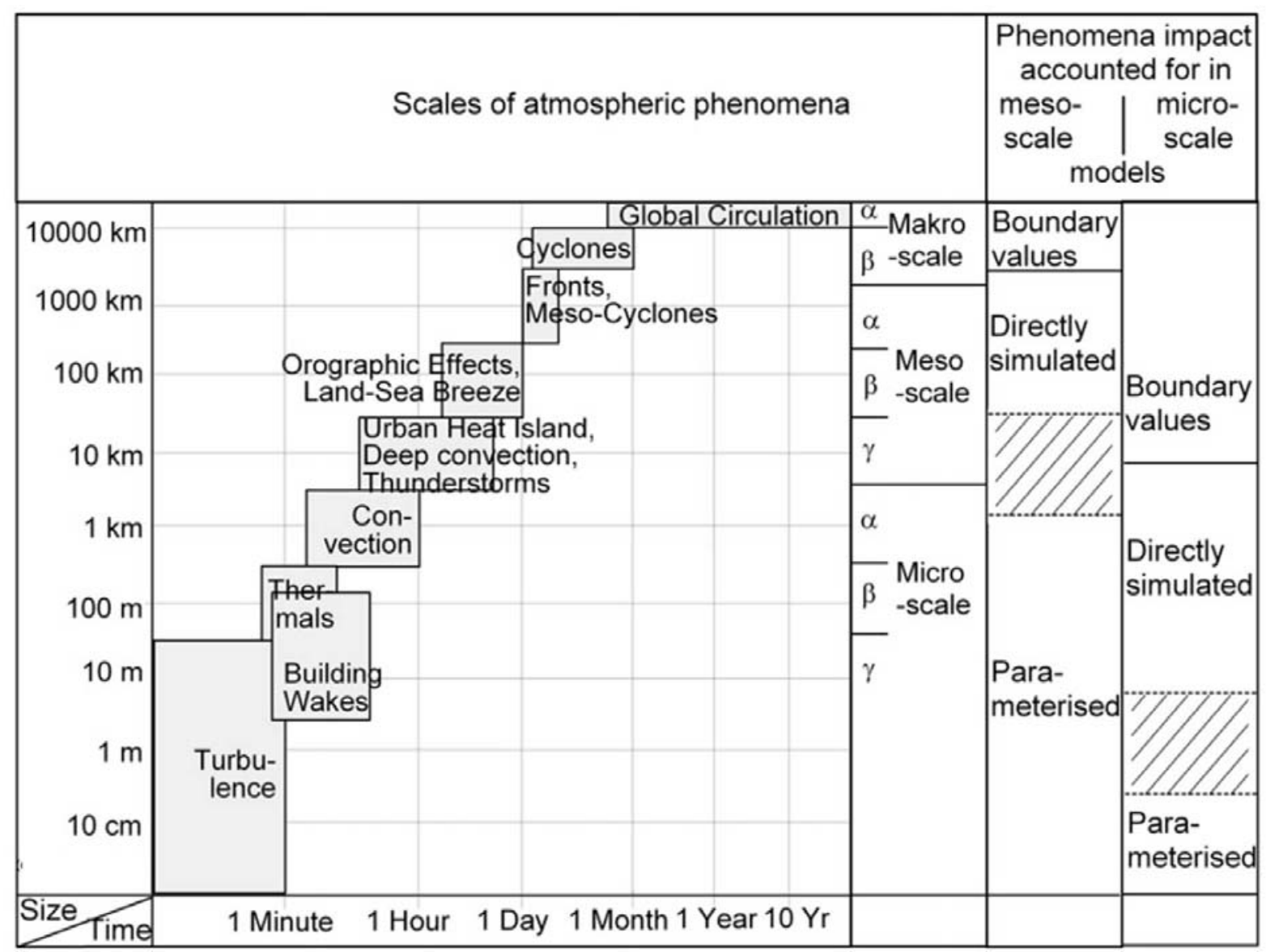

Figure 1. Spatial and temporal scales of atmospheric phenomena and how these phenomena are treated in Reynolds-averaged Navier-Stokes (RANS) mesoscale or obstacle resolving microscale models (right columns) (Schlünzen et al. 2011, (C) Elsevier). The characteristic scales are based on Orlanski (1975) and Randerson (1976), the model scales are an update of diagrams by Schlünzen (1996) and Moussiopoulos et al. (2003). Dashed areas in the right columns indicate the currently used RANS model resolutions and the resulting possibly resolvable minimum phenomena sizes (Schlünzen et al. 2011). 
a

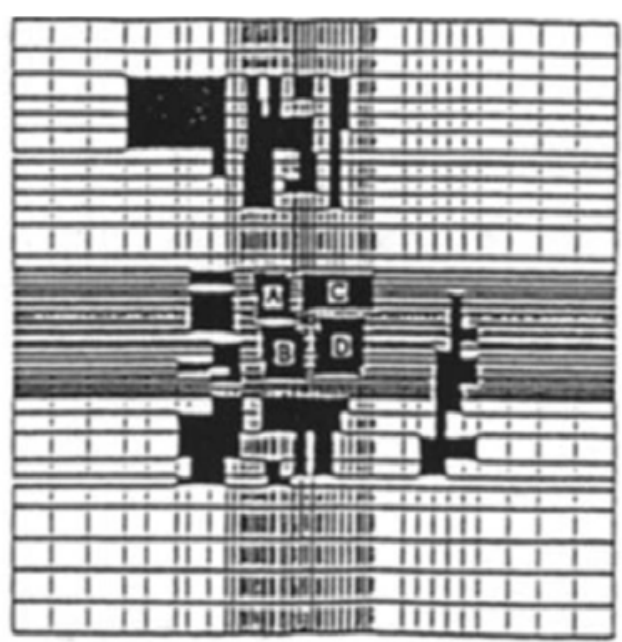

C

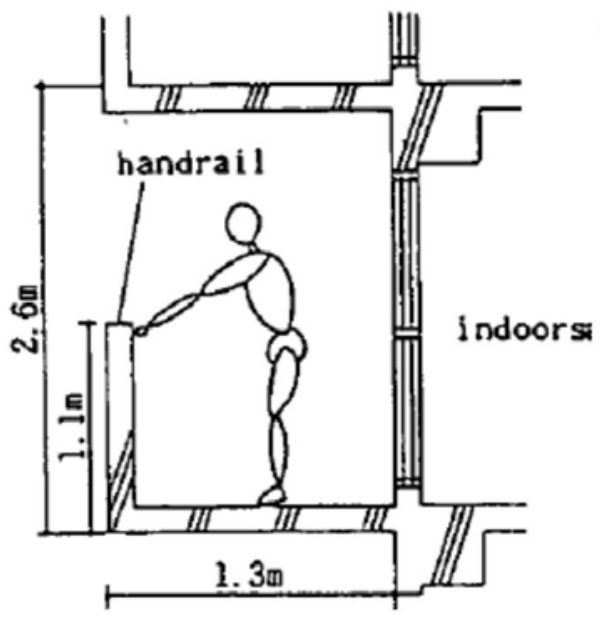

e

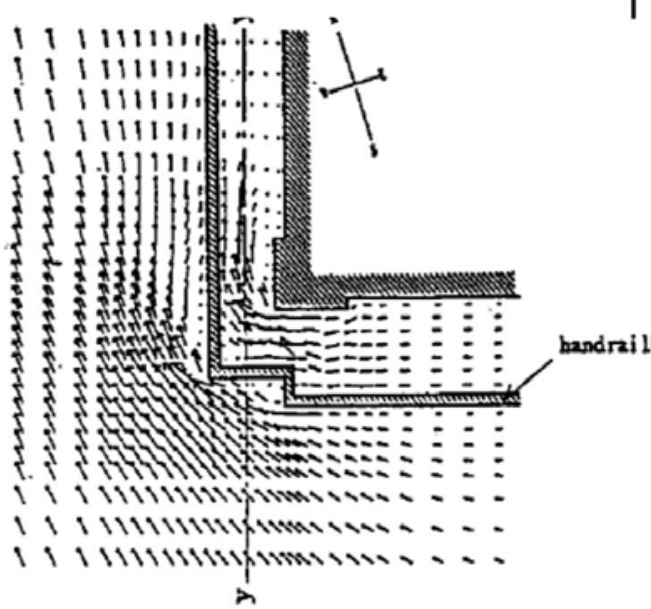

d

f b

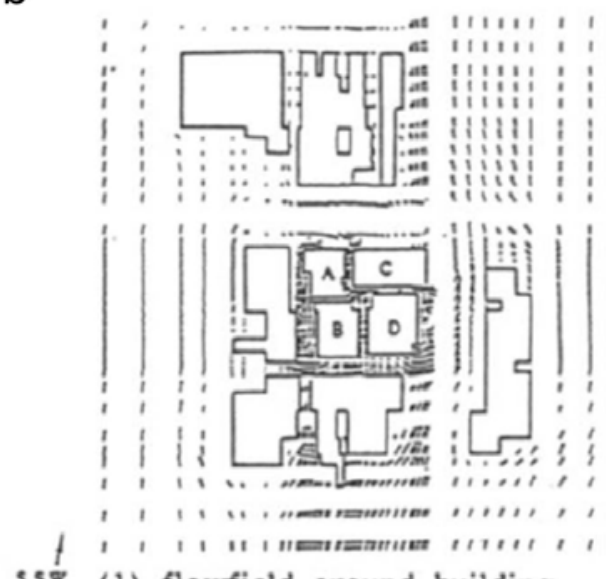

(1) flowfield around building complex and surroundings
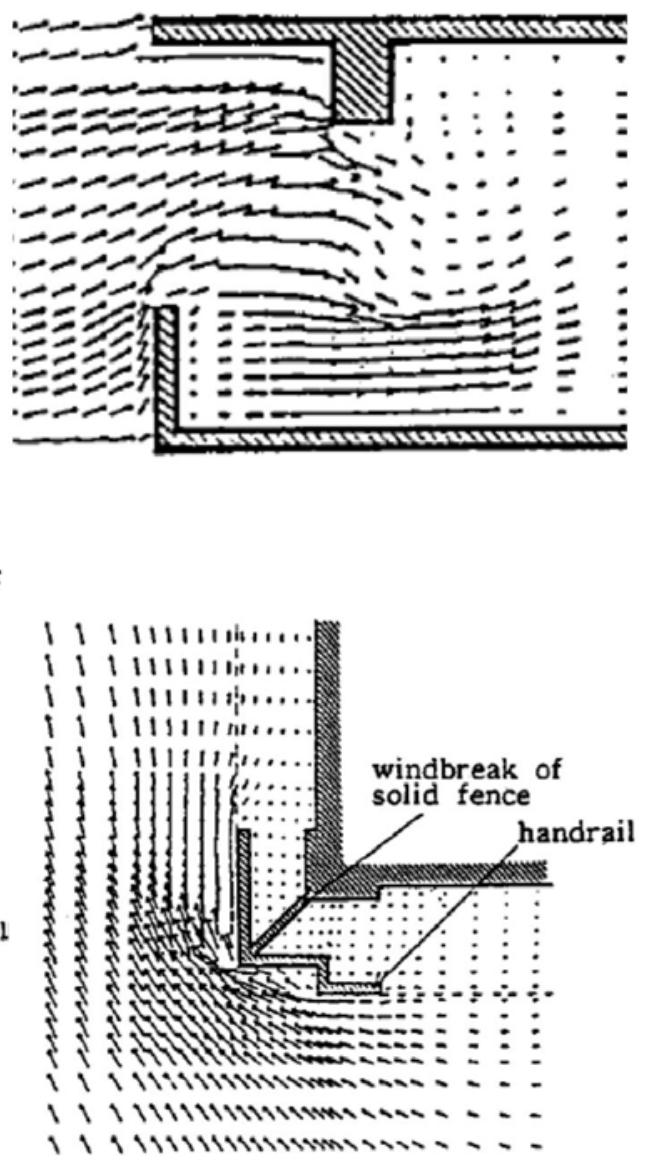

Figure 2. CFD study of the airflow around four buildings to be located on an urban renewal site in a city located near Tokyo. A is a 4-storey building, B a 19-storey building, C a 20 -storey building and D a 7 -storey building. (a) Plan view of computational grid with 120,120 cells; (b) Velocity vector field near ground level (1.5 m height) for SSW wind; (c) Detailed view of balcony at SW corner of building B; (d) Velocity vector field in vertical plane near corner of building B; (e-f) Velocity vector field in horizontal plane at $1.5 \mathrm{~m}$ height at $13^{\text {th }}$ floor without and with windbreak by solid fence (Murakami 1990b, (C) Elsevier). 
a

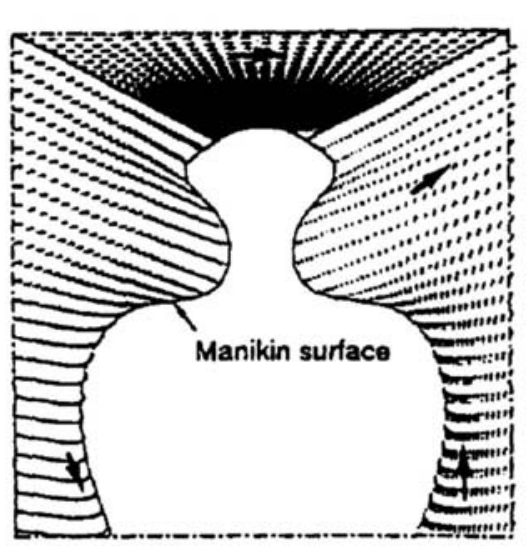

C

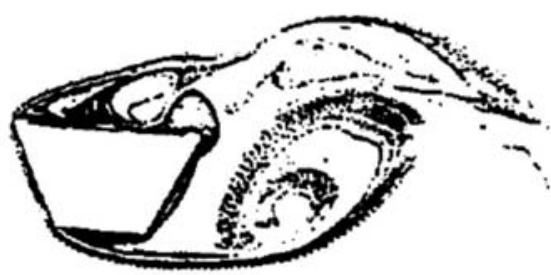

$\mathrm{e}$

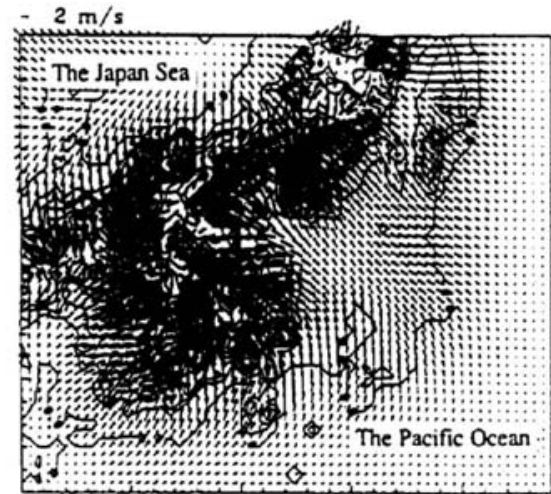

$b$

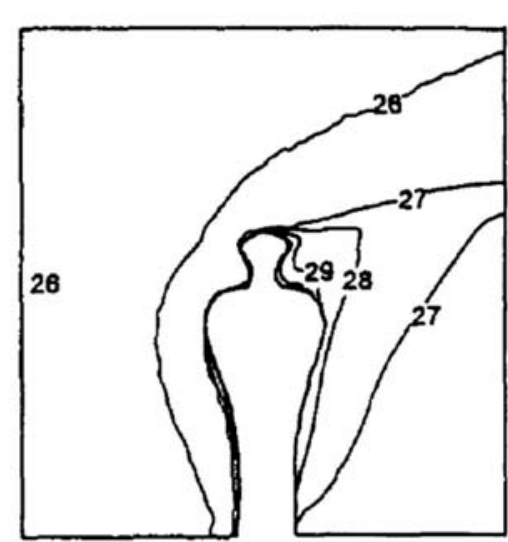

d

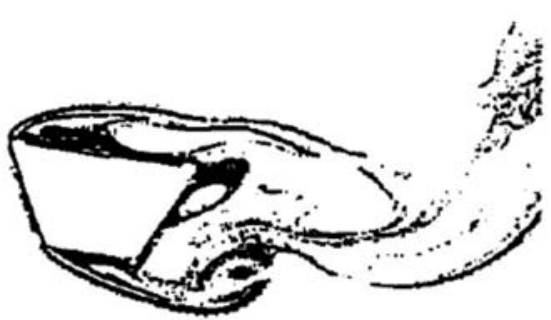

f

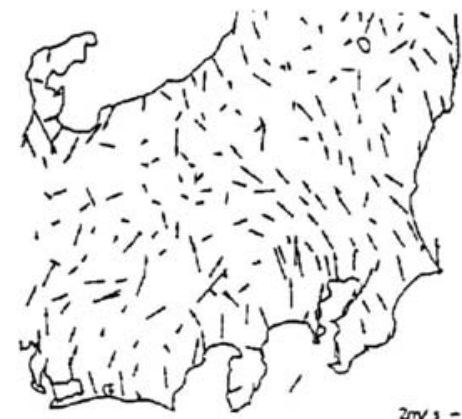

Figure 3. $(\mathrm{a}, \mathrm{b})$ Velocity and temperature fields around a human body exposed to a weak cross wind, illustrating a rising plume around the human body which is transported downward by the cross wind; (c,d) Wind flow around a real-shaped bridge deck with angle of attack (c) $4^{\circ}$ and (d) $8^{\circ}$; (e) Velocity vector field over the central part of Japan, where the Japanese Alps are located; (f) Corresponding measurement results (Murakami 1997, (C) Elsevier). 
a

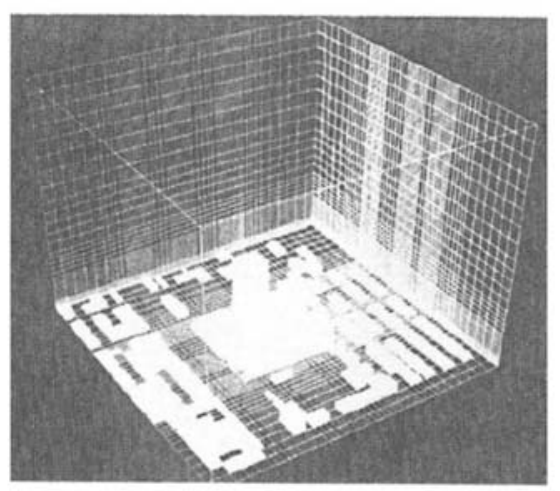

C

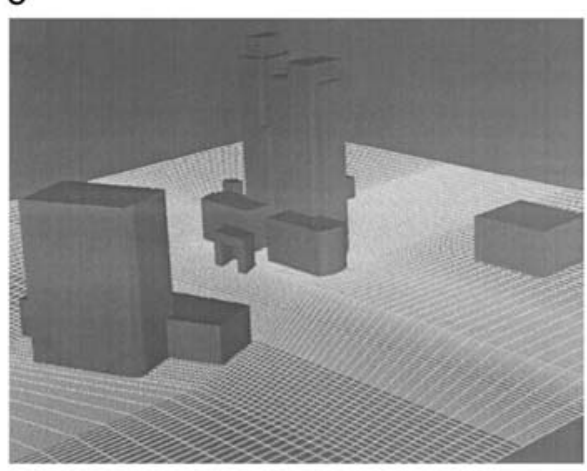

e

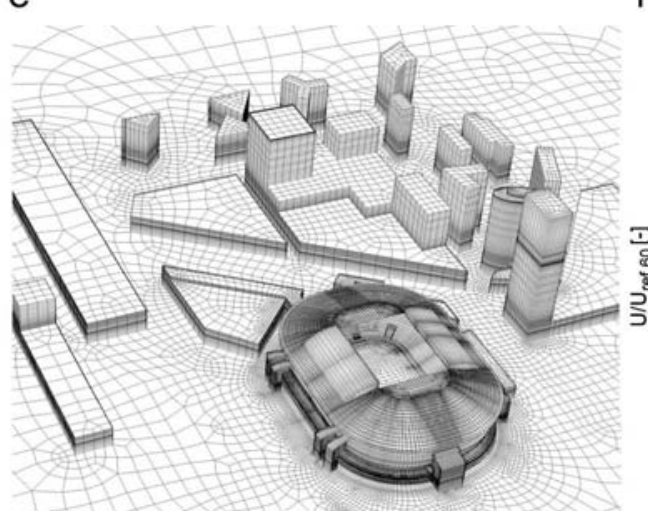

b

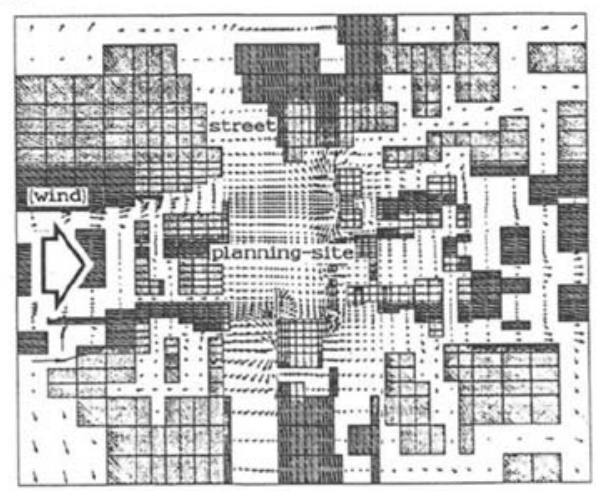

d

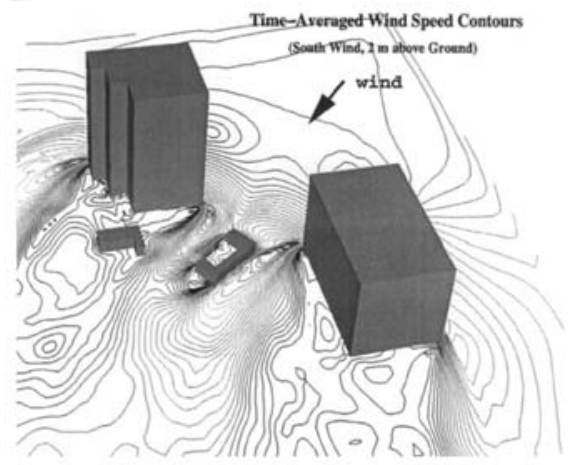

f

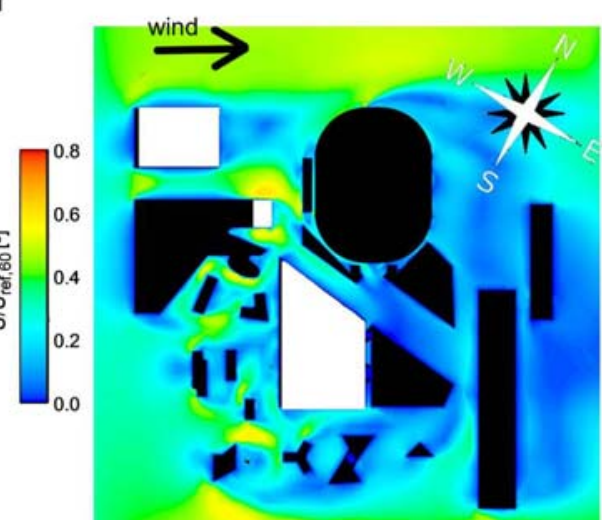

Figure 4. Examples of CFD studies of pedestrian-level wind conditions in urban areas: (a-b) Grid (38895 finite elements) and wind-velocity vectors based on steady RANS simulations (Gadilhe et al., 1993, (C) Elsevier), (cd) Grid (total cell count unknown) and wind speed contours based on LES (He and Song, 1999, (C Elsevier), (e-f) Grid (2.8 million cells) and wind speed ratio contours, based on steady RANS (Blocken and Persoon, 2009, (c) Elsevier). 
a
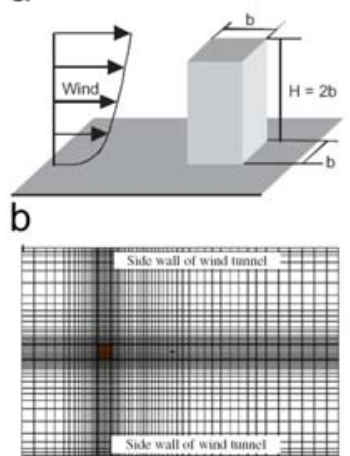

C
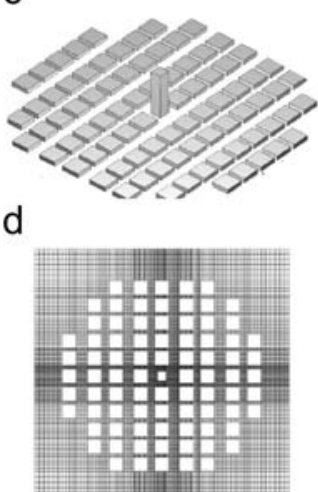

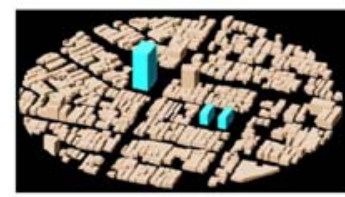

f

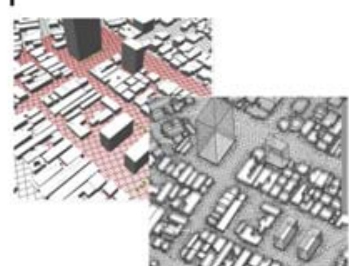

g

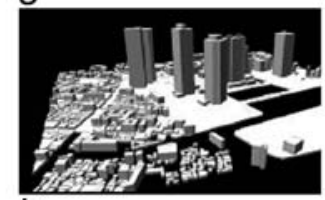

$\mathrm{h}$

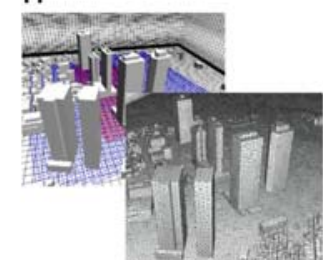

Figure 5. Building configurations in the validation studies by Yoshie et al. (2007), (a-b) Geometry and structured grid ( 0.1 million cells) of isolated building, (c-d) Geometry and structured grid (1.3 million cells) of high-rise building surrounded by low-rise buildings, (e-f) Geometry, immersed-boundary ( 0.25 million cells) and body-fitted ( 0.8 million cells) grids of building complex in actual urban area (Niigata), (g-h) Geometry, immersed-boundary (2.95 million cells) and body-fitted (1.18 million cells) grids of building complex in actual urban area (Shinjuku, Tokyo). Courtesy of R. Yoshie and Y. Tominaga (2010).

a

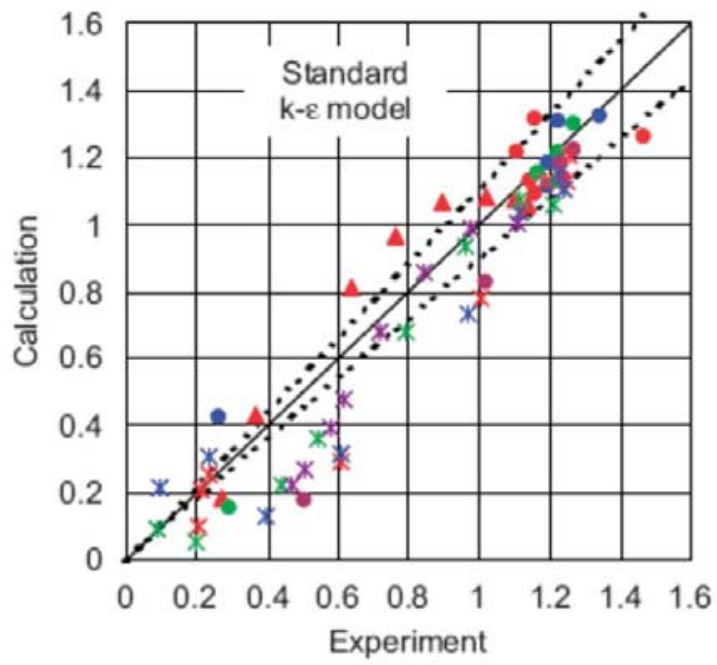

b

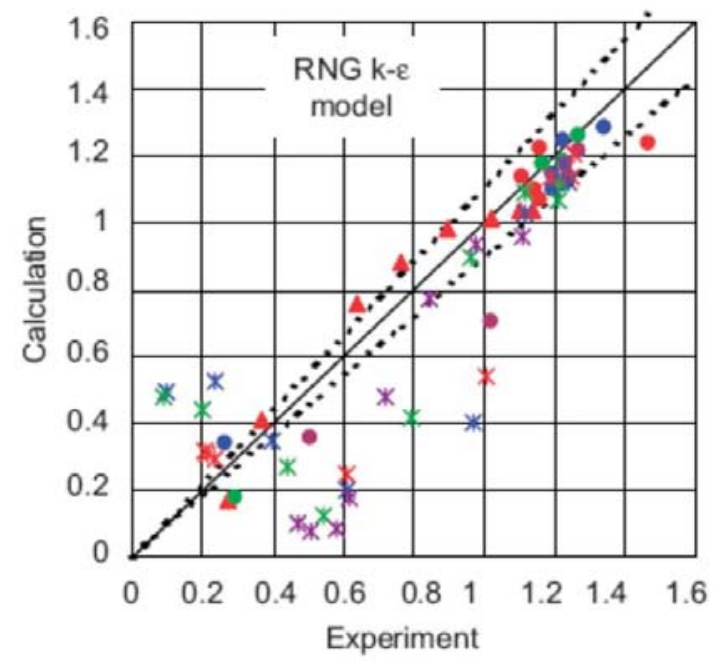

Figure 6. Comparison of CFD results and wind-tunnel measurements of wind speed ratio for the isolated building (see Figure 5a) by Yoshie et al. (2007): (a) steady RANS with standard k- $\varepsilon$ model, (b) steady RANS with RNG k- $\varepsilon$ model. The symbols refer to: $\Delta=$ front of building; $\mathrm{o}=$ side of building; $\mathrm{x}=$ behind building. The different colours refer to a variety of positions in front, beside and behind the building. Courtesy of R. Yoshie and Y. Tominaga (2010). 


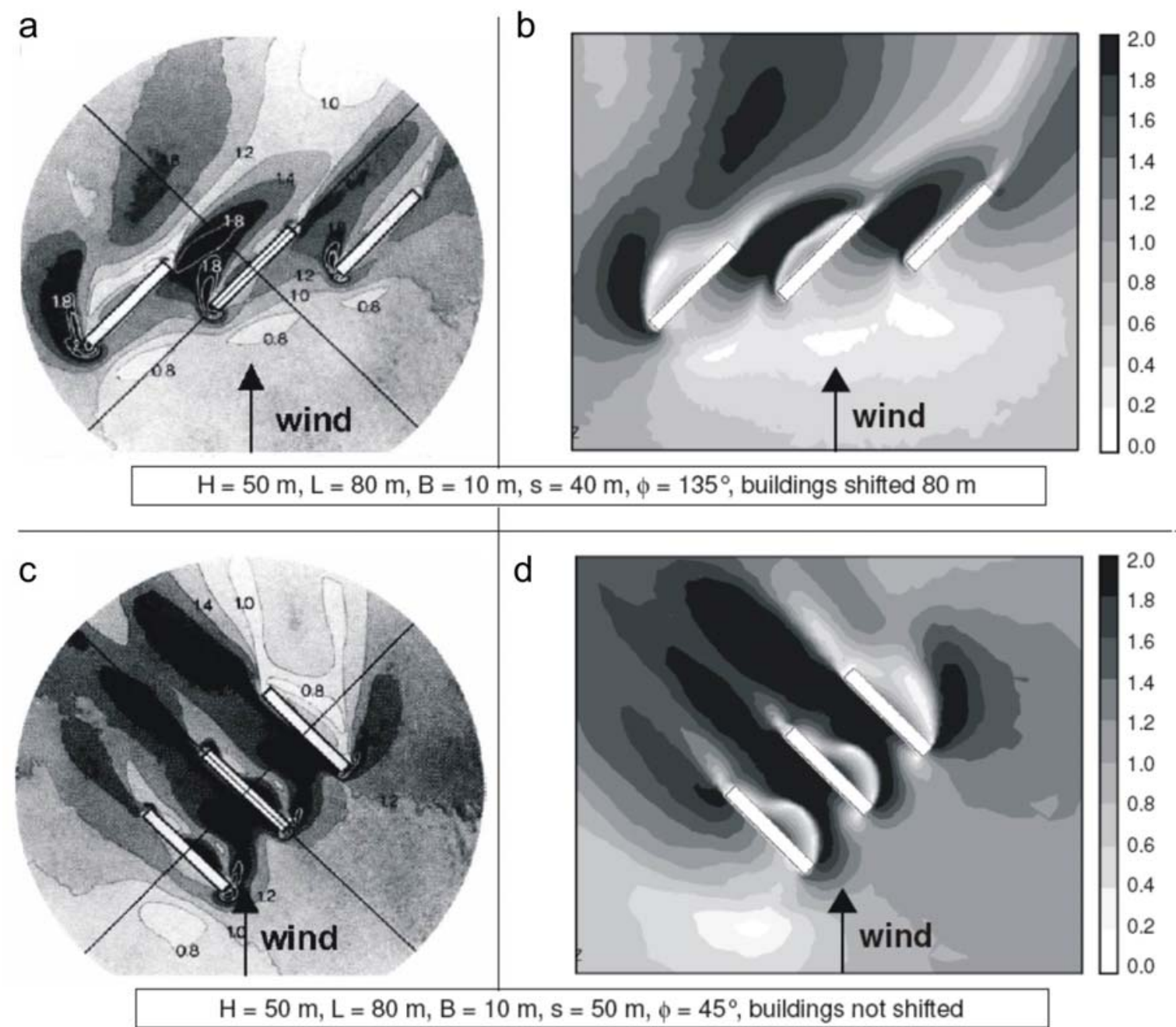

Figure 7. Validation study for parallel building configurations by Blocken and Carmeliet (2008): (a) Sanderosion contour plots of the amplification factor $\mathrm{U} / \mathrm{U}_{0}$, (b) CFD results for $\mathrm{U} / \mathrm{U}_{0}(1.5$ million cells); (c) Sand erosion plots of $\mathrm{U} / \mathrm{U}_{0}$, (d) CFD results for $\mathrm{U} / \mathrm{U}_{0}(0.7$ million cells $)$. 
a

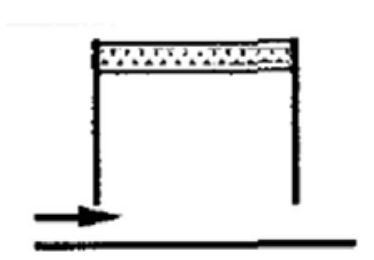

d

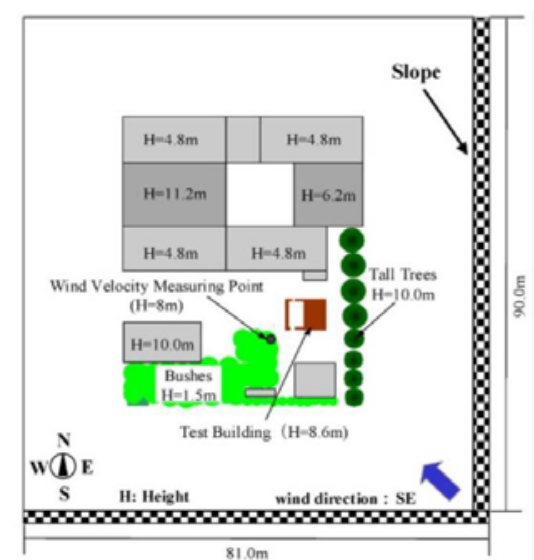

g

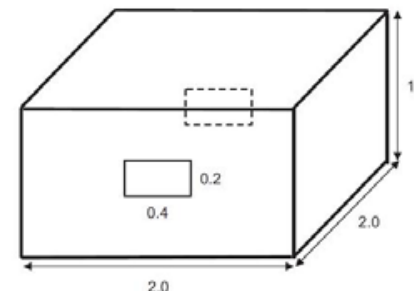

20 b

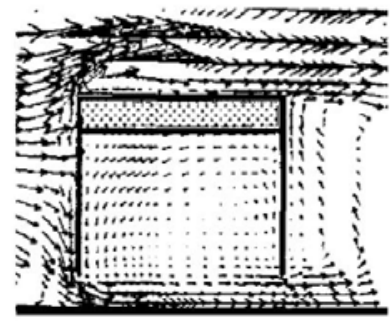

e
C

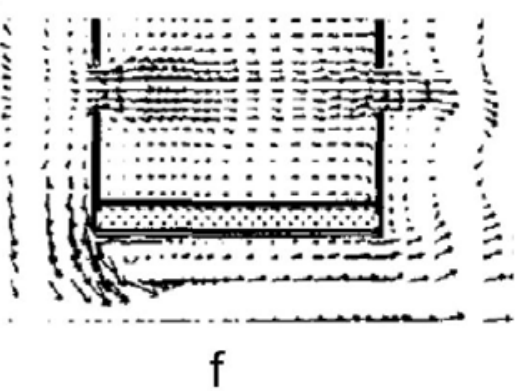

f
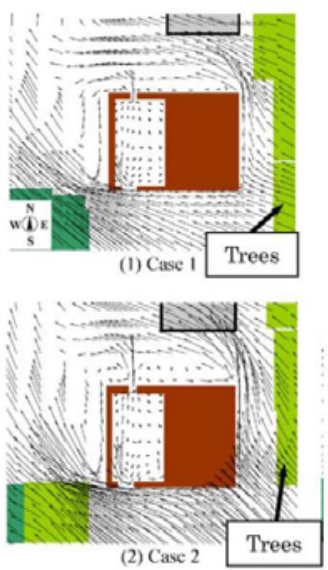

i

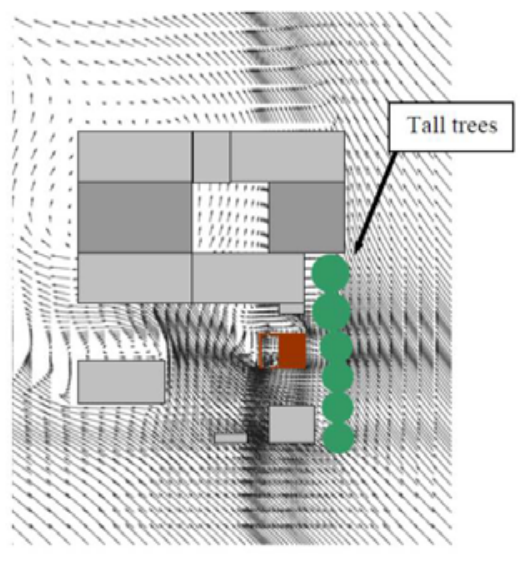

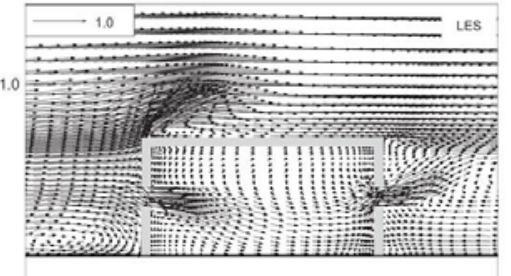
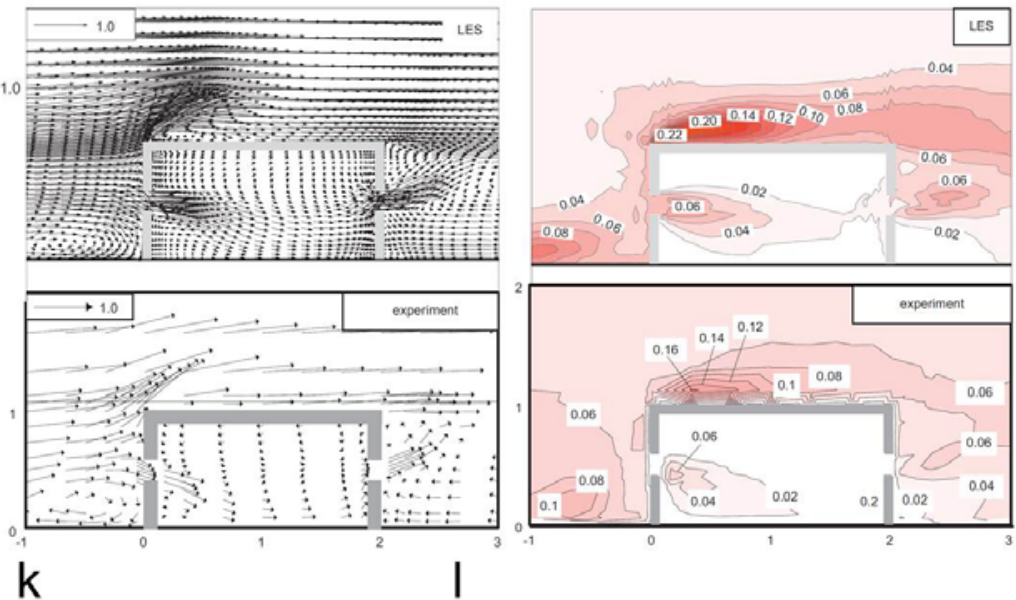

j

k
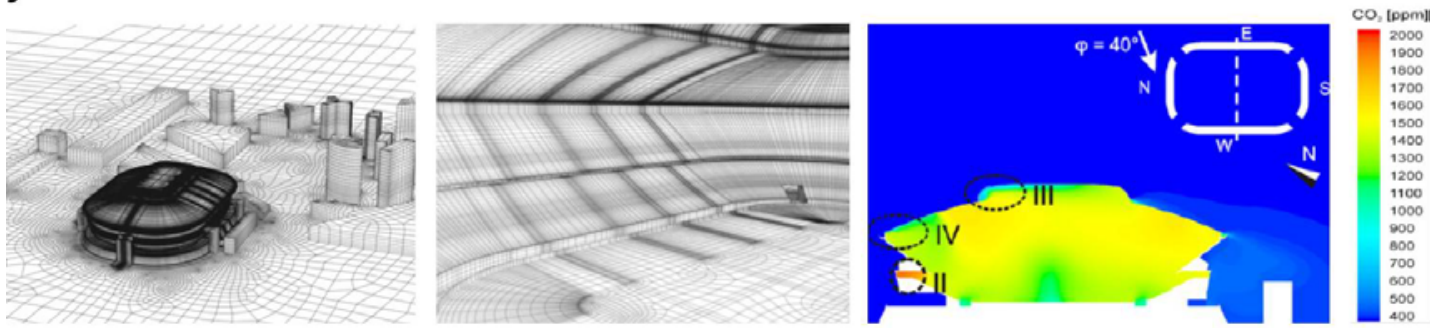

Figure 8. Examples of CFD studies of wind-induced cross-ventilation of buildings. (a) Isolated generic building model; (b) corresponding mean velocity vector field in vertical plane and (c) in horizontal plane as a result of LES simulations (Kato et al., 1992, (c) Elsevier). (d) Computational domain; (e) Horizontal distribution of velocity vectors at $4.5 \mathrm{~m}$ height in Case1 (2:00 p.m.); (f) Horizontal distribution of velocity vectors (zone A, at 4.5m height) (Mochida et al. 2005, (C) Elsevier); (g) Building geometry and dimensions (normalised by building height); (h) Velocity vector field in vertical centreplane obtained by LES and windtunnel experiments; (i) Same for turbulent kinetic energy (Hu et al., 2008, (C) Elsevier); (j) Computational grid for Amsterdam ArenA stadium (5.6 million control volumes); (k) Inside view of computational grid; (1) Distribution of $\mathrm{CO}_{2}$ concentration in vertical centreplane (van Hooff and Blocken 2010a, 2013, (C Elsevier). 
(a) Coupled approach

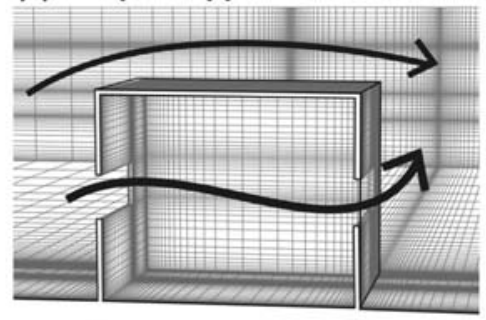

$\left[\begin{array}{c}\text { Outdoor wind flow } \\ \text { Indoor air flow }\end{array}\right]$ (b) Decoupled approach

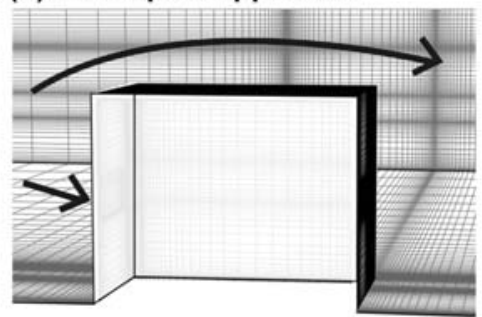

Outdoor wind flow

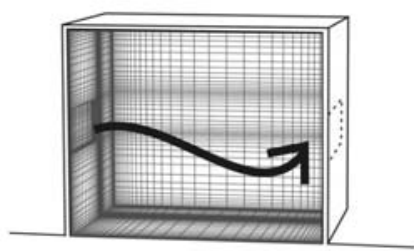

Indoor air flow

Figure 9. Schematic representation of (a) coupled and (b) decoupled approach for analysis of wind-induced cross-ventilation of buildings (from Ramponi and Blocken 2012a, (C) Elsevier)
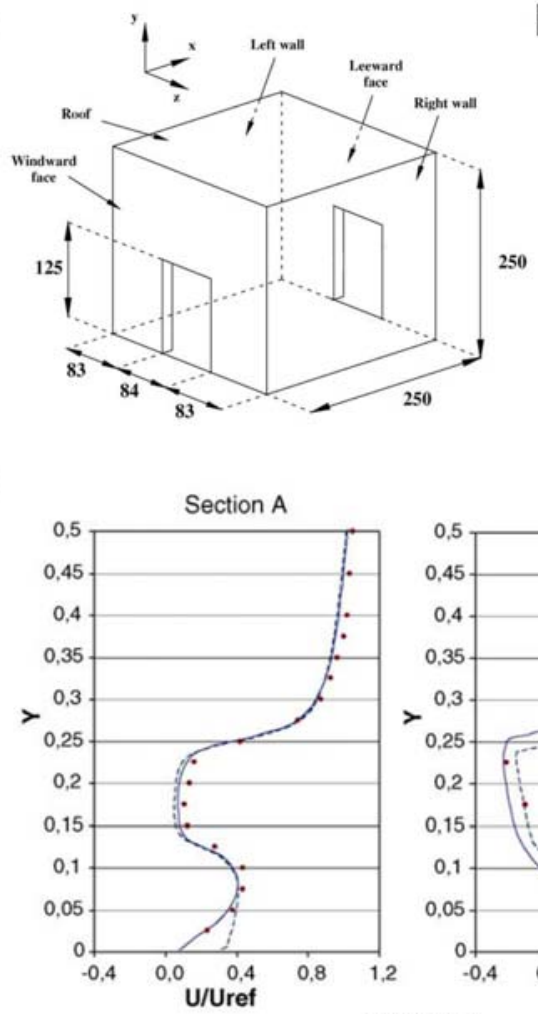

b
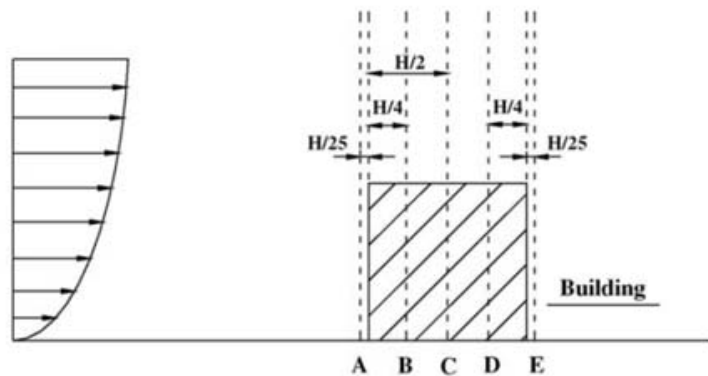

Section B
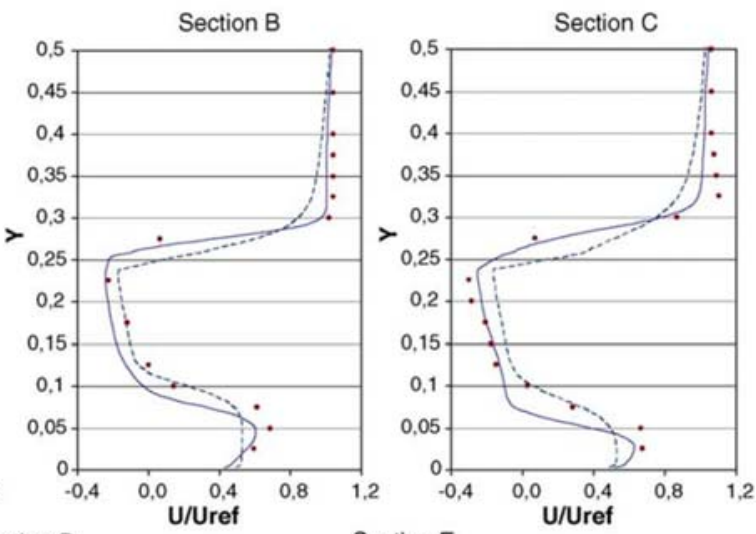

Section E

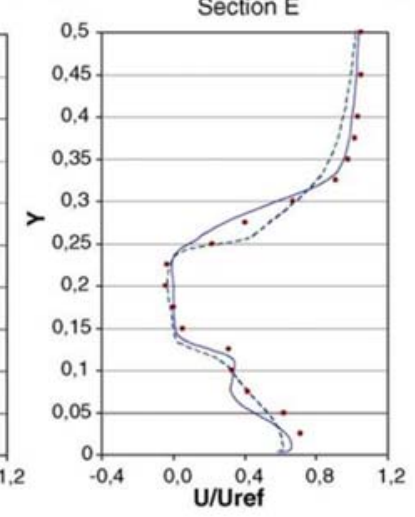

Figure 10. (a) Building geometry with dimensions in mm (modified from Evola and Popov 2006, (C) Elsevier); (b) Sections A-E along which experimental and numerical results are compared; (c) Vertical profiles of ratio of horizontal velocity component to reference wind speed: dots are wind-tunnel results, solid lines are results

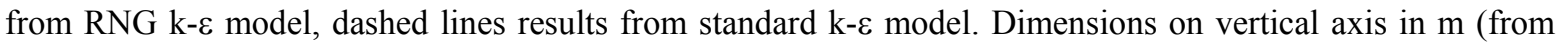
Evola and Popov 2006, (C) Elsevier). 


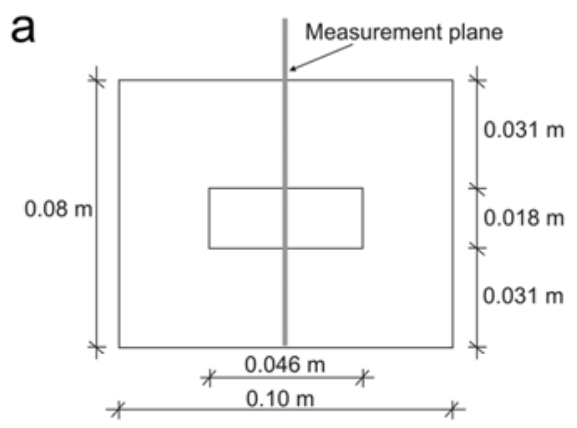

C

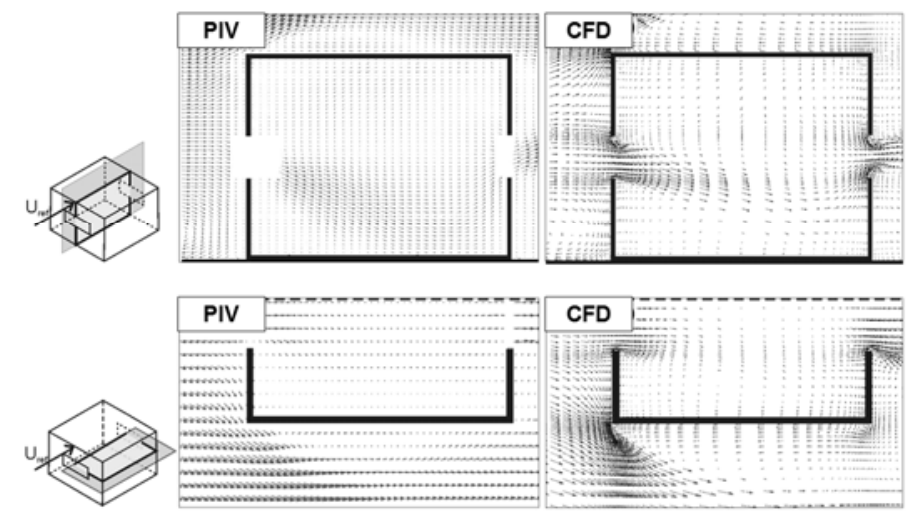

b
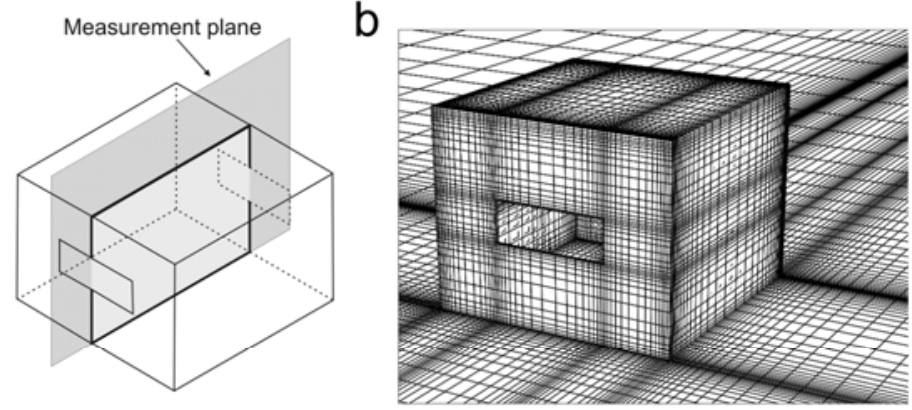

d

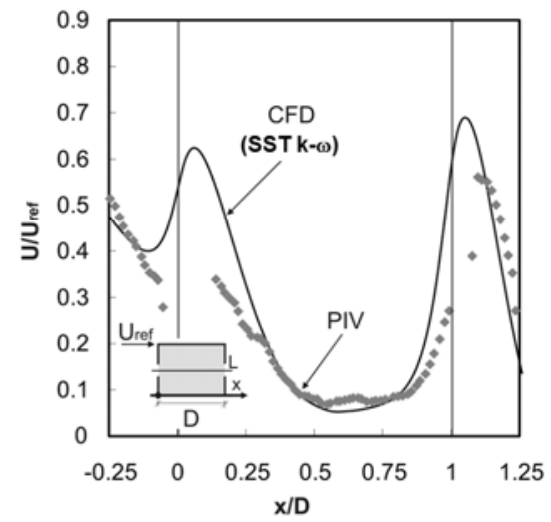

Figure 11. (a) Building geometry and indication of vertical measurement plane; (b) Computational grid (575,247 cells); (c) Comparison of PIV and CFD (SST k- $\omega$ ) velocity vector fields in vertical centreplane and horizontal plane at mid-height through the openings; (d) Comparison of streamwise wind speed ratio $\mathrm{U} / \mathrm{U}_{\text {ref }}$ from PIV and CFD (SST k- $\omega$ ) along centreline (Ramponi and Blocken 2012a, C Elsevier). 
a
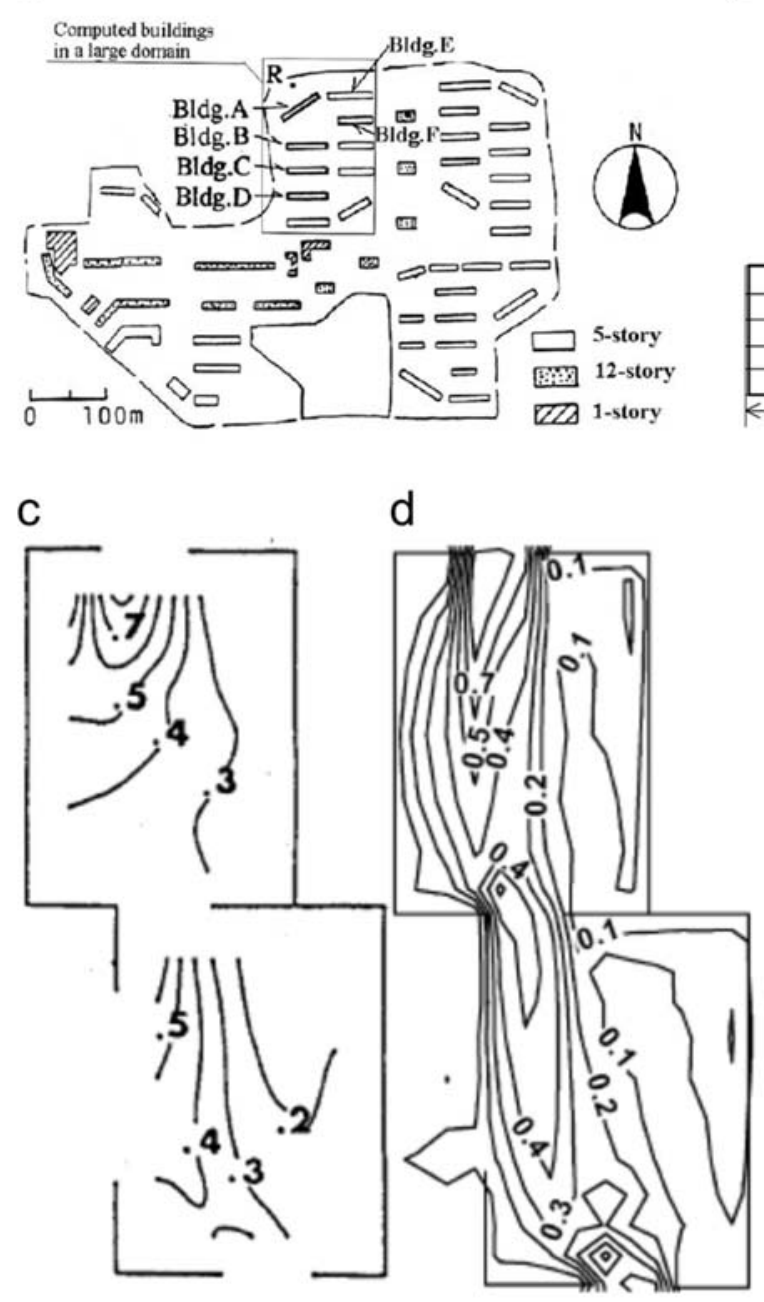
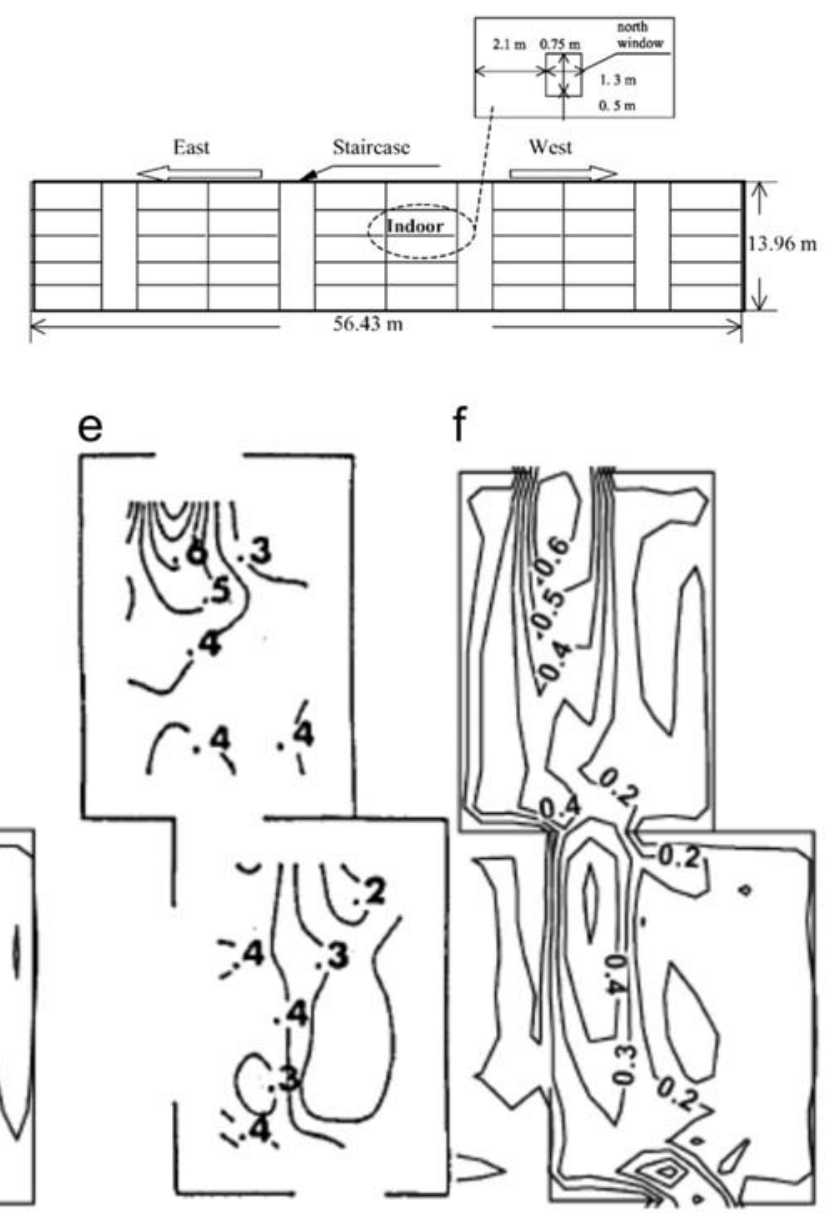

Figure 12. (a) Layout of building group with indication of building A; (b) Dimensions of building A containing the two rooms under study; (c-f) Contours of wind speed (m/s) obtained from (c) wind-tunnel measurements; (d) LES with fixed wind direction; (e) on-site measurements; (f) LES with varied wind direction (Jiang and Chen 2002, (c) Elsevier) 
a

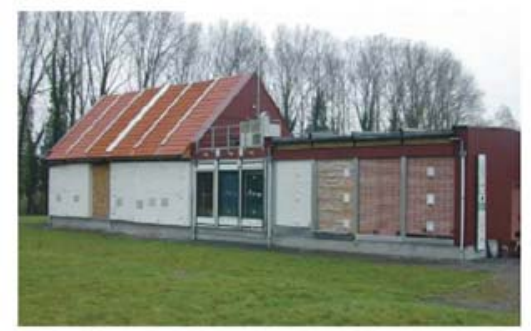

C

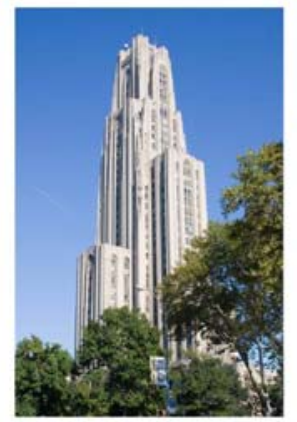

d

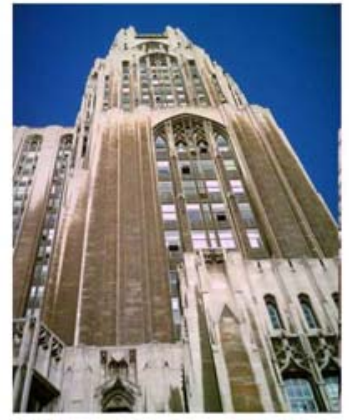

f
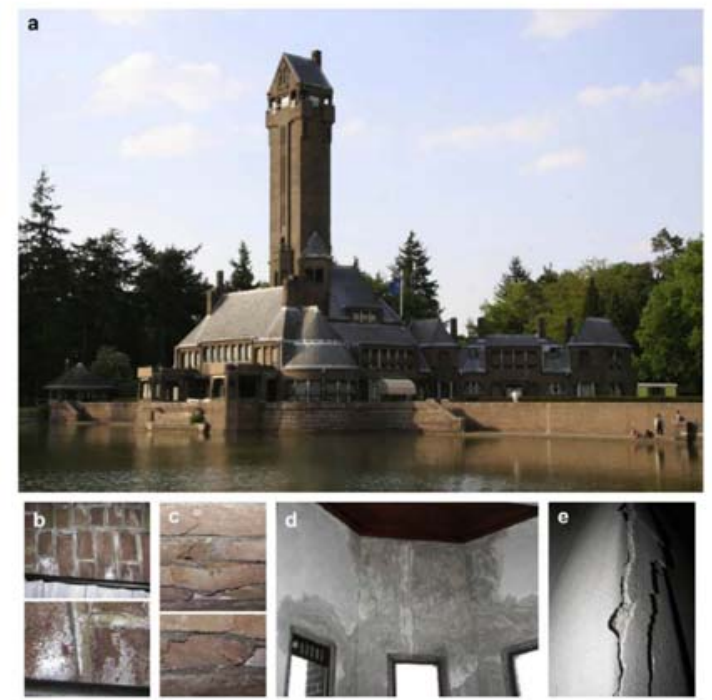

b

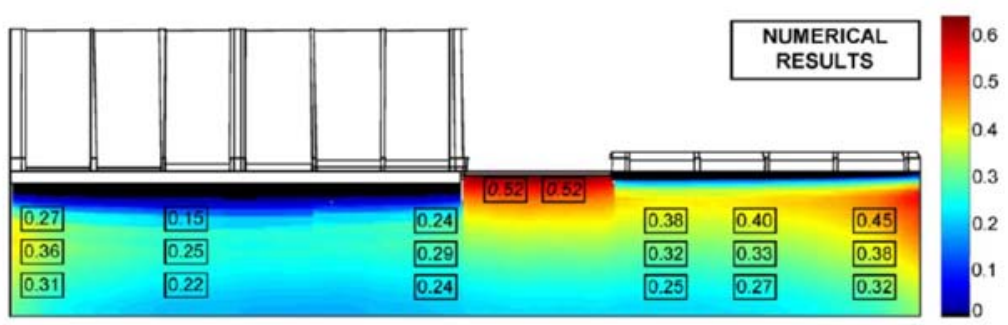

e

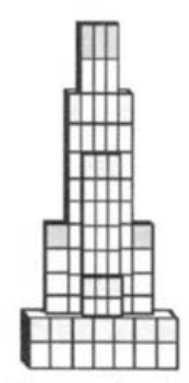

$\mathrm{U}_{6 \mathrm{~m}}=1 \mathrm{~m} / \mathrm{s}$

$\mathrm{g}$

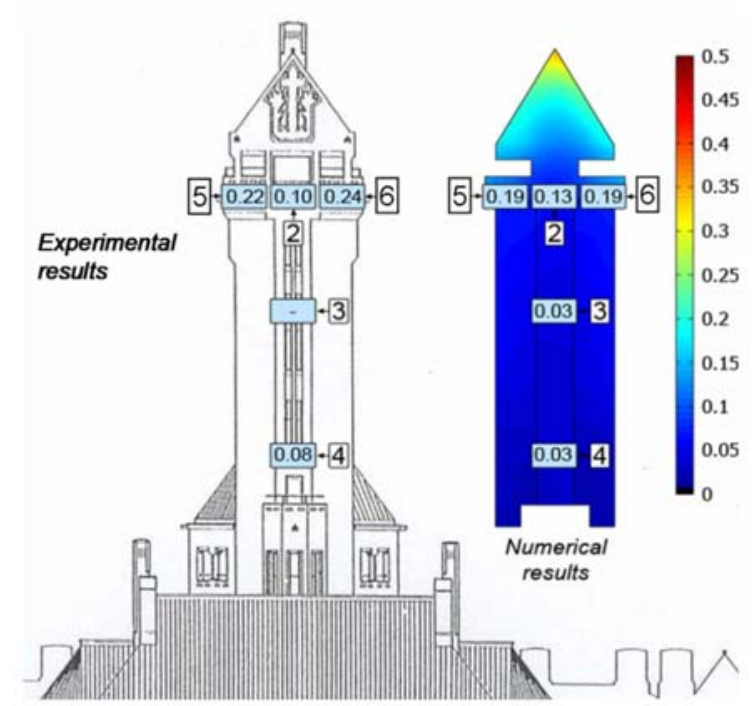

Figure 13. CFD validation studies of WDR on building facades. (a) VLIET test building in Leuven, Belgium (Blocken and Carmeliet 2005, (C) Elsevier); (b) catch ratio contours on south-west facade after rain event with south-west wind direction (Blocken and Carmeliet 2007b, (C) Elsevier); (c) Cathedral of Learning. (d) Cathedral of learning with surface soiling patterns (courtesy of C. Bailey 2010); (e) catch ratios on south-west facade for different reference wind speeds (Tang and Davidson 2004, (C Elsevier); (f) Hunting Lodge St. Hubertus in the Netherlands, with indication of moisture-related damage (Briggen et al. 2009, (C) Elsevier); (g) Comparison of measured (left) and simulated (right) catch ratios at the end of a rain event with wind direction perpendicular to the facade (Briggen et al. 2009, (C) Elsevier). 